Journal of the Scientific Agricultural Society of Finland Vol. 48: 203-304, 1976

Maataloustieteellinen Aikakauskirja

\title{
TRANSMISSION OF COCOA VIRUSES BY MEALYBUGS (Homoptera: Pseudococcidae)
}

Selostus: Villakirvat kaakaopuun virusten siirtäjinä

\author{
OSMO ROIVAINEN ${ }^{1}$ ) \\ Cocoa Research Institute of Ghana, P. O. Box 8, Tafo, Ghana \\ 1) now in Agricultural Research Centre, Department of \\ Pest Investigation, 01301 Vantaa 30, Finland
}

TO BE PRESENTED, WITH THE PERMISSION OF THE Section of Mathematics and Natural. Sciences of the Philosophical Faculty of the UniverSITY OF HELSINKI, FOR PUBLIC CRITICISM IN Lecture Room of Deparment of Zoology, Pohjoinen Rautatiekatu 13, on 20th August 1976, AT 12 o'CLOCK NOON 


\section{TO ELSIE}




\section{Preface}

In the course of preparing this study I have received help from many persons. Since this work started early in 1966 it is possible that some valuable assistance may have been overlooked.

Dr. R. H. Kenten, Dr. J. T. Legg and Dr. G. K. Owusu gave very useful criticism at various stages of progress of the work. Advice on statistical matters was given by Mr. N. A. Goodchild, Dr. S. C. Pearse and Mr. P. Walker. Prof. Y. Seppälä helped in some mathematical questions. I note with pleasure the support given by Prof. L. Cutcomp, Dr. Leo E. LaChance, Dr. D. A. Lindquist and Mr. O. E. S. Lloyd of the International Atomic Energy Agency. At the early stages of this work it was very useful to meet Prof. A. F. Posnette and get his expert advice on various aspects of the work and suggestions on useful lines of investigation. Mr. E. K. Tetteh was very helpful in matters concerning the literature.

My supporting staff, and others directly involved in the execution of the various experiments, statistical calculations and other aspects of the work, were the following: Mr. E. O. Agyare, Mr. B. S. Asare, Mr. M. E. Bonku, Mr. J. K. Bonney, late Mr. E. M. Ewool, Mrs. M. Ewool, Mr. E. M. Ewool Jr., Miss A. Vasarainen and Mr. Y. E. K. Yirenkyi. All these persons gave invaluable assistance in the cource of this study.

My teacher in zoology, Prof. E. Palmén, has encouraged me in many ways and followed the progress of this work with keen interest.

The language of this paper was inspected by Mrs. L. Ritarsalo.

I gratefully acknowledge the help of all these people and wish to express my sincere gratitude to them.

Permission to publish this paper has been obtained from Dr. E. J. A. Asomaning, Director of the Cocoa Research Institute, Tafo, Ghana, and the International Atomic Energy Agency, Vienna, Austria.

I am grateful to the Scientific Agricultural Society of Finland for accepting this study into the journal of the society.

Uppsala, 26 November 1975

Osmo Roivainen 



\section{CONTENTS}

Abstract

1. INTRODUCTION

2. EXPERIMENTAL TECHNIQUES, CONDITIONS AND MATERIALS ............ 211

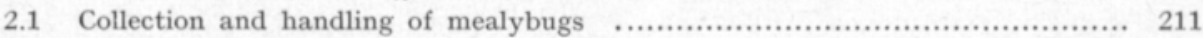

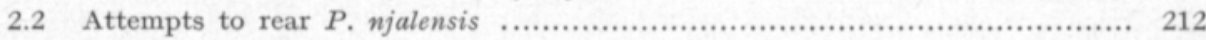

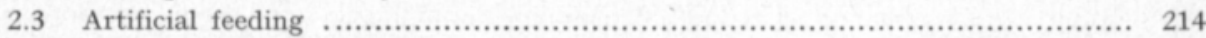

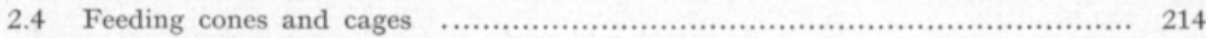

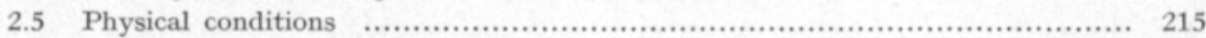

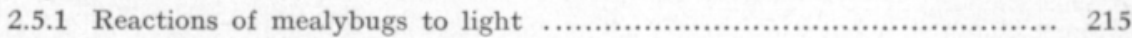

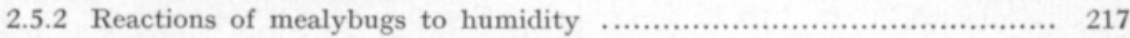

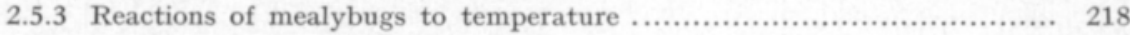

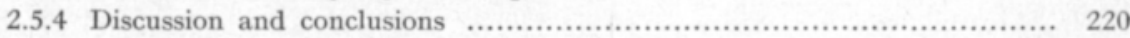

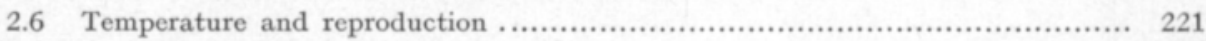

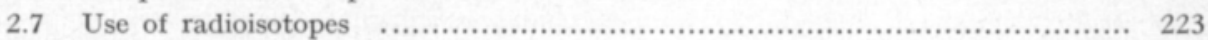

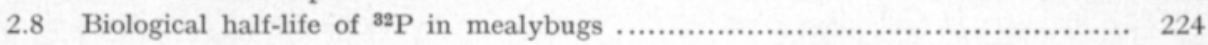

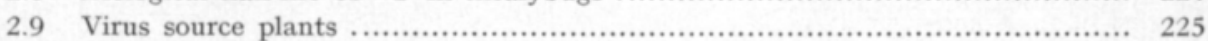

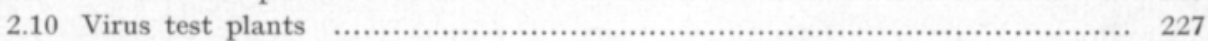

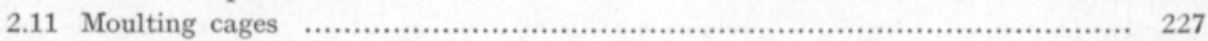

2.12 The standard virus transmission experiment ..................................... 227

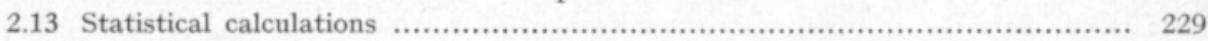

3. EFFECT OF VARIOUS FACTORS ON VIRUS TRANSMISSION ................... 229

3.1 Relationship between food uptake and infection rate ........................... 231

3.2 Relationship between plant and mealybug radioactivity ....................... 232

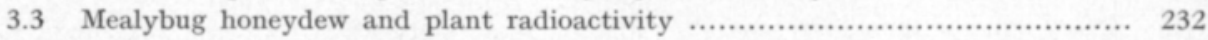

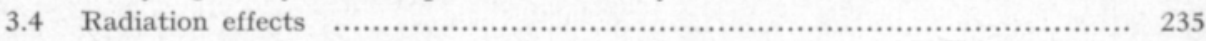

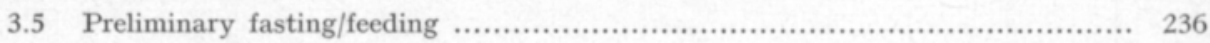

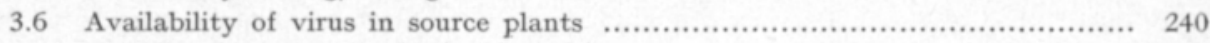

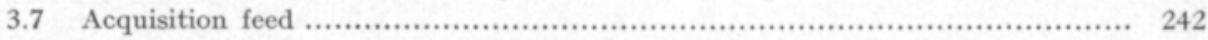

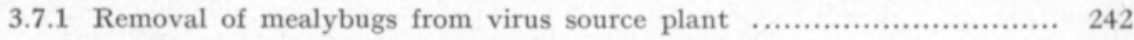

3.7.2 Length of acquisition feed with CSSV $1 \mathrm{~A}$ and $P$. njalensis ............... 244

3.7.3 Length of acquisition feed with other isolates and $P$. njalensis ......... 246

3.7.4 Length of acquisition feed with CSSV $1 \mathrm{~A}$ and $F$. virgata ............... 248

3.7.5 Acquisition of virus from liquid leaf extract ................................. 248

3.8 Persistence of virus in mealybugs after acquisition feed ........................ 251

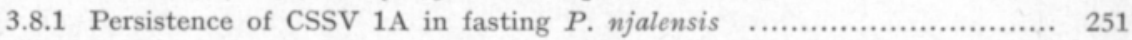

3.8.2 Persistence of CSSV 1A in feeding $P$. njalensis ............................. 251

3.8.3 Consecutive transmission of virus by a single mealybug ................. 255

3.8.4 Persistence of CMLV $1 \mathrm{C}$ in fasting $P$. njalensis .......................... 255

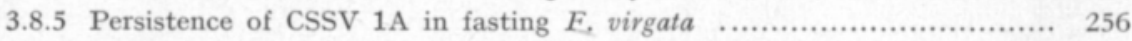

3.8.6 Relationship between virus persistence and time ........................ 257

3.8.7 Persistence of virus through postacquisition moulting $\ldots \ldots \ldots \ldots \ldots \ldots \ldots \ldots . \ldots . \ldots . \ldots . \ldots 258$

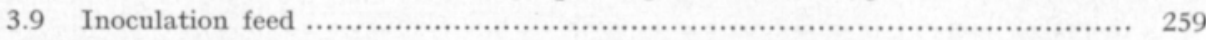

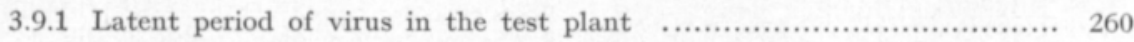

3.9.2 Number of mealybugs on test plants during inoculation feed ............ 261 
3.9.3 Inoculation feed on different cocoa types as test plants ................. 261

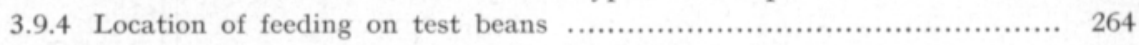

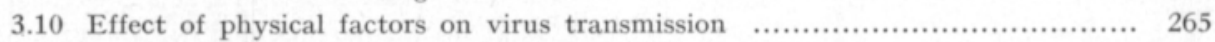

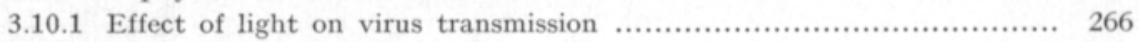

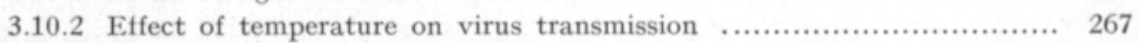

3.11 Relationship between virus uptake, persistence and infectivity of mealybugs 267

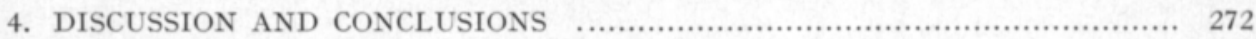

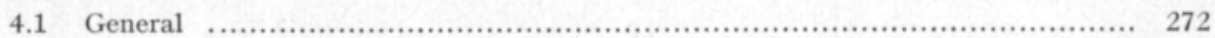

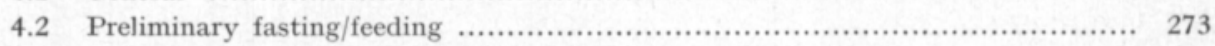

4.3 Availability of virus in source plants ........................................... 274

4.3.1 Availability of virus in different cocoa types .............................. 276

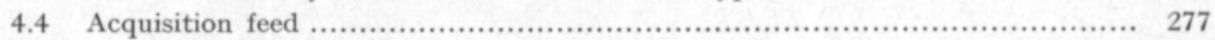

4.4.1 General conditions during acquisition feed $\ldots \ldots \ldots \ldots \ldots \ldots \ldots \ldots \ldots \ldots \ldots \ldots, 277$

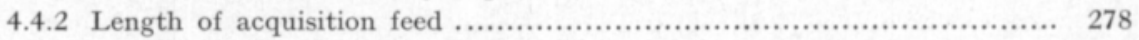

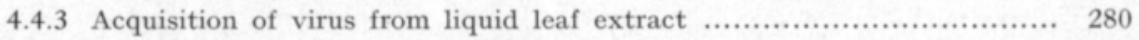

4.5 Persistence of virus in mealybugs after acquisition feed . ...................... 281

4.5.1 Persistence of virus in fasting/feeding mealybugs ........................ 281

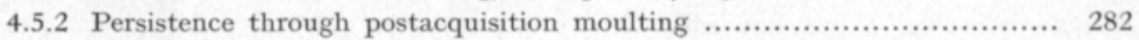

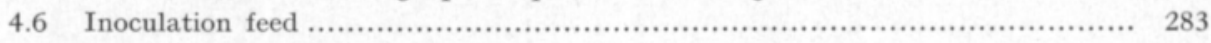

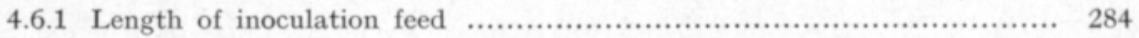

4.6.2 Number of mealybugs on test plants during inoculation feed ........... 284

4.6.3 Inoculation feed with virus resistant/tolerant cocoa. . .................... 285

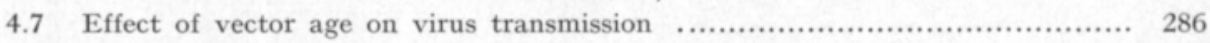

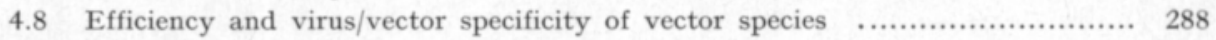

4.9 Effect of physical factors on virus transmission ................................ 289

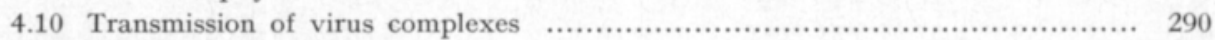

4.11 Latent period of virus in the vector ........................................ 291

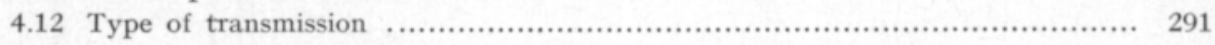

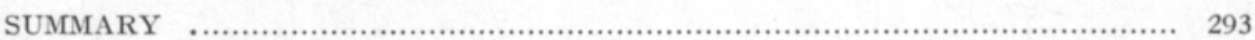

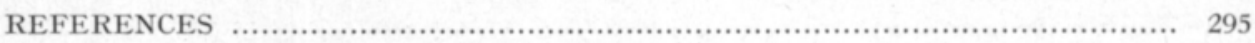

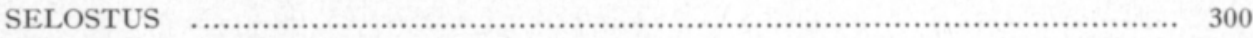

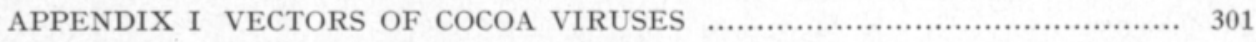

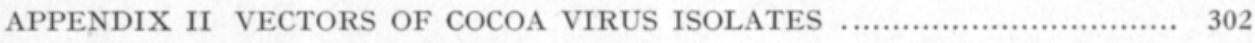

APPENDIX III INSECTS THAT HAVE FAILED TO TRANSMIT ANY OF THE

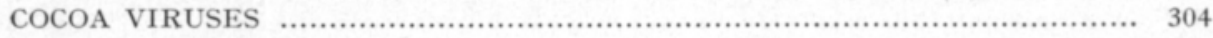




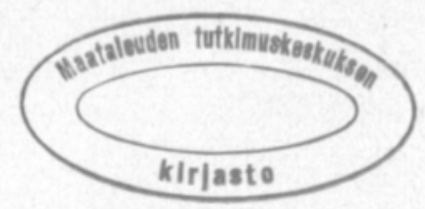

Rorvainen, O. 1976. Transmission of cocoa viruses by mealybugs (Homoptera Pseudococcidae). J. Scient. Agric. Soc. Finl. 48: 203-304.

\begin{abstract}
Several mealybug species reacted positively towards light and high humidity. Planococcoides njalensis (Laing) had a thermopreferendum at $20-25^{\circ} \mathrm{C}$. and $25-$ $33^{\circ} \mathrm{C}$. was optimum for reproduction with a partial fecundity of 92 nymphs per female. $\mathrm{T} \frac{1}{2}$ biol. of ${ }^{32} \mathrm{P}$ in the species was $11.4-15.3$ days. Food uptake from virus infected plants was positively related to the infectivity of $P$. njalensis with cocoa swollen shoot virus isolate 1A. Plant and mealybug radioactivity were positively correlated. Amount of honeydew excreted by the species and the radioactivity of the honeydew were positively correlated. Frequency distribution of ${ }^{32} \mathrm{P}$ in $\mathrm{P}$. njalensis after feeding on ${ }^{32} \mathrm{P}$-active seedlings or sucrose solution was similar. Radiation effects on infectivity of mealybugs were not detected at $30 \mu \mathrm{Ci} / \mathrm{ml}$ of ${ }^{32} \mathrm{P}$ in seedling culture solution.

With CSSV $1 \mathrm{~A}$ and $P$. njalensis, preliminary fasting increased the rate of settling down to feed, the food uptake and infectivity of mealybugs. Virus was transmitted more often from stems than leaves of source plants. Groups of seedlings of $29-54$ days old were almost equally good sources of virus for mealybugs and availability varied more between individual source plants. Mealybugs removed their stylets from source plants in 240 seconds. The length of acquisition access time for maximum transmission was $48-72$ hours. Virus was not acquired during short feeds of up to one hour. Virus was acquired from infected seedlings by mealybugs via a parafilm membrane. Acquisition of virus from liquid leaf extract was rare. Virus persisted in mealybugs up to $72-96$ hours and loss of infectivity was exponential with a $\mathrm{T} \frac{1}{2}$ of $12-13$ hours. Virus persisted in the mealybugs through postacquisition moulting. Mealybugs vere seemingly more efficient vectors after postacquisition feeding than fasting, Latent period of virus in the test plants was short and over $98 \%$ of the test plants showed virus symptoms in three months. With different numbers of mealybugs on test plants during the inoculation feed, the infection rate was as expected. The use of mealybugs while testing virus resistant and tolerant cocoa is demonstrated. Location of feeding mealybugs on test beans did not influence the infection rate. Virus transmission by mealybugs was not affected by light or darkness. The food uptake was highest and virus was transmitted most often in $29-36^{\circ} \mathrm{C}$. The transmission of CSSV isolate $1 \mathrm{M}$ or cocoa mottle leaf virus isolate $1 \mathrm{C}$ with $P$. njalensis as the vector, or CSSV 1A with Ferrisia virgata (Cockerell) was similar to that of CSSV 1A with P. njalensis as the vector. A formula is given to describe the increase of infectivity in mealybugs during acquisition feed.
\end{abstract}

\title{
1. Introduction
}

Our knowledge of viruses transmitted by mealybugs (Pseudococcidae) is almost entirely based on the extensive research carried out with cocoa swollen shoot disease, a scourge in the cultivation of the cocoa plant (Theobroma cacao 
L.) and one of the most economically damaging of all plant virus diseases. The disease was first discovered in Ghana by Steven (1936), and Posnette (1940) showed through successful graft transmission that it was caused by a virus. Posnette (1947 a) also gave a detailed description of the virus.

The search for vectors of cocoa swollen shoot virus (CSSV) started in about 1940 (Posnette 1941, Cotterell 1943), and Box (1945) as well as Posnette and STRICKLAND (1948) confirmed that mealybugs were the vectors of this virus.

Subsequently, other mealybug transmitted cocoa viruses have been found, and cocoa viruses occur also in Nigeria, Ivory Coast, Togo, Sierra Leone, Trinidad and Sri Lanka. Some aspects of cocoa viruses were reviewed by THRESH (1958 a, b) and Thresh and Tinsley (1959). A general account was prepared by Dale (1962). Rorvainen (1973) has reviewed the ecology of cocoa viruses and their mealybug vectors. The most up-to-date general review on cocoa viruses was recently made by THOROLD (1975).

Cocoa viruses and isolates obtained from different localities differ usually in symptoms and may also differ in host range, virulence and characteristics of mealybug transmission. There is little information on the relationships between West African isolates and those from other countries, and even the relationships between the various West African isolates themselves are not entirely clear. Thresh and Tinsley (1959) classify the West African mealybug transmitted isolates into two groups, cocoa swollen shoot virus (CSSV) and cocoa mottle leaf virus (CMLV), on basis of symptoms, host range and vector specificity. Kenten and LEgG $(1967,1971)$, however, have shown that these two groups of viruses have many similarities and are serologically related, and this suggests that both groups should be referred to as CSSV $(* / *: * / *: \mathrm{U} / *: \mathrm{S} / \mathrm{Cc})$. The status of cocoa Trinidad virus (CTV) is not clear as serological tests have not been done, but some dissimilarities between CTV and the West African viruses suggest that these are different viruses (PosnetTe 1944, BAKer and Dale 1947, Kirkpatrick 1950). For the sake of convenience CMLV, CSSV and CTV are treated as distinct viruses in this paper. Little is known about the Ceylon cocoa virus (CCV) which is also transmitted by mealybugs (CARTER 1956). Two other distinct cocoa viruses are known, the cocoa yellow mosaic virus (CYMV) and the cocoa necrosis virus (CNV), but neither are mealybug-borne (Posnette 1950, Attafuah and Brunt 1960, Blencowe et al. 1963, Owusu 1971 a).

Several species of mealybugs are known to transmit one or more of the four cocoa viruses or their different isolates (see Appendix I and II). Much information on characteristics of transmission comes from the numerous contributions dealing with Planococcoides njalensis (Laing). Some other species, e.g. Ferrisia virgata (Cockerell), Planococcus citri (Risso), and Dysmicoccus brevipes (Cockerell), have also been studied but to a lesser extent, and little is known about the transmission characteristics of the other vector species. Among the most important transmission characteristics studied by many authors and reviewed by DALe (1962), RoIvainen (1973), and Thorold (1975), are that mealybugs usually require several hours of acquisition feed on infected plants to become infective, but can then infect a healthy plant in less than an hour. 
The transmitting efficiency of $P$. njalensis increases with prolonged feeding on infected plants and maximum efficiency is obtained after an acquisition feed of 16 hours or more. The infectivity of vectors is usually lost soon and not more than two plants have been infected consecutively by the same mealybug. In terms of a maximum, however, the virus has persisted up to about two days in starving mealybugs. Virus can occasionally be acquired and transmitted by mealybugs within five hours. The virus generally affects mainly conducting tissue (KNIGHT and TINSLEY 1958) and, according to more recent investigations by ENTwISTLE and LONGWORTH (1963), it is obvious that mealybugs acquire virus from the phloem and must deposit virus in the phloem to infect a plant.

In general, viruses with intermediate transmission characteristics are called semi-persistent in a system which designates transmission as persistent (circulative) or non-persistent (stylet-borne) (SYlvester 1958). In such a system the mealybug transmitted cocoa viruses best fall into the group of semi-persistent viruses. As to the mechanism of transmission, evidence has been presented to support the view that some semi-persistent viruses are stylet-borne, although there is no general agreement that all the viruses of this group are stylet-borne. Recently RoIVAinen (1971) has reported successful persistence of CSSV through a moult in $P$. njalensis, which suggests circulative transmission mechanism of this virus in the mealybug vectors.

The experimental work of the present study was carried out in 1966-71 at the Cocoa Research Institute of Ghana, and some interim reports on the progress of this work have been made available earlier (RoIvaINEN 1968, 1969, $1970,1971,1972 \mathrm{a}, \mathrm{b})$. The aim of the present paper is to give coherent and up-to-date views of the various factors which have an influence upon the relationships between the viruses of the cocoa plant and their mealybug vectors. Much of the scattered information on mealybug transmission of cocoa viruses is available only in the various reports of the West African Cocoa Research Institute or, following the dissolution of the West African Research Organizations in 1962, in reports of the Cocoa Research Institutes of Ghana and Nigeria, and these reports have a very restricted distribution. Part of this information is conflicting and some of it is difficult to assess because details of experimental procedures are lacking or obscure.

Together with presentation of primary experimental data the purpose of this study is to collate and critically assess published information on the basic aspects of the cocoa/virus/vector relationships to provide a firm basis for further work and to indicate useful lines of investigation. The natural spread of virus by vectors or control measures are not discussed in this paper. However, some relevant aspects of vector biology are included as deemed necessary.

\section{Experimental techniques, conditions and materials}

\subsection{Collection and handling of mealybugs}

Most of the virus transmission tests were done with $P$. njalensis, but also with $F$. virgata to some extent. $P$. njalensis was collected in the field as colonies 
on cocoa pods or young cocoa shoots. When these parts of the plant are tapped and left for a few minutes, most of the insects withdraw their stylets and can be collected easily with a fine brush without damaging them. The collection was done by a team of 'bug-hunters' which brought in the daily catch from various cocoa plantations of the Cocoa Research Institute. Because of possible differences between the daily collections, control tests were carried out when necessary. A collection brought into the laboratory consisted of mealybugs in all stages of development, and in preliminary experiments the collection was used without refinements as to different stages or impurities of honeydew and waxy skin secretions. In most of the experiments, however, only young nymphs of known age were used. These were obtained from reproduction cages specially constructed for the purpose (Fig. 1). The cage consisted of two small chambers separated from each other by a wire or plastic net of a mesh that the adult females could not walk through. Field collected adult females were introduced into one of the two chambers and after one day or a few days newlyborne nymphs, reproduced by the females, could be collected from the other chamber. Nymphs adhering to the waxy covering of the females could be separated mechanically by tapping and shaking the cage and using the net as a sieve at the same time. F. virgata was collected from cocoa to some extent, but most often from a variety of ornamental plants. This mealybug species was handled in the reproduction cages like $P$. njalensis.

\subsection{Attempts to rear $P$. njalensis}

Large numbers of mealybugs were often needed for various experiments, but the method of obtaining supplies by field collection had its drawbacks. The risk of collecting from virus infected trees meant that mealybugs had to

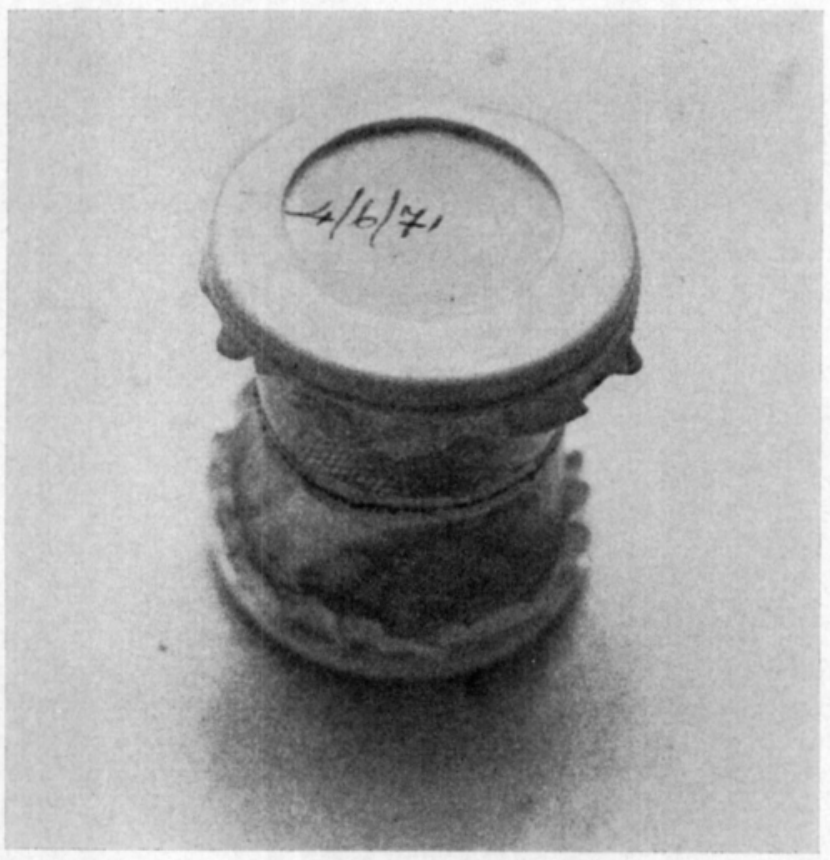

Fig. 1. A two chamber reproduction cage with filter paper between the snap-on lids and chambers. The net in between the chambers keeps adults in one chamber but nymphs can easily leave this chamber and enter the other. 
be starved to free them from possible contamination of virus, or by the use of reproduction cages, virus free nymphs could be obtained because transovarial passage of virus does not occur (DALE 1958). In both cases some mealybugs were lost always. Furthermo1e, there were periodic shortages of mealybugs during the dry season or after the harvest of cocoa pods and, therefore, supplies could not be maintained at a satisfactory level continuously. Thus a suitable method of mass-breeding mealybugs of clonal origin would have been extremely useful.

Two experiments were carried out to rear $P$. njalensis. In the first, two wild Theobroma-species and five types of cultivated cocoa were tested. Seven replicate seedlings of each species and type were grown in plastic buckets and later infested with mealybugs and attending ants, Crematogaster striatula Emery. Mealybug numbers were assessed about every four weeks by counting the live adult females on the seedlings.

The mealybugs had obvious difficulties in becoming established on $T$. grandiflora and $T$. obovatum. On cultivated cocoa they were more at home at first, but after a while there were hardly any ants left and the mealybug numbers on all the host plants showed a decreasing trend during the experiment (Table 1).

In the second experiment, six Theobroma-species and an unknown species of Herrania were tested. Seven replicate seedlings of each species were grown in plastic buckets and later infested with mealybugs and attending ants, Crematogaster africana (Mayr). The infestation took place by putting 20 females on each seedling every week during a period of 12 weeks. The ants were introduced in a large carton nest and they were found soon all over the seedlings. Population assessment of the mealybugs was started a fortnight after the last infestation and was repeated every fortnight up to 12 weeks.

There were marked differences between the plant species tested and the cultivated cocoa was the best host plant among the species (Table 2). But again the ant numbers started to diminish and there was thus an overall decrease of mealybugs at the end of the experiment.

It is evident that the success of a technique for mass-rearing of $P$. njalensis is dependent on providing favourable conditions for host plants, mealybugs

Table 1. Food plant preference of $P$. njalensis. Mean number of adult females on seedlings at monthly intervals, months after infestation.

\begin{tabular}{|c|c|c|c|c|c|c|c|c|}
\hline \multirow{2}{*}{ Plant species and variety } & \multicolumn{8}{|c|}{ Months } \\
\hline & 1 & 2 & 3 & 4 & 5 & 6 & 7 & 8 \\
\hline \multicolumn{9}{|l|}{ T. cacao L. } \\
\hline Amazon $\mathbf{x}$ Cundeamor hybrid ............. & 63 & 44 & 52 & 31 & 23 & 15 & 9 & 11 \\
\hline Trinitario $\mathrm{x}$ Amazon hybrid ................ & 58 & 23 & 33 & 25 & 25 & 16 & 7 & 5 \\
\hline Inter-Amazon hybrid ...................... & 54 & 32 & 34 & 27 & 19 & 15 & 15 & 9 \\
\hline Unselected Amelonado open pollinated & 50 & 35 & 49 & 41 & 28 & 28 & 17 & 9 \\
\hline Amelonado $x$ Amazon hybrid ............. & 30 & 19 & 35 & 19 & 17 & 14 & 8 & 4 \\
\hline T. grandiflora K. Schum. ................. & 15 & 22 & 28 & 28 & 10 & 8 & 9 & 8 \\
\hline$T$. obovatum Bern .......................... & 10 & 7 & 12 & 8 & 9 & 4 & 1 & 1 \\
\hline
\end{tabular}


Table 2. Food plant preference of $P$. njalensis. Mean number of adult females on seedlings at two week intervals, weeks after infestation.

\begin{tabular}{|c|c|c|c|c|c|c|}
\hline \multirow{2}{*}{ Plant species } & \multicolumn{6}{|c|}{ Weeks } \\
\hline & 2 & 4 & 6 & 8 & 10 & 12 \\
\hline 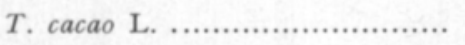 & 117 & 180 & 189 & 208 & 199 & 130 \\
\hline T. speciosa Spreng ..................... & 80 & 81 & 81 & 73 & 58 & 69 \\
\hline T. bicolor Humb. \& Bonpl. ...... & 39 & 44 & 45 & 44 & 36 & 21 \\
\hline T. microcarpa (Mart.) Sprague ... & 31 & 33 & 40 & 49 & 40 & 67 \\
\hline$T$. grandiflora $\mathrm{K}$. Schum. .......... & 11 & 20 & 20 & 19 & 26 & 37 \\
\hline$T$. obovatum Bern ..................... & 6 & 6 & 6 & 8 & 12 & 5 \\
\hline Herrania sp. A (indet) ............. & 1 & 6 & 5 & 4 & 4 & 8 \\
\hline
\end{tabular}

and associated ants; in the absence of ants, mealybugs soon become smothered by moulds which develop on the honeydew. In these two tests such conditions could not be established for the attending ants. It is worth noting that several authors have tried to breed $P$. njalensis, or other mealybug species infesting cocoa, on different food plants with or without the attending ants, but always however, with discouraging results (NICOL 1950, KIRKPATrick 1950, ANon. 1951 a, 1953 a, Donald 1954 a, b, c, 1955, 1957, Decker 1956, 1957, Okusanya 1971).

\subsection{Artificial feeding}

Mealybugs were sometimes fed on sucrose and other solutions in feeding tubes. These were glass tubes about $4.0 \mathrm{~cm}$ long and with an inner diameter of about $0.8 \mathrm{~cm}$. A double parafilm sachet was fixed to one end of the tube and the other was closed with a foam polythene plug after introducing the mealybugs. Conical vacuum flasks were used sometimes instead of glass tubes. The sachet containing the liquid diet between the two sheets of parafilm was prepared as described by MitTler and DADD (1964).

\subsection{Feeding cones and cages}

In many experiments mealybugs were fed on cocoa seedlings by using the paper cone technique of Posnette and Strickland (1948). According to this technique, a conical piece of paper is fixed near the terminal bud of the seedling and the mealybugs are placed inside the cone. Because many mealybugs disappeared into the soil or otherwise escaped from the cones, this technique was replaced by confining the mealybugs into feeding cages which were fixed on the seedlings. A description of such feeding cages has been published by MARKKULA (1963). In this investigation the cages had an outer diameter of $2.5 \mathrm{~cm}$, they were about $3.0 \mathrm{~cm}$ thick, and the diameter of the inner feeding space was $1.2 \mathrm{~cm}$ (Fig. 2). These cages had several advantages; the mealybugs could not escape, they were not exposed to external hazards, and they readily settled down to feed inside the cage (Fig. 3). 
Fig. 2. Two feeding cages for mealybugs attached around the stem of a virus infected seedling.

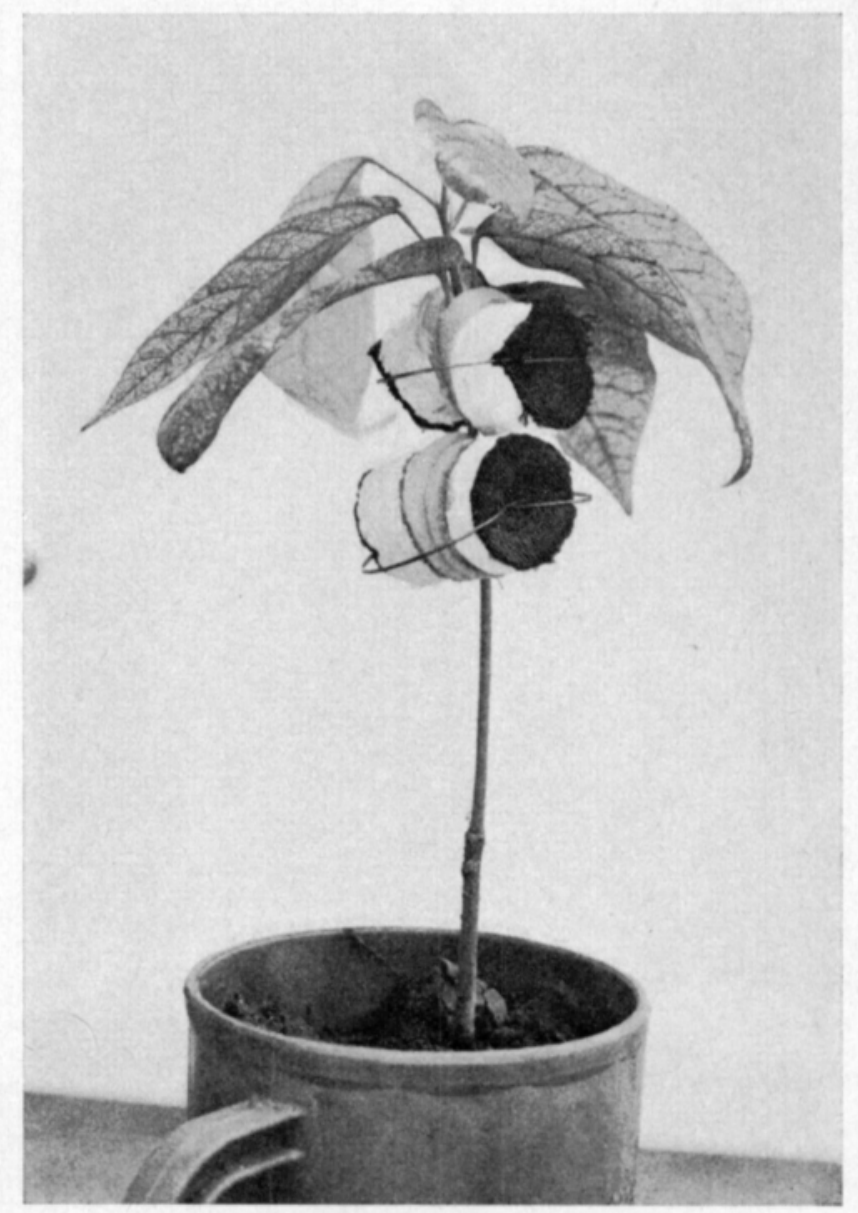

\subsection{Physical conditions}

Handling of insects and other short term manipulations were usually carried out in air-conditioned laboratory rooms where the temperature varied between 20 and $28^{\circ} \mathrm{C}$. depending on outside conditions. The relative humidity varied from 40 to $70 \%$ in these rooms and the variation was indirectly proportional with the temperature. The experiments proper were done sometimes in an ordinary laboratory room with a considerably high temperature and humidity (Fig. 4). For most experiments, however, two growth chambers were used with standard conditions of $25-27^{\circ} \mathrm{C}$., $55-75 \%$ of relative humidity, and about 2000 foot candles of fluorescent light. Due to technical difficulties it was impossible to reproduce these standard conditions in some experiments. The deviations are shown in connection with those experiments. The standard conditions were arrived at after some experimentation described in the following.

\subsubsection{Reactions of mealybugs to light}

Light reactions of mealybugs were investigated in air-conditioned laboratory at $25-27^{\circ} \mathrm{C}$. and $40-60 \% \mathrm{RH}$. A wooden box measuring $30 \times 30 \times 30 \mathrm{~cm}$ was used and the open top of the box was covered by a thick black cloth around 


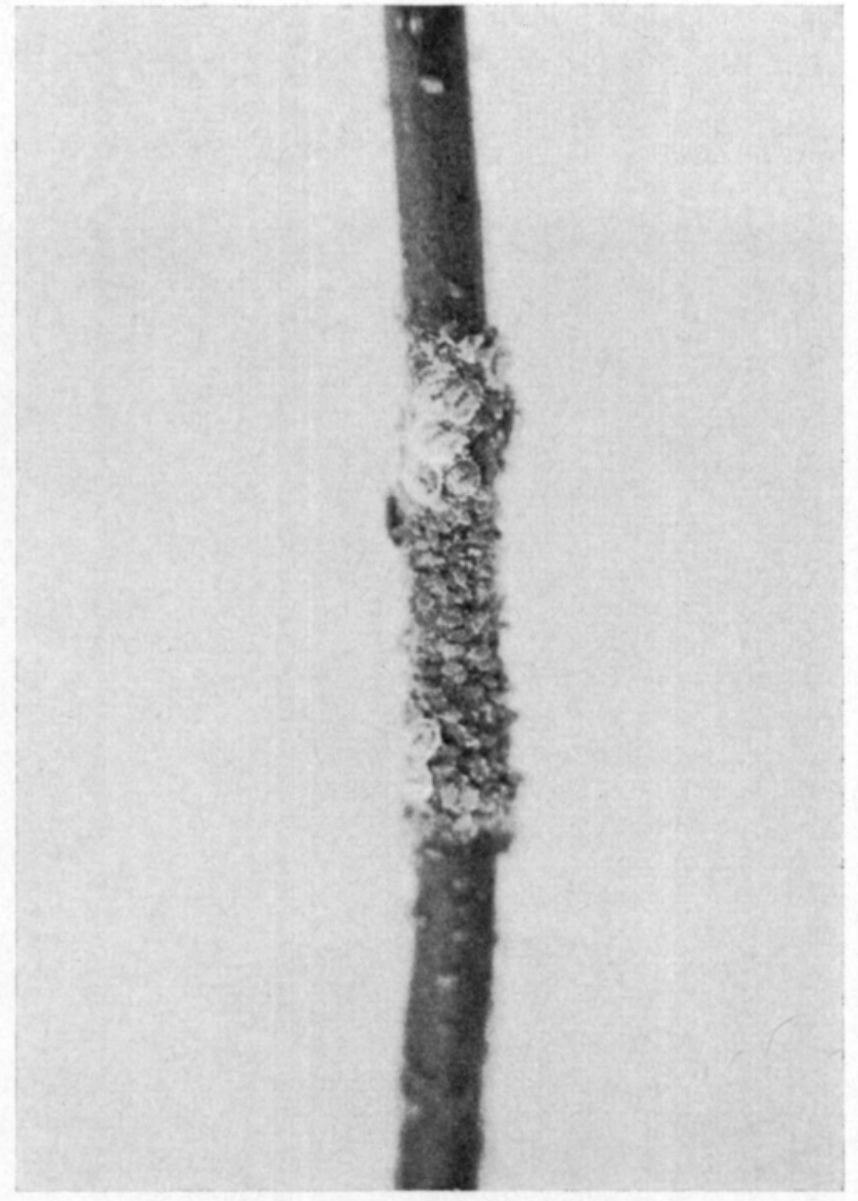

Fig. 3. Feeding mealybugs forming a dense mat around a stem of a cocoa seedling; a typical scene when the feeding cage is removed. Also note the presence of some larger adult females.

the neck and head of the observer (ref. old-fashioned photographers). Inside the box on the floor there was a microscope lamp with a $12 \mathrm{~V} 5.2 \mathrm{~W}$ bulb in one of the corners of the box. The lamp gave a beam of light on the experimental area at about $15^{\circ}$ angle from horizontal towards vertical. The experimental area was a horizontal piece of white paper on the floor of the box (Fig. 5). The area was divided into squares measuring about $1.6 \mathrm{~cm}^{2}\left(0.25 \mathrm{inch}^{2}\right)$ each, and the set-up of squares was $9 \times 17$.

Before mealybugs were introduced into the system, the temperature was measured in different places of the experimental area and at different distances from the light source. This was done with a copper-constantan thermocouple connected into a potentiometer (Foster Portable Potentiometer Model 3155APX). This instrument could not detect any differences in the temperature at different places of the experimental area. Thus the amount of radiant heat must have been very small.

Mealybug nymphs $0-3$ days old were introduced into the system one at a time and were liberated at the starting point which was in the middle of the beam of light at one end of the experimental area. The movements of the nymphs were recorded whenever they entered a new square of the area. This way of recording gave four possible directions of movement with equal chances, 


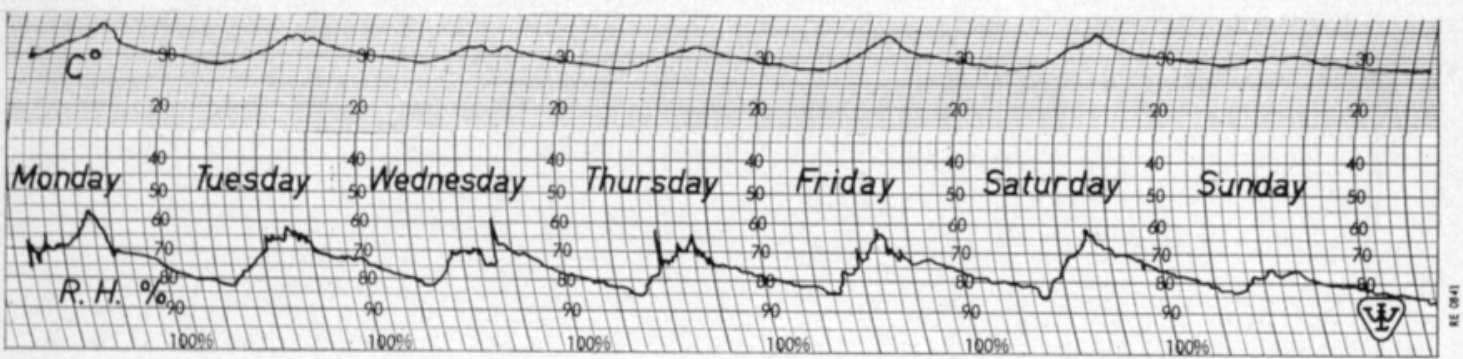

Fig. 4. Typical temperature and humidity conditions in an ordinary laboratory room. Recorded 19-26 June 1967.

namely, towards the light, away from the light, at right angles to the beam of light to the left, and to the right. Twenty nymphs of $P$. njalensis, $P$. citri and $F$. virgata were used in the experiment. The experiment was stopped each time when the nymph left the experimental area, and a new nymphs was introduced. The nymphs were obtained from reproduction cages kept in standard conditions but in dark for three days.

All the three mealybug species behaved similarly. On the whole about $56 \%$ of the movements were directed against the beam of light, $36 \%$ of the movements were at right angles either to the left or right, and only $8 \%$ of the movements were directed away from the light (Table 3 ).

\subsubsection{Reactions of mealybugs to humidity}

Humidity reactions of mealybugs were studied in a growth chamber in controlled temperature conditions of $25-27^{\circ} \mathrm{C}$. and with the lights off. Experiments were carried out in a linear gradient apparatus which was built according to Youdeower (1967) but modified and smaller in size. The apparatus was a rectangular perspex box measuring $21.0 \times 5.0 \times 4.2 \mathrm{~cm}$ with a removable top and a false floor of 200 mesh wire gauze at $1.0 \mathrm{~cm}$ from the top. Below the false floor there were five dishes with graded aqueous solutions of sodium hydroxide (MADGE 1961) to produce a humidity gradient in the experimental

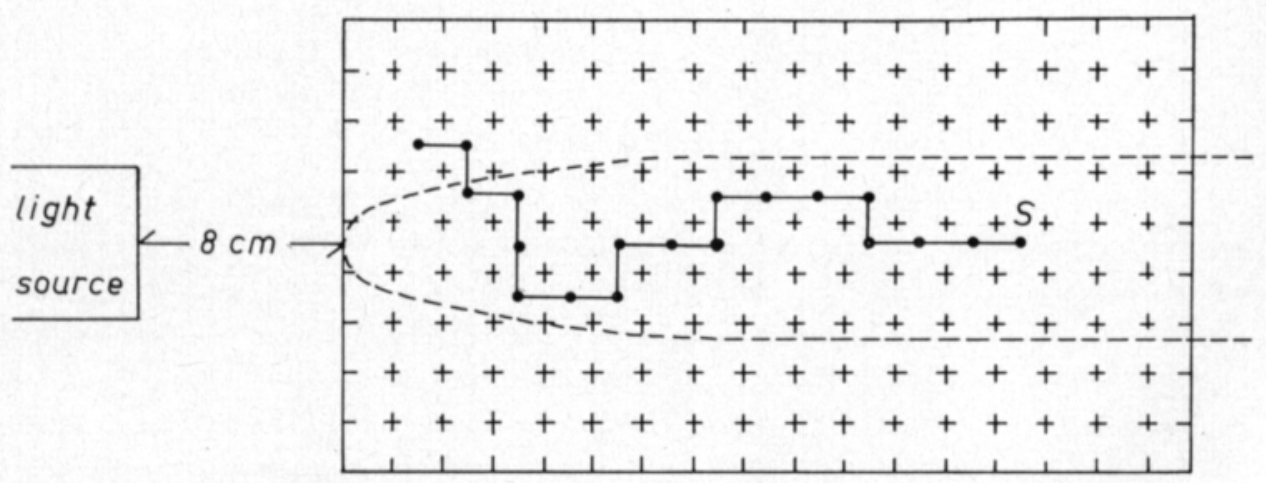

Fig. 5. Reactions of mealybugs to light. The experimental area with a track of movement as recorded $(\bullet)$, starting point $(\mathrm{S})$, and the beam of light indicated by the broken line. 
Table 3. Movement of $P$. njalensis, $F$. virgata and $P$. citri in a beam of light. Frequency of movement observed towards given direction, mean of 20 nymphs, with expected frequencies in parentheses.

\begin{tabular}{|c|c|c|c|c|}
\hline \multirow[b]{2}{*}{$\begin{array}{l}\text { Species and } \\
\text { frequency }\end{array}$} & \multicolumn{4}{|c|}{ Direction of movement } \\
\hline & $\begin{array}{l}\text { Towards } \\
\text { the light }\end{array}$ & $\begin{array}{c}\text { At right } \\
\text { angles to } \\
\text { the beam, } \\
\text { right }\end{array}$ & $\begin{array}{c}\text { At right } \\
\text { angles to } \\
\text { the beam, } \\
\text { left }\end{array}$ & $\begin{array}{c}\text { Away from } \\
\text { the light }\end{array}$ \\
\hline \multicolumn{5}{|l|}{ P. njalensis } \\
\hline 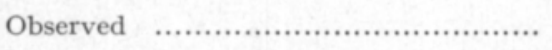 & 159 & 61 & 49 & 30 \\
\hline 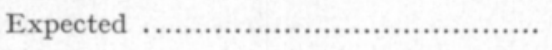 & $(74.75)$ & $(74.75)$ & $(74.75)$ & $(74.75)$ \\
\hline \multicolumn{5}{|l|}{ F. virgata } \\
\hline 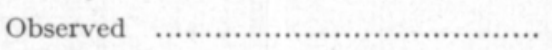 & 158 & 40 & 43 & 11 \\
\hline 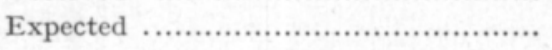 & $(63.00)$ & $(63.00)$ & $(63.00)$ & $(63.00)$ \\
\hline \multicolumn{5}{|l|}{ P. citri } \\
\hline Observed & 118 & 36 & 53 & 22 \\
\hline Expected & $(57.25)$ & $(57.25)$ & $(57.25)$ & $(57.25)$ \\
\hline
\end{tabular}

chamber which measured $17.0 \times 0.9 \times 0.7 \mathrm{~cm}$. The top was hermetically sealed with a rubber gasket, and small pieces of cobalt thiocyanate paper on the floor indicated different relative humidities (Solomon 1945). A central hole in the top, through which the insects were introduced, was sealed with a cover slip. Food was available above each hydroxide container as $2 \mathrm{~cm}$ long pieces of young cocoa shoots wrapped tightly in parafilm.

The nymphs were obtained from reproduction cages which were kept in a growth chamber in standard conditions but in darkness for two days. In each test the nymphs were allowed to stay in the experimental chamber for 24 hours before the chamber was opened and the number of insects counted on different shoot pieces. The number of nymphs varied in each replicate test depending on the availability of nymphs.

The nymphs reacted positively to high humidities and tried to avoid low humidities (Table 4). This happened with all the mealybug species tested and in every replicate test irrespective of different numbers of nymphs.

\subsubsection{Reactions of mealybugs to temperature}

Temperature reactions of mealybugs were tested in a linear temperature gradient apparatus which was constructed according to YoudEoweI (1968) but with some modifications. The gradient was composed of a wide U-shaped copper bar, $18 \mathrm{~cm}$ long, $2 \mathrm{~cm}$ wide and $1 \mathrm{~cm}$ deep. The bar was covered with a removable perspex top having nine equidistant holes for thermometers. A rubber gasket closed the system hermetically. Both ends of the bar were inside different water tanks, one with ice and water, and the other with an electric heater and a thermostat immersed in water. The whole system was insulated with porous polystyrene. The nymphs were obtained from cultures in reproduc- 
Table 4. Frequency distribution of $P$. njalensis, $F$. virgata, $P$. citri and $P$. longispinus in a humidity gradient apparatus at $25-27^{\circ} \mathrm{C}$. with the preferred humidity in various places of the apparatus. Expected frequencies in parentheses.

P. njalensis

Relative humidity, \%

Frequency, total of 6 replicates ...........

Expected

10
142

(574.4)

Relative humidity, $\%$

Frequency, total of 4 replicates

Expected

95

1184

(555.0)

Relative humidity, \%

Frequency, total of 4 replicates ......

Expected

$(260.8)$

F. virgata

Relative humidity, $\%$

Frequency, total of 6 replicates .......

Expected

90

21

(15.2)

Relative humidity, $\%$

Frequency, total of 7 replicates .......

Expected

3

P. citri

Relative humidity, \% ....

Frequency, total of 8 replicates .......

Expected

Relative humidity, \%

Frequency, total of 5 replicates

Expected

162

(238.2)

Relative humidity, \%

Frequency, total of 5 replicates .......

Expected

$\begin{array}{rrrr}30 & 50 & 70 & 90 \\ 394 & 406 & 721 & 1209 \\ (574.4) & (574.4) & (574.4) & (574.4) \\ 20 & 95 & 20 & 95 \\ 101 & 530 & 181 & 779 \\ (555.0) & (555.0) & (555.0) & (555.0) \\ 95 & 20 & 95 & 20 \\ 458 & 71 & 685 & 72 \\ (260.8) & (260.8) & (260.8) & (260.8)\end{array}$

\section{$P$. longispinus}

Relative humidity, \%

\begin{tabular}{rrrrr}
90 & 10 & 90 & 10 & 90 \\
86 & 15 & 38 & 6 & 38 \\
$36.6)$ & $(36.6)$ & $(36.6)$ & $(36.6)$ & $(36.6)$ \\
10 & 90 & 10 & 90 & 10 \\
0 & 5 & 1 & 29 & 2 \\
$(7.4)$ & $(7.4)$ & $(7.4)$ & $(7.4)$ & $(7.4)$ \\
\hline
\end{tabular}

Frequency, totalof 2 replicates .......

Expected

Relative humidity, \%

tion cages maintained in standard conditions in darkness for two days. These $0-2$ day old nymphs were allowed to stay in the gradient for six hours. Ten $1 \mathrm{~cm}$ long pieces of parafilm covered cocoa shoots were put in between the thermometers for the nymphs to settle on and feed.

The nymphs reacted more positively to temperatures of about $20-25^{\circ} \mathrm{C}$. than to higher or lower temperatures (Table 5). It is possible, however, that the actual preferred temperature range is somewhat higher because the humidity 
Table 5. Frequency distribution of $P$. njalensis nymphs in a linear temperature gradient apparatus.

\begin{tabular}{|c|c|c|c|}
\hline $\begin{array}{l}\text { Temperature } \\
\text { regime, } \mathrm{C}^{\circ} \text {. }\end{array}$ & & $\begin{array}{l}\text { Frequency, total } \\
\text { of } 12 \text { replicates }\end{array}$ & $\begin{array}{l}\text { Expected } \\
\text { frequency }\end{array}$ \\
\hline $15.0-18.0$ & 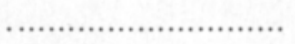 & 102 & (123.9) \\
\hline $18.5-20.5$ & 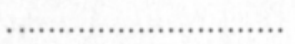 & 328 & (123.9) \\
\hline $22.0-24.0$ & 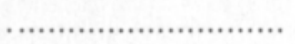 & 214 & (123.9) \\
\hline $24.5-26.0$ & 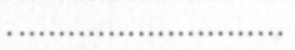 & 175 & (123.9) \\
\hline $27.5-29.0$ & ............................ & 104 & (123.9) \\
\hline $29.5-31.5$ & 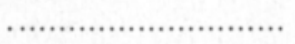 & 105 & (123.9) \\
\hline $32.0-34.0$ & 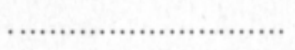 & 86 & (123.9) \\
\hline $34.5-37.0$ & 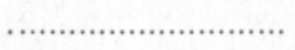 & 77 & (123.9) \\
\hline $37.0-40.0$ & 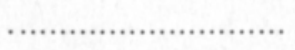 & 42 & (123.9) \\
\hline $41.0-45.5$ & 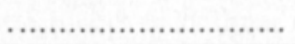 & 6 & (123.9) \\
\hline
\end{tabular}

was not controlled, and thus the nymphs may have responded more positively to the higher relative humidity of the lower temperatures.

\subsubsection{Discussion and conclusions}

Information was required on reactions of virus transmitting mealybugs towards light, humidity and temperature to establish favourable feeding conditions in which virus transmission experiments could be carried out successfully. Posnette and Strickland (1948) report that 'all stages of $P$. njalensis are negatively phototrophic, and this response can be utilized for a bulk removal of these insects from cacao pods. The pods are placed in a Berlese-Tullgren funnel fitted with a $40 \mathrm{~W}$ electric bulb, and a collecting tube ... A large proportion of the nymphs and young adults migrate into the tube ... In this case it is probably a seeming negative response to light because the insects may have responded to temperature rather than to light. Apart from this report there appear to be no further references dealing with reactions of virus transmitting cocoa mealybugs towards light, humidity or temperature.

Detailed studies do exist, however, on some other mealybug species. According to Salama (1970 a) the reaction of young females of Planococcus vitis Nied. towards light is a typical negative tropotaxis at $60 \mathrm{~W}$ illumination. In contrast, Parlatoria oleae (Colvee) is said to be a photopositive species, the reaction being reversed at high intensities of light (HAFEz et al. 1967).

The cocoa mealybugs tested in this study all reacted positively to light of low intensity. Although no specific experiments were carried out in other light conditions, it was observed from time to time that the intensity of 2000 foot candles inside the growth chamber attracted nymphs of $P$. njalensis or $F$. virgata when the nymphs were kept on a black sheet of glass outside but near the illuminated observation window of the chamber. Moreover, inside the growth chamber in standard conditions, nymphs of $P$. njalensis settled down easily to feed in the feeding cages on cocoa seedlings. When the feeding cage was removed and the nymphs were exposed, most of them still remained settled for the next 24 hours. However, if these seedlings were taken outside the labor- 
atory, then, in the presence of sunlight and heat, the exposed nymphs withdrew their stylets and moved down the stem to hide themselves in the soil in a matter of a few minutes. This reaction was slower on a half-cloudy day when the sun was not directly visible. Similar photic response towards direct sunshine has been reported by SALAMA (1970 b) for Mycetaspis personatus (Comstock) in Egypt. It is possible, therefore, that several mealybug species respond positively to light of low intensity and negatively to high intensity light.

Like some other insects, cocoa mealybugs display a definite response towards various relative humidities or different temperatures. No particular temperature can be described as the optimum and we are rather dealing here with a wide zone of preference. Cocoa mealybugs appear to prefer high humidities when they are pre-conditioned at $60-75 \% \mathrm{RH}$. According to Salama (1970 a) $P$. vitis has a very wide zone of thermopreferendum extending from 16 to $34^{\circ} \mathrm{C}$. and, as far as can be judged, also this species prefers high humidities except when preconditioned at $95 \% \mathrm{RH}$ which resulted in the mealybugs showing indifference to humidity alternatives.

\subsection{Temperature and reproduction}

Field collected females of $P$. njalensis were brought into laboratory where the adhering nymphs were carefully separated. Then these clean females were put into reproduction cages, 20 females into each cage, and the cages were kept in three different temperature regimes in the growth chambers for 44 hours. After this the cages were opened and the contents examined. There were marked differences between the three temperature regimes tested and the temperature of $25-27^{\circ} \mathrm{C}$. appeared to be more favourable for reproduction by the fasting females than the higher temperatures. There were differences also in the rate of mortality of females and of nymphs in the three temperature regimes (Table 6).

In another experiment, field collected females of $P$. njalensis were cleaned and put into reproduction cages at a rate of 20 per cage, and the cages were then kept in five different temperature regimes till the females were dead or moribund. The cages were opened daily and all the newly-borne nymphs were removed and counted. The cages were replicated four times, and there were four female populations collected from different places near the laboratory. Each population was tested simultaneously in two growth chambers in a control temperature of $25-27^{\circ} \mathrm{C}$. and in one other temperature regime in order to check for population differences.

Table 6. Reproduction of fasting females of $P$. njalensis at different temperatures during a 44 hour period.

\begin{tabular}{|c|c|c|c|c|c|}
\hline $\begin{array}{l}\text { Temperature } \\
\text { regime, } \mathrm{C}^{\circ} .\end{array}$ & $\begin{array}{l}\text { Number of } \\
\text { alive females }\end{array}$ & $\begin{array}{c}\text { number } \\
\text { alive }\end{array}$ & $\begin{array}{c}\text { number } \\
\text { dead }\end{array}$ & $\begin{array}{l}\text { Nymphs } \\
\text { rate of } \\
\text { reproduction }\end{array}$ & $\begin{array}{c}\text { survivors } \\
\text { per female }\end{array}$ \\
\hline $25-27$ & 80 & 1484 & 9 & 18.7 & 18.5 \\
\hline $31-33$ & 80 & 805 & 69 & 10.9 & 10.1 \\
\hline $36-38$ & 39 & 39 & 356 & 4.9 & 0.5 \\
\hline
\end{tabular}


Some reproduction occurred in all the temperature regimes but the highest yield of nymphs was obtained at temperatures between 25 and $33^{\circ} \mathrm{C}$. (Table 7). There was at least some reproduction up to 13 days in the most favourable temperature conditions, however, most of the reproduction occurred during the first seven days (Fig. 6). Also, the reproducing females became moribund sooner in the high temperatures. The highest rate of reproduction during the first 24 hour period occurred at the highest temperature (Table 8).

According to Strickland (1951) P. njalensis has a fecundity of 6-90 nymphs with a mean at 36 . This is a strikingly low figure, though his experiments

Table 7. Reproduction of fasting females of $P$. njalensis at different temperatures. Control temperature $25-27^{\circ} \mathrm{C}$. with relative humidity at $55-75 \%$.

\begin{tabular}{ccc}
\hline $\begin{array}{c}\text { Temperature } \\
\text { regime, } \mathrm{C}^{\circ}\end{array}$ & $\begin{array}{c}\text { Relative } \\
\text { humidity, } \%\end{array}$ & $\begin{array}{c}\text { Mean number of nymphs per } \\
\text { female } \pm \text { S.E. } \mathrm{x} \mathrm{t} 95 \%\end{array}$ \\
\hline $22-24$ & $60-80$ & $\left.63.6 \pm 20.2^{\mathrm{b} 1}\right)$ \\
Control & & $96.9 \pm 18.6^{\mathrm{e}}$ \\
$28-30$ & $55-75$ & $114.7 \pm 17.1^{\mathrm{c}}$ \\
Control & & $73.7 \pm 52.9^{\mathrm{abe}}$ \\
$31-33$ & $55-75$ & $81.2 \pm 28.8^{\mathrm{b}}$ \\
Control & & $85.3 \pm 38.9^{\mathrm{be}}$ \\
$34-36$ & $50-70$ & $36.2 \pm 9.7^{\mathrm{a}}$ \\
Control & & $111.0 \pm 20.0^{\mathrm{e}}$ \\
\hline
\end{tabular}

1) In this and some other tables, numbers followed by the same letter are not significantly different at $5 \%$ level.

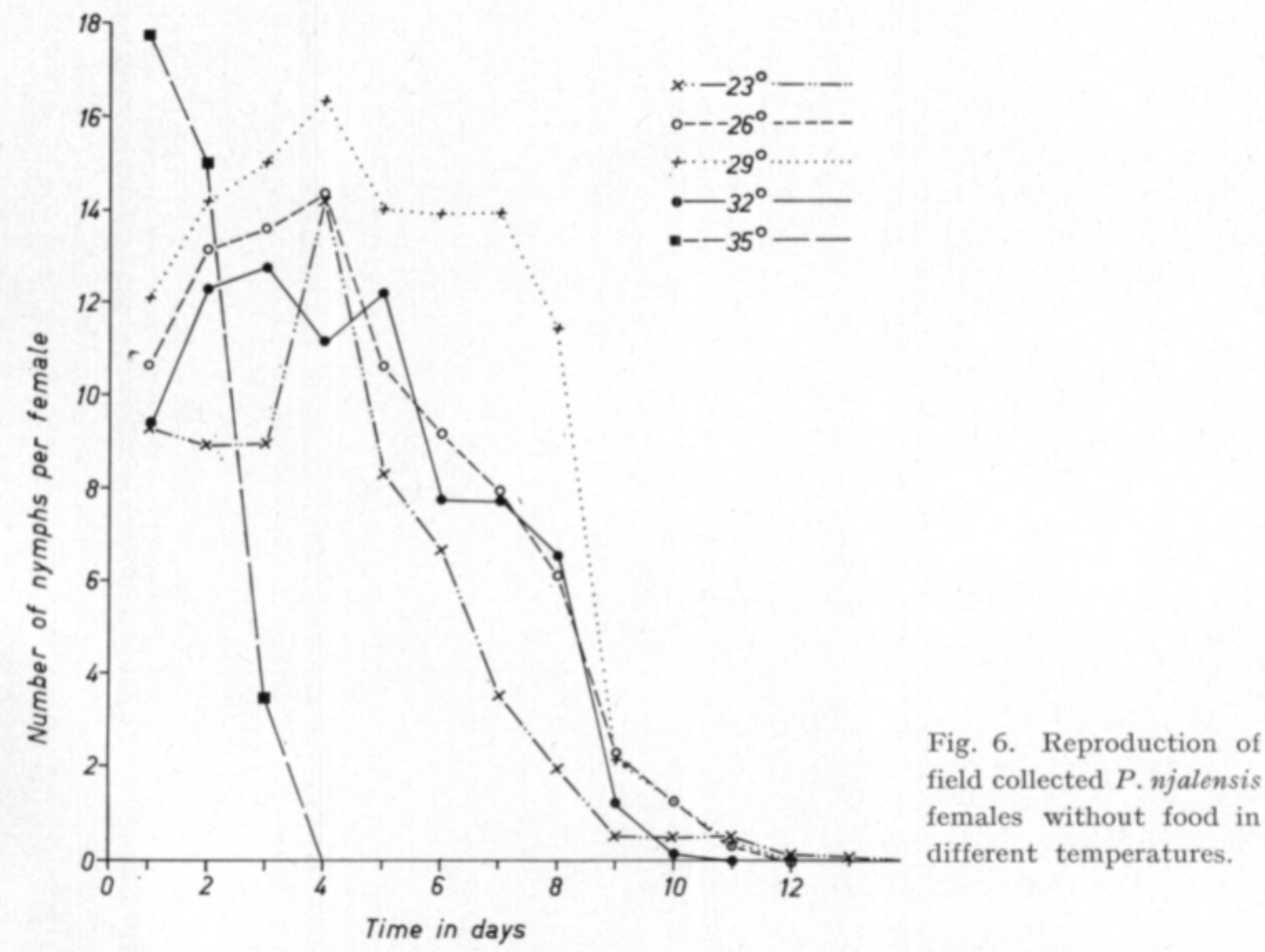


Table 8. Reproduction of fasting females of $P$. njalensis at different temperatures during a 24 hour period.

\begin{tabular}{ccc}
\hline $\begin{array}{c}\text { Temperature } \\
\text { regime, } \mathrm{C}^{\circ}\end{array}$ & $\begin{array}{c}\text { Relative } \\
\text { humidity, } \%\end{array}$ & $\begin{array}{c}\text { Mean number of nymphs per } \\
\text { female } \pm \text { S.E. x } \mathrm{t} 95 \%\end{array}$ \\
\hline $22-24$ & $60-80$ & $9.3 \pm 3.3^{\mathrm{a}}$ \\
$25-27$ & $55-75$ & $10.7 \pm 2.6^{\mathrm{a}}$ \\
$28-30$ & $55-75$ & $12.1 \pm 3.7^{\mathrm{a}}$ \\
$31-33$ & $55-75$ & $9.4 \pm 3.2^{\mathrm{a}}$ \\
$34-36$ & $50-70$ & $17.7 \pm 4.6^{\mathrm{b}}$ \\
\hline
\end{tabular}

were carried out in laboratory conditions, where the temperature and humidity were not recorded, and which may have been less favourable for reproduction. Besides, he used the term fecundity to indicate the maximum number of nymphs surviving after the first moult. In the present study the rate of reproduction was tested in different temperatures with field collected females which may have reproduced already while still in the field. Thus, the values obtained represent only a part of the total fecundity. However, these partial fecundity values average about 92 at control temperature of $25-27^{\circ} \mathrm{C}$. and, therefore, the total fecundity in terms of number of live nymphs reproduced is probably well over a hundred in favourable conditions. This suggestion agrees with results obtained by some other authors on several mealybug species other than P. njalensis (James 1937, Hafez and Salama 1970, Seuge et al. 1971).

\subsection{Use of radioisotopes}

The use of radioisotopes was based on the early work of Cornwell (1957), who studied the uptake and translocation of ${ }^{32} \mathrm{P}$ in seedlings and mature cocoa trees. In the present study, radioisotopes were used in many experiments and they were obtained from The Radiochemical Centre, Amersham, England. ${ }^{32} \mathrm{P}$ was used as orthophosphate in a solution containing $1 \mathrm{mg} / \mathrm{ml}$ phosphorus buffer $\mathrm{pH} 7{ }^{35} \mathrm{~S}$ was in the form of carrier free sulphate in an aqueous solution, $\mathrm{pH}$ 6-8. Most often these commercial isotope products were used to label virus source plants to detect the subsequent feeding of mealybugs in various conditions. Virus infected cocoa seedlings were washed in tap water to clean the roots from soil and other debris and then the roots were immersed into complete culture solution in a 50 or $\mathbf{1 0 0} \mathrm{ml}$ conical flask. Two layers of parafilm were used to seal the flask and fresh radioactive culture solution was added when necessary. The culture solution containing the radioisotope had a specific activity of about $30 \mu \mathrm{Ci} / \mathrm{ml}$ which was sufficient in most cases for satisfactory levels of uptake by seedlings and by mealybugs from these seedlings. The culture solution was the one used in mineral uptake studies at the Cocoa Research Institute as a standard culture solution (LOCKARD and Asomaning 1963, Hutcheon communication by letter 4 Oct. 1971), and it contained various chemicals (Table 9 ).

When mealybugs were removed alive from labelled seedlings or feeding media for radioactivity measurements they were put into special cages mounted 
Table 9. Chemical composition of the standard culture solution.

\begin{tabular}{|c|c|c|}
\hline Element & ppm & Source \\
\hline Nitrogen.............. & 70 & $\mathrm{Ca}\left(\mathrm{NO}_{3}\right)_{2} \cdot 4 \mathrm{H}_{2} \mathrm{O}$ \\
\hline 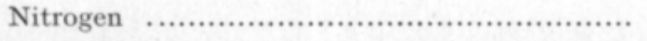 & 40 & $\mathrm{CO}\left(\mathrm{NH}_{2}\right)_{2}$ \\
\hline 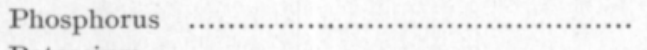 & 24 & $\mathrm{~K}_{2} \mathrm{HPO}_{4}$ \\
\hline 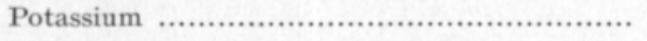 & 60 & $\mathrm{~K}_{2} \mathrm{HPO}_{4}$ \\
\hline 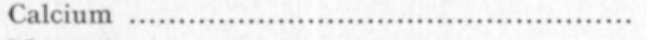 & 100 & $\mathrm{Ca}\left(\mathrm{NO}_{3}\right)_{2} \cdot 4 \mathrm{H}_{2} \mathrm{O}$ \\
\hline 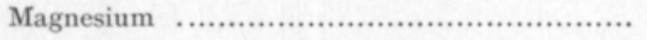 & 40 & $\mathrm{MgSO}_{4} \cdot 7 \mathrm{H}_{2} \mathrm{O}$ \\
\hline 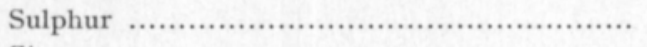 & 54 & $\mathrm{MgSO}_{4} \cdot 7 \mathrm{H}_{2} \mathrm{O}$ \\
\hline 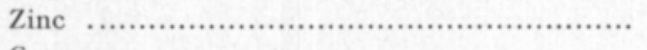 & 0.5 & $\mathrm{ZnSO}_{4} \cdot 7 \mathrm{H}_{2} \mathrm{O}$ \\
\hline Copper............. & 0.02 & $\mathrm{CuSO}_{4} \cdot 5 \mathrm{H}_{2} \mathrm{O}$ \\
\hline 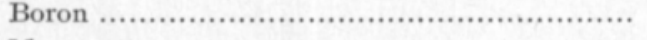 & 0.5 & $\mathrm{H}_{3} \mathrm{BO}_{3}$ \\
\hline 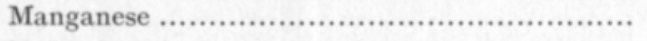 & 1 & $\mathrm{MnSO}_{4} \cdot 4 \mathrm{H}_{2} \mathrm{O}$ \\
\hline Molybdenum . ............................................. & 0.02 & $\left(\mathrm{NH}_{4}\right)_{6} \mathrm{Mo}_{7} \mathrm{O}_{24} \cdot 4 \mathrm{H}_{2} \mathrm{O}$ \\
\hline 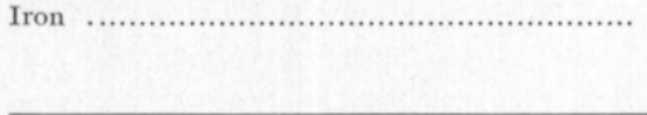 & 5 & $\begin{array}{l}\text { FeEDTA (chelated iron pre- } \\
\text { pared from } \mathrm{FeSO}_{4} \cdot 7 \mathrm{H}_{2} \mathrm{O}+ \\
\mathrm{Na}_{2} \text { EDTA) }\end{array}$ \\
\hline
\end{tabular}

on planchets (Fig. 7), but when there was no need to preserve them alive, they were counted in between two sheets of adhesive tape on a planchet.

The radioactivity determinations were made with a mains operated autoscaler (Panax type 7502) combined with a manual change lead castle GMtube assembly. Two sets of equipment secured speedy and trouble-free measurements. Due consideration was given to different errors in measurements and correction factors as described by CHASE and RABINOwITz (1962).

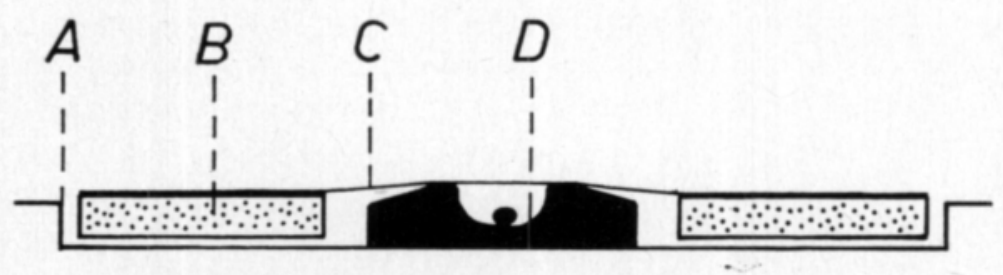

Fig. 7. Cage for measurement of radioactivity from alive mealybugs. $\mathrm{A}=$ aluminium counting planchet, $\mathrm{B}=$ iron ring, $\mathrm{C}=$ thin plastic film (Saran Wrap) glued to the ring, $\mathrm{D}=\mathrm{a}$ mealybug in ebonite cage glued to the planchet.

\subsection{Biological half-life of ${ }^{32} \mathrm{P}$ in mealybugs}

Biological half-life of ${ }^{32} \mathrm{P}$ in mealybugs was determined in insectary conditions and also in the growth chambers. In the insectary experiment, virus infected cocoa seedlings were kept in culture solution containing $30 \mu \mathrm{Ci} / \mathrm{ml}$ of ${ }^{32} \mathrm{P}$ for three days before $0-2$ day old nymphs of $P$. njalensis were introduced and given a feeding access time of 48 hours. After feeding, the nymphs were grouped according to their level of radioactivity and these groups were put on different ordinary cocoa seedlings. After every 24 hours one nymph was taken from each 
seedling, washed thoroughly in $1 \%$ sodium phosphate water solution to remove the excreta from the skin, and counted for radioactivity. Initially there were ten seedlings, each with a group of ten nymphs, but because some nymphs disappeared into the soil, the experiment could not be continued any longer than up to four days. To facilitate regression all original count rates were taken as 100 counts and the others were reduced or increased accordingly. This procedure gave a biological half- life of $\mathbf{1 5 . 3}$ days for ${ }^{32} \mathrm{P}$, and the effective half-life is thus 7.4 days (Fig. 8).

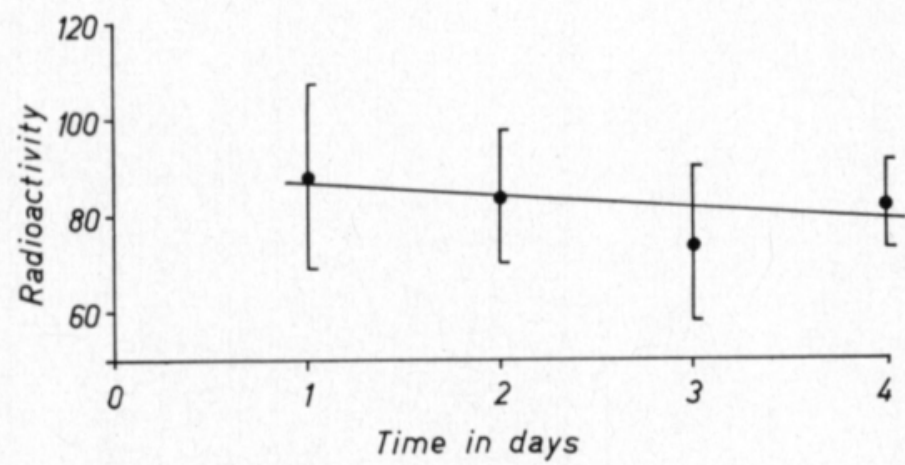

Fig. 8. Biological half-life of ${ }^{32} \mathrm{P}$ in first instar nymphs of $P$. njalensis in insectary conditions $\mathrm{y}=89.17-2.91 \mathrm{x} ; \mathrm{r}=-0.604 ; \mathrm{T}_{\frac{1}{2} \text { biol. }}=15.32$ days; $\mathrm{T}_{\frac{1}{2} \text { eff. }}=7.40$ days.

The other experiment was carried out in growth chambers at $25-27^{\circ} \mathrm{C}$. and $60-80 \% \mathrm{RH}$. Virus infected cocoa seedlings were kept in culture solution containing $22 \mu \mathrm{Ci} / \mathrm{ml}$ of ${ }^{32} \mathrm{P}$ for three days before $0-2$ day old nymphs of $P$. njalensis were placed on them. After a feeding access time of two days the nymphs were removed and they were counted for radioactivity. Then these nymphs were put on non-radioactive seedlings at a rate of one per each seedling, and removed two nymphs at a time every 24 hours. Counting was done before and after the nymphs had been washed in $1 \%$ sodium phosphate water solution.

Again, to facilitate regression all original counts were taken as 100 counts and the others were transformed accordingly. When these transformed values are plotted against time, two regression lines can be drawn (Fig. 9). One ( $\left.y_{1}\right)$ gives an idea of what is actually observed when mealybugs are removed from the seedlings and counted for radioactivity directly. The other $\left(y_{2}\right)$ describes the true rate of excretion of ${ }^{32} \mathrm{P}$ (washed nymphs) with $\mathrm{T} \frac{1}{2}$ biol. $=11.4$ days, and the effective half-life, $\mathrm{T} \frac{1}{2}$ eff. $=6.3$ days. Thus, in these experimental conditions, a large part of the excrements fell off the nymphs while still on the seedlings. Because of this, the correction factor for biological half-life was calculated as the difference of the two regression lines.

\subsection{Virus source plants}

Young cocoa seedlings of the Amelonado-type with prominent symptoms of virus were used as standard virus source plants. Source plants were produced, according to standard procedure at the Cocoa Research Institute (LEGG 


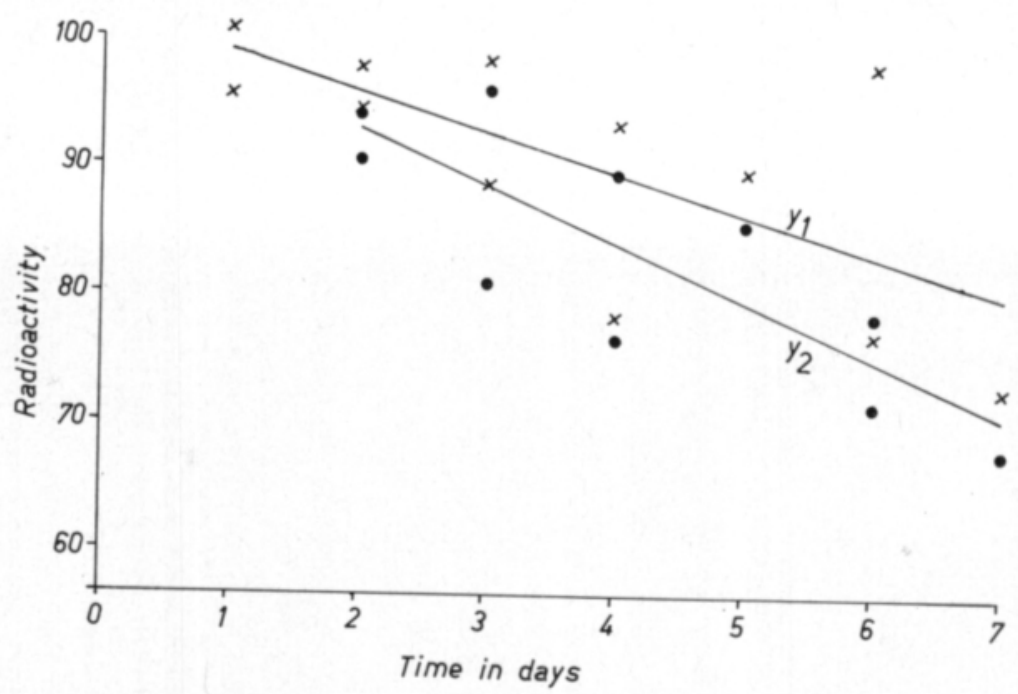

Fig. 9. Biological half-life of ${ }^{32} \mathrm{P}$ in first instar nymphs of $P$. njalensis at $25-27^{\circ} \mathrm{C}$. and $60-80 \%$ RH. $y_{1}(x)$ and $y_{2}(\bullet)$ indicate radioactivity of nymphs before and after chemical removal of ${ }^{32} \mathrm{P}$ contaminated surface excreta of the nymphs, respectively. $\mathrm{y}_{1}=102.11-3.16 \mathrm{x} ; \mathrm{r}=-0.674^{*}$, $\mathrm{T}_{\frac{1}{2}}=16.16$ days. $\mathrm{y}_{2}=101.82-4.46 \mathrm{x} ; \mathrm{r}=-0.814^{* *} ; \mathrm{T}_{\frac{1}{2} \text { biol. }}=11.41$ days; $\mathrm{T}_{\frac{1}{2} \text { eff. }}=6.35$ days.

and Bonney 1968 a), by putting infective mealybugs on cocoa beans for 24 hours after which the beans were planted into ordinary soil in wooden boxes. Germinated seedlings usually produced prominent leaf symptoms in about four to six weeks after planting of the beans (Fig. 10).

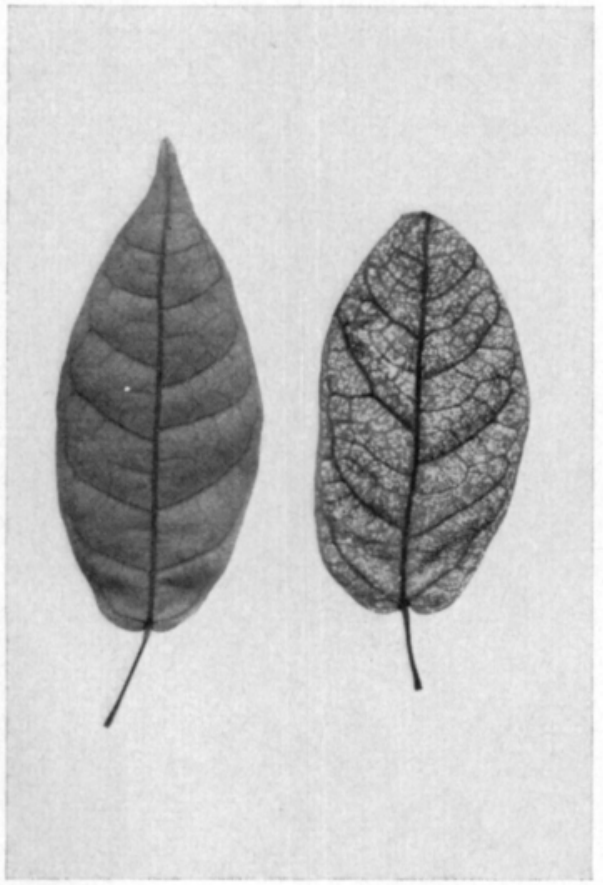

Fig. 10. Typical symptoms of disease caused by CSSV 1A isolate in Amelonado type cocoa. Healthy leaf on the left, virus infected on the right. 


\subsection{Virus test plants}

Cocoa beans of the Amelonado-type, after removal of the testa and one cotyledon, were used as standard test plants. The technique was first described by Posnette (1947 b). Prepared beans were kept in block watch glasses with the infective insects and covered with a sheet of glass (Fig. 11). After feeding access time the beans were dipped into $1 \%$ nicotine sulphate solution to kill the mealybugs and then planted into ordinary soil in wooden boxes. The germinated seedlings were examined for symptoms of virus until they were three months old and sometimes up to four months, starting from the date of planting.

\subsection{Moulting cages}

In some experiments the effect of moulting on virus transmission was investigated (RoIVAINEN 1971). For this purpose mealybug nymphs were allowed to moult in special moulting cages which consisted of dimple type planchets commonly used as sample holders in radioisotope counting. The planchets were painted black inside to facilitate the examination of exuvial skins and the dimples were covered by round microscope cover glasses (Fig. 12). The handling of planchets was made easier by glueing them on pieces of cardboard.

\subsection{The standard virus transmission experiment}

In virus transmission experiments there are many variables which may affect the final results. We have already discussed the standardization of temperature, humidity and light during the experiments in the growth chambers. However, virus source plants were always kept in an insectary before the onset

Fig. 11. Cocoa beans. An intact or full bean (above), and a half bean with typical involutions after removing one of the cotyledons (below).

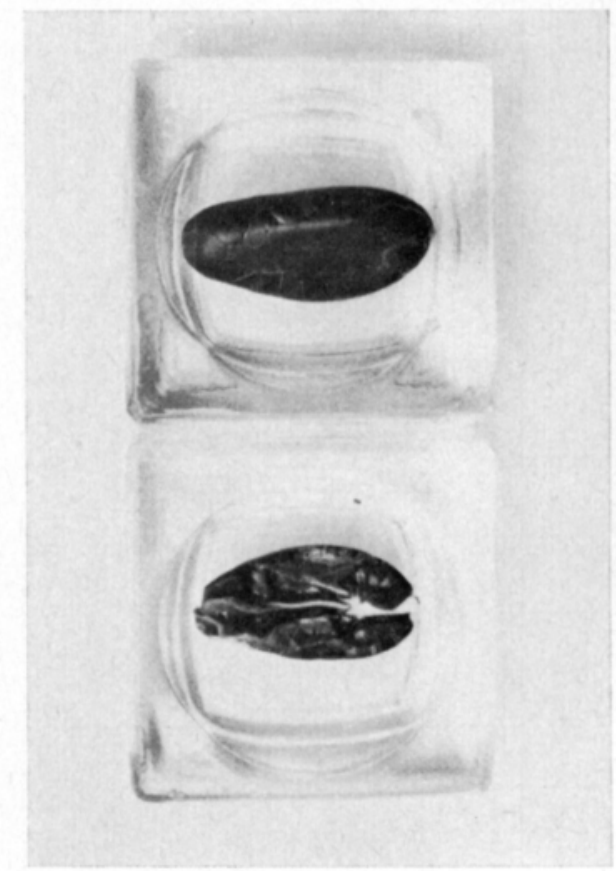




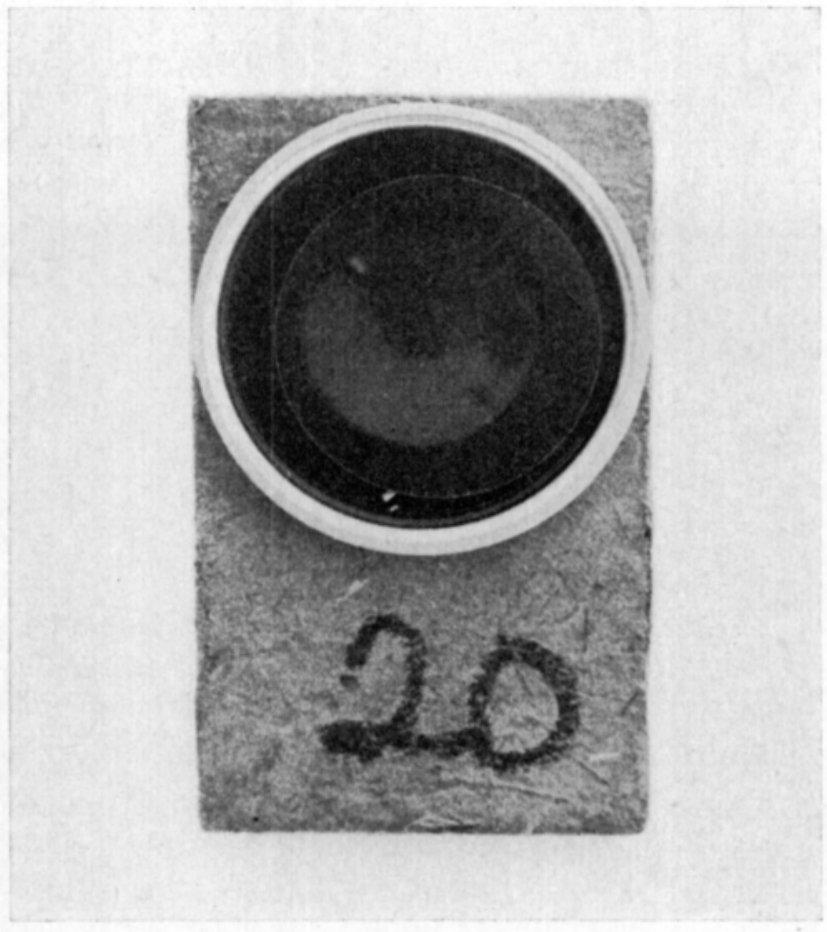

Fig. 12. Dimple type black painted planchet used as a moulting cage. The cage is covered by a round microscope cover glass.

of the acquisition access time and test plants were kept similarly after inoculation access time. Therefore the source and test plants were subject to considerable changes of humidity and temperature (Fig. 13), as well as light.

In a virus transmission experiment with mealybugs as vectors, there are several consecutive stages during which the insects must be transferred from one place to another. Firstly, the mealybugs are collected in the field (first handling of females), secondly the females are cleaned from adhering nymphs and introduced into the reproduction cages (second handling of females). After a few days the reproduction cages are opened and the newly-borne nymphs are collected from the cages on a petri dish (first handling of nymphs). Then, with a dry brush the nymphs are transferred into feeding cages and fixed around the stem of seedlings (second handling of nymphs). After feeding access time the nymphs are removed from the seedlings by tapping them off on a sheet of glass painted black underneath to facilitate detection of nymphs (third handling of nymphs). One by one the nymphs are picked up from the sheet of glass with a moistened brush and transferred on test beans (fourth handling of nymphs) (Fig. 14). Thus the nymphs are handled at least four times during the experiment, and if radioisotopes are used to measure the feeding of nymphs while on the seedlings, there are two more handlings.

It is obvious that excessive though necessary handling of insects can cause damage to them and particularly to their delicate mouthparts, depending on the skill of the operator. For these reasons, transmission experiments were carried out in such a way that there was only one operator for each consecutive stage of an experiment or, if more than one, the duties were randomized. Some other sources of error were also avoided as much as possible by standardizing 


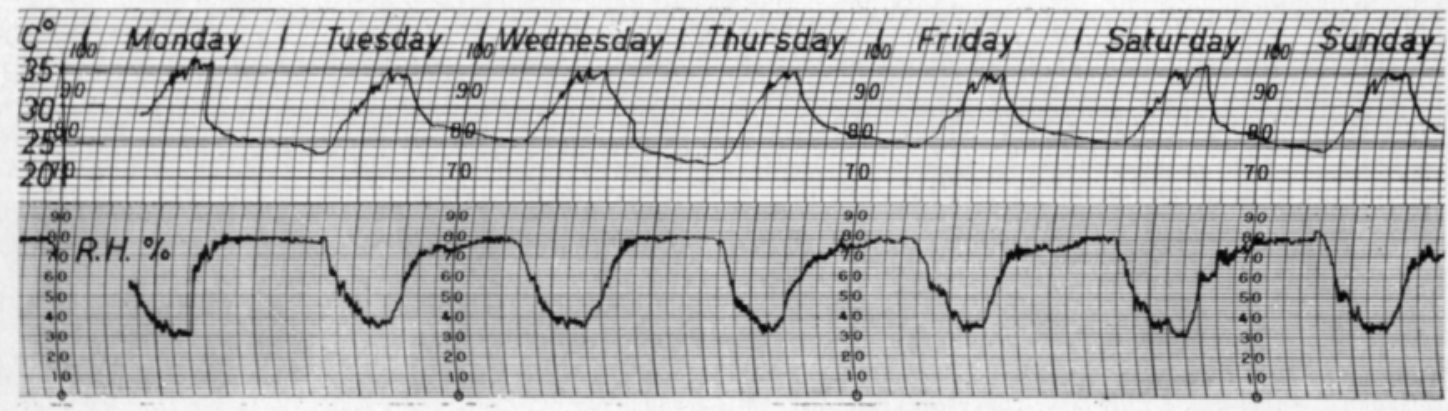

Fig. 13. An example of typical temperature and humidity conditions in an insectary. Recorded 15-22 December 1969.

the selection of source plants, the preparation of test beans, and the spotting of the symptoms of virus in the test plants (Fig. 15).

\subsection{Statistical calculations}

The statistical methods used in this study are mostly those of SNEDECOR and Cochran (1968). Usually, where results are expressed as means, the standard error of the mean $\left(\mathrm{S} . \mathrm{E} .=\mathrm{s}_{\mathbf{x}}\right)$ is given, sometimes also with confidence limits (t $95 \%$ ). The Yates correction was applied in the chi-square tests. The significance of results is indicated with asterisks; thus ${ }^{*},{ }^{* *}$ and ${ }^{* * *}$ denote 95,99 and $99.9 \%$ levels of significance. Other procedures pertaining to statistical methods are reported in the text.

\section{Effect of various factors on virus transmission}

The process of virus transmission by mealybugs can be divided conveniently into different consecutive stages or periods: a) period before acquisition feeding, during which the mealybugs may either starve or feed, and the term used is preliminary fasting or feeding, b) the time the mealybugs spend on virus infected source plant or preparation is often called acquisition feeding time, however, the more exact acquisition access time (AAT) is preferred in this paper, c) the period between cessation of acquisition access time and the next feed on a healthy plant is termed postacquisition fasting or feeding to indicate fasting or feeding after AAT but before the test feeding, d) finally, the period of feeding of mealybugs on a healthy plant is called inoculation access time (IAT). The terms described above and often used elsewhere in the text are mostly those by WELSH (1961), but suggestions made by TELIZ et al. (1966) have been considered as well. When the feeding of mealybugs is discussed in this paper, the term 'feeding' indicates access to feed rather than actual feeding, or at least the duration of actual feeding process is not known. The term infection rate of Posnette and Robertson (1950) is widely used to indicate the proportion of test plants that show symptoms of virus after IAT. 

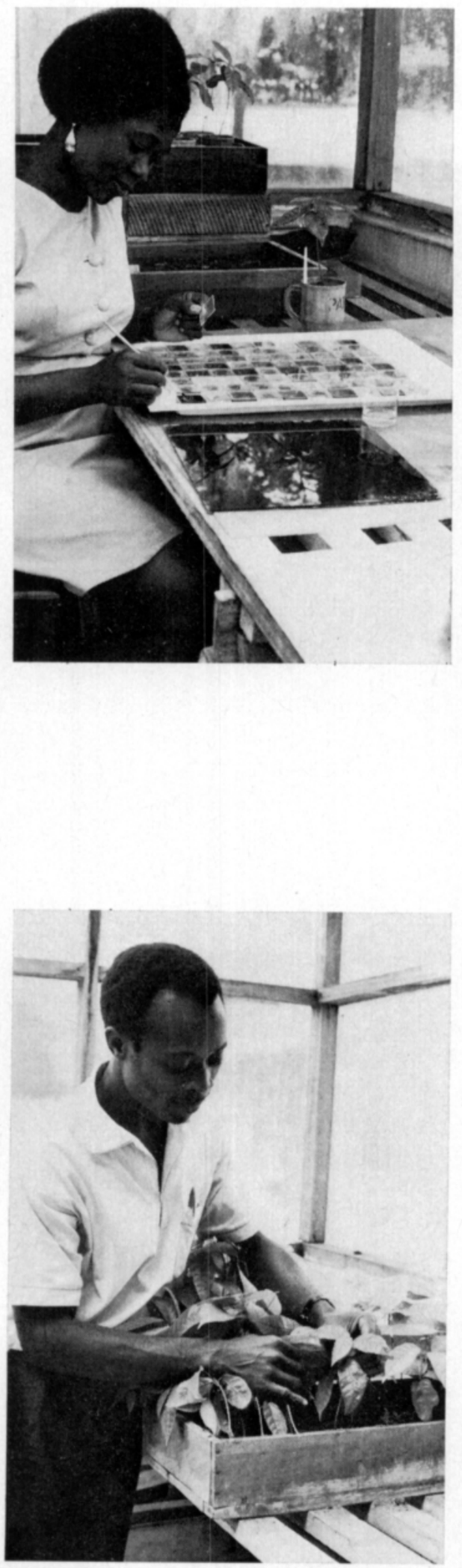

Fig. 14. A virus transmission experiment in progress. Virus source plant at the background in a plastic mug. The operator is transferring a nymph with a moistened brush on to a half bean test plant in a block watch glass.
Fig. 15. Spotting the symptoms of virus disease in leaves of seedlings at three to four leaf stage in the insectary. 


\subsection{Relationship between food uptake and infection rate}

Of the methods for measuring the rate of food or virus uptake by the mealybugs, the most simple and sensitive appeared to be the use of radioisotopes. Hamilon (1935) was the first to use radioisotopes for measuring the food uptake by aphids, and this pioneer work was continued by others (DAY and McKinnon 1951, Day and Irzykiewicz 1953, Watson and Nixon 1953, Banks and Nixon 1959, Duffus and Gold 1967). It appears from these investigations that interpretation of the virus uptake rate in terms of radioactivity measurement is complicated mainly by two unknown factors: a) the isotope may be unevenly distributed in the plant tissue or within the cells, and b) there is no assurance that the distribution of virus is closely correlated with the distribution of the isotope in the plant. In the present study these difficulties were largely overcome by using quite a high number of mealybugs in replicates of treatments so that great variability could be tolerated in the tests. An example is given in the following experiments.

Twelve seedlings infected with CSSV 1A isolate were grown up to four leaf stage in ordinary soil. The roots of these seedlings were then immersed into $45 \mathrm{ml}$ of culture solution in $100 \mathrm{ml}$ conical flasks. The solution was made radioactive by adding ${ }^{32} \mathrm{P}$ to obtain a specific activity of $27.5 \mu \mathrm{Ci} / \mathrm{ml}$. The flasks were sealed with polythene film and thick cloth to support the seedlings.

After two days of radioactivity uptake the seedlings were infested with all stages of field collected $P$. njalensis using the paper cone technique. These insects were subject to preliminary fasting of 48 hours, and were now allowed an AAT of 24 hours on the seedlings, after which all the young nymphs were removed, their radioactivities were measured, and they were put on cocoa half bean test plants at a rate of five per bean. The nymphs with the most equal count rates were put on the same bean and, thus, various levels of radioactivity in the nymphs could be established on different test plants. An IAT of 24 hours was allowed on the beans after which the nymphs were killed and the beans were planted into ordinary soil. The germinated seedlings were examined for symptoms of virus in the normal way.

A total of 243 test beans were infested with nymphs but seven test beans did not germinate or the test seedlings died before the end of the experiment. Discarding these, there were 236 test plants and 64 of them $(27 \%)$ developed symptoms of virus. The radioactivity of the nymphs varied from background $(12 \mathrm{cpm})$ to $4887 \mathrm{cpm}$ and the distribution was very skew. To correct this, a $\log (n+1)$ transformation was applied to the sum of original count rates of five nymphs on each test bean. The mean $\log (\mathrm{n}+1)$ radioactivity of the transmitters was $2.39 \pm 0.11$ (S. E.), and that of the non-transmitters $1.35 \pm 0.05$ (S. E.) $\left(\mathrm{t}=8.61^{* * *}\right)$. There was a distinct positive correlation between the infection rate and the count rate of the nymphs (Fig. 16).

This experiment was repeated with six source plants. However, the specific activity of the culture solution was increased up to $60 \mu \mathrm{Ci} / \mathrm{ml}$ and the efficiency of the counting equipment was improved. Out of 121 test plants $29(24 \%)$ became infected. The transmitters had a mean $\log (\mathrm{n}+1)$ radioactivity of $2.51 \pm$ $0.15 \mathrm{cp} 100 \mathrm{~s}$ (S. E.), and the non-transmitters $1.47 \pm 0.06 \mathrm{cp} 100 \mathrm{~s}$ (S. E.) $(\mathrm{t}=$ $\left.6.44^{* * *}\right)$. 


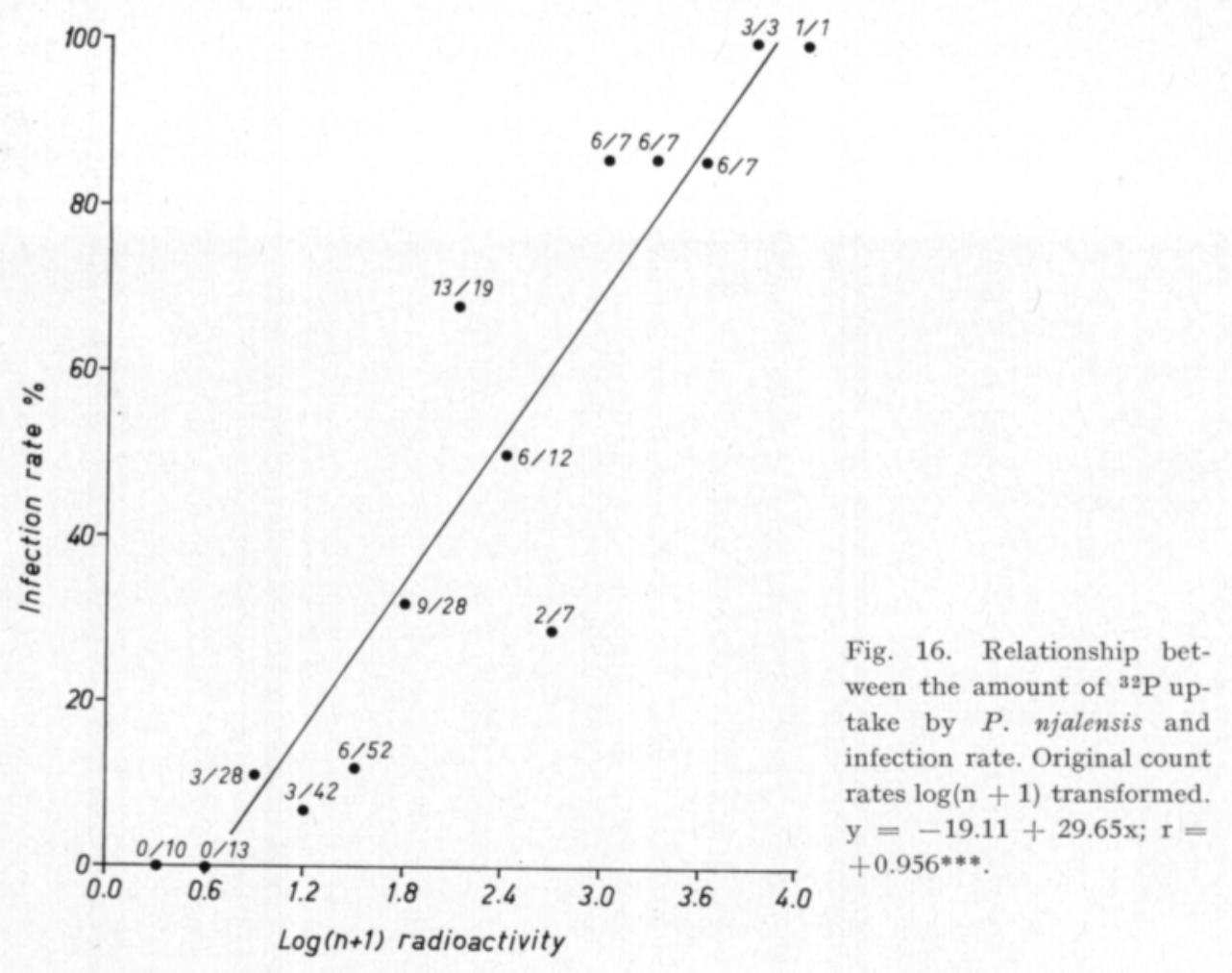

When the test beans were infested with single infective nymphs, $34(11 \%)$ out of 313 test plants became infected. In this case the mean $\log (n+1)$ radioactivities of the transmitters and the non-transmitters were $2.52 \pm 0.09$ (S. E.) and $1.84 \pm 0.04$ (S. E.) $\operatorname{cp} 100 \mathrm{~s}\left(\mathrm{t}=7.01^{* * *}\right)$, respectively.

\subsection{Relationship between plant and mealybug radioactivity}

All stages of $P$. njalensis were fed on $20^{32} \mathrm{P}$-active cocoa seedlings in laboratory conditions by using the paper cone technique. After 8, 16, 24, 48 and 120 hours feeding access time the mealybugs were removed from four seedlings at a time, the radioactivity of the bugs was measured and the mean count rate of the mealybugs was calculated for each seedling. The radioactivity of the seedlings was determined by cutting off that part of stem the mealybugs were feeding on, and after drying, ashing, and digestion in $\mathrm{HCl}$ an aliquot was taken, dried and counted. The relationship between mealybug radioactivity and plant radioactivity showed a high positive correlation; within treatments the correlation coefficient was $+\mathbf{0 . 5 7 * * *}$. Between treatments there was no significant difference in the radioactivity of the seedlings.

\subsection{Mealybug honeydew and plant radioactivity}

Several attempts were made to cut off the stylets of $P$. njalensis while feeding in order to collect radioactive sap exuding from the cut ends of the stylets. By relating the volume and the radioactivity of the sap, more could have been 
Table 10. Volume and ${ }^{32} \mathrm{P}$-activity of honeydew excreted by five young females of $P$. njalensis feeding on different places on the stem of a cocoa seedling.

\begin{tabular}{cccc}
\hline Female No. & $\begin{array}{c}\text { Number of daily } \\
\text { honeydew samples } \\
\text { collected }\end{array}$ & $\begin{array}{c}\text { Mean honeydew } \\
\text { production, } \\
\mu \mathrm{l} / \text { day }\end{array}$ & $\begin{array}{c}\text { Mean radioactivity of } \\
\text { honeydew, cp100s/0.1 } \\
\mu 1 / \text { day }\end{array}$ \\
\hline 1 & 11 & $0.03 \pm 0.07^{\mathrm{a}}$ & $2600 \pm 830^{\mathrm{a}}$ \\
2 & 7 & $0.14 \pm 0.08^{\mathrm{b}}$ & $2640 \pm 970^{\mathrm{a}}$ \\
3 & 12 & $0.14 \pm 0.06^{\mathrm{b}}$ & $2840 \pm 980^{\mathrm{a}}$ \\
4 & 12 & $0.10 \pm 0.01^{\mathrm{b}}$ & $2910 \pm 740^{\mathrm{a}}$ \\
5 & 10 & $0.13 \pm 0.08^{\mathrm{b}}$ & $4110 \pm 2340^{\mathrm{a}}$ \\
\hline
\end{tabular}

learned about the distribution of radioactivity in the tissues of cocoa seedlings where mealybugs feed. However, all these attempts failed because a satisfactory conventional way of cutting the stylets could not be developed, and more sophisticated means, e.g. laser, were not available.

Attention was then turned to the rate of excretion of honeydew which is a measure of the feeding activity. Labelling the food plant would yield radioactive honeydew and the count rate could be related to the volume excreted. Comparing different mealybugs and feeding sites to the volume and radioactivity of the honeydew, the pattern of distribution of the radioactivity in the plant could be described.

In order to minimize the variation between mealybugs, young non-reproductive females of clonal origin were used in the experiment. An $80 \mathrm{~cm}$ tall cocoa seedling growing in ordinary soil in a pot was infested with these young females of $P$. njalensis in laboratory conditions. Excretion of honeydew indicated that five of the females had settled down to feed on different places along the stem. The plant was then watered around the stem with equal daily volumes of culture solution containing ${ }^{32} \mathrm{P}$. The watering was done in such a way that with one daily watering a specific activity of about $5 \mu \mathrm{Ci} / \mathrm{ml}$ soil was obtained. Immediately after the second watering, the honeydew was collected every morning with calibrated glass capillaries from the five mealybugs. The volumes were recorded and the dried collections were counted for radioactivity.

One of the five females produced honeydew consistently at a lower rate but of higher specific activity than the other four (Table 10). This indicates that there was variation, probably between the radioactivities of different feeding sites, and also between different mealybugs. However, considering all the honeydew samples collected, there was a significant correlation between the volume excreted and the count rate, although diversity was experienced between the individual samples (Fig. 17). This relationship is clearly manifested when both the volume and radioactivity of the daily honeydew samples are plotted against time in a cumulative way (Fig. 18).

Another means of learning more about the pattern of distribution of radioactivity in the plants, and also in the mealybugs, was to compare the amount of food uptake by the mealybugs while feeding on labelled plants and labelled sucrose solution in the same experiment. Four ${ }^{32} \mathrm{P}$-active cocoa seedlings and 


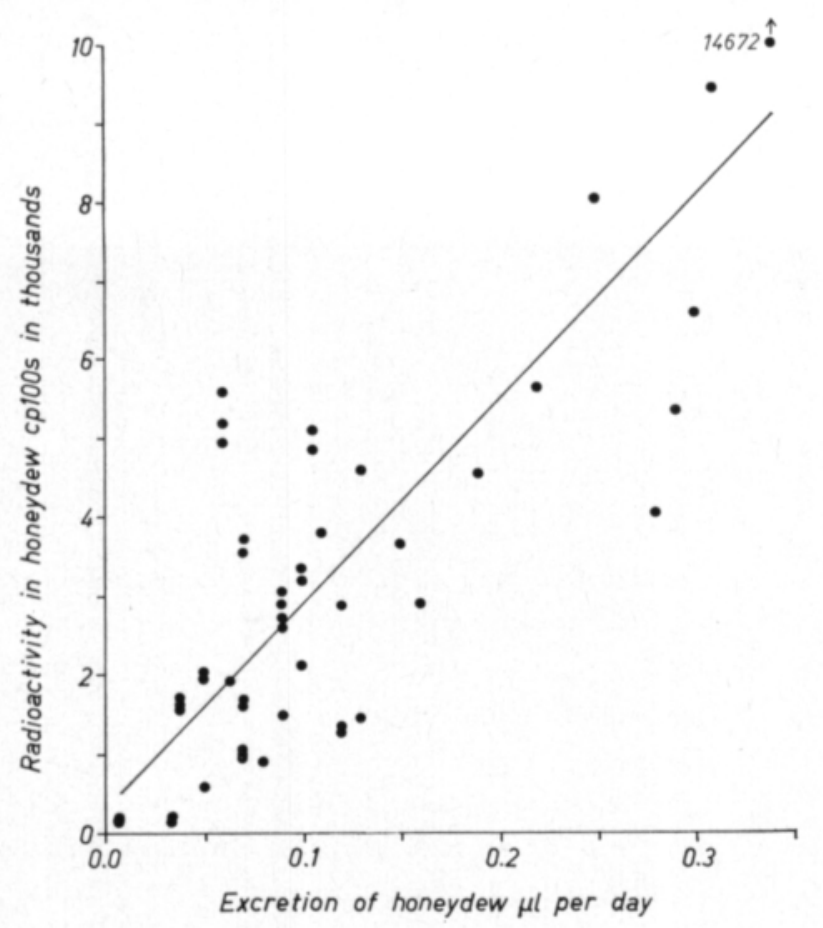

Fig. 17. Relationship between the volume and ${ }^{32} \mathrm{P}$-activity of honeydew excreted by young females of $P$. njalensis. $\mathrm{y}=$ $31.36+25.79 \mathrm{x} ; \mathrm{r}=+0.801^{* * *}$.

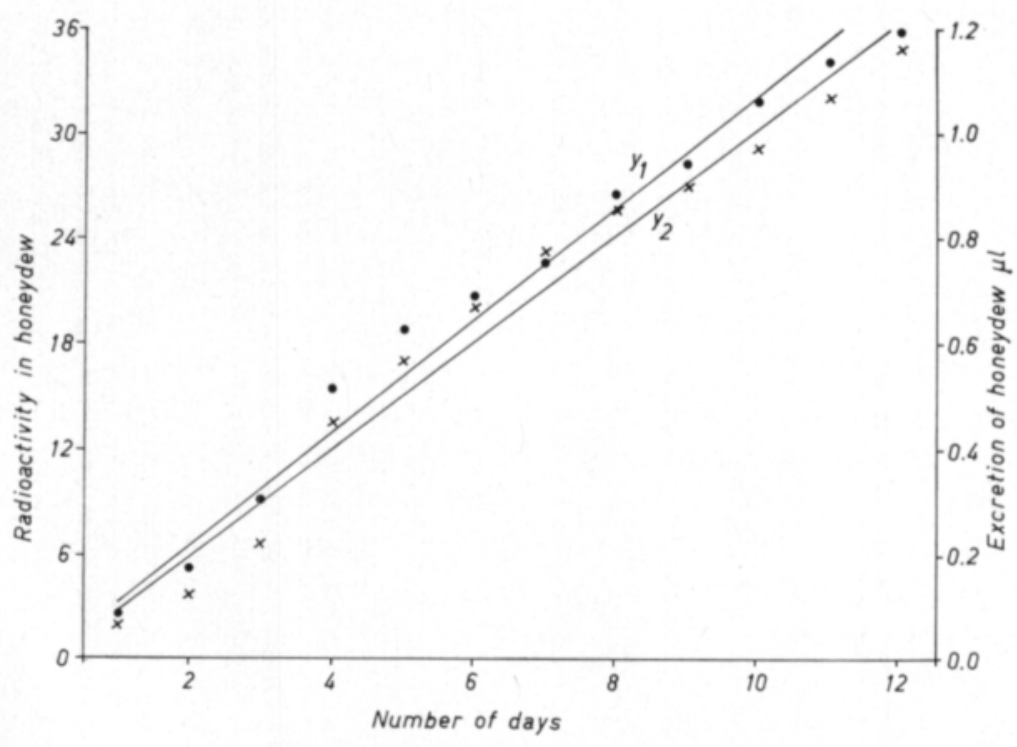

Fig. 18. Amount of ${ }^{32} \mathrm{P}$-activity and honeydew excreted by $P$. njalensis. Cumulative amount of radioactivity in the honeydew in cp100s in thousands $(\bullet) ; y_{1}=-0.27+3.06 x ; r=+0.988^{* * *}$ Cumulative amount of honeydew in $\mu \mathrm{l}(\mathrm{x}) ; \mathrm{y}_{2}=0.030+0.103 \mathrm{x} ; \mathrm{r}=+0.989 * * *$. 
sucrose in parafilm sachets were used as food sources. The experiment was carried out in laboratory conditions with young nymphs of $P$. njalensis which were allowed to feed for five days before their radioactivities were determined. The radioactive plants were prepared in the normal way, and the liquid diet contained $10 \%$ sucrose in distilled rain water with $37.2 \mu \mathrm{Ci} / \mathrm{ml}$ of ${ }^{32} \mathrm{P}$.

The results are tabulated as follows:

Food source

Labelled seedlings

Labelled solution
Number of nymphs

396

396
Mean radioactivity of nymphs
$\log (\mathrm{n}+1) \mathrm{cp} 100 \mathrm{~s} \pm \mathrm{S} . \mathrm{E}$.
$2.430 \pm 0.028$

$2.002 \pm 0.024$
Range

$0.5-3.9$

$0.7-2.9$

The pattern of distribution of the count rates around their means indicates that much variation in food uptake can be expected even if the nymphs feed on homogeneously labelled preparations, and that this variation, due to the feeding behaviour, is increased through another source of variation, the uneven distribution of radioactivity, when the nymphs feed on seedlings. However, the overall pattern of distribution of the count rates in the nymphs, after feeding on labelled seedlings, is such that it well describes the amount of food uptake in large populations of nymphs (Fig. 19).

\subsection{Radiation effects}

Although no anomalies were ever experienced in any experiment where radioisotope techniques were used, one specific experiment was carried out in standard conditions in the growth chamber to investigate radiation effects. Eight CSSV 1A infected cocoa seedlings were put into culture solution containing $30 \mu \mathrm{Ci} / \mathrm{ml}$ of ${ }^{32} \mathrm{P}$ in $50 \mathrm{ml}$ conical flasks. A similar treatment was given to another

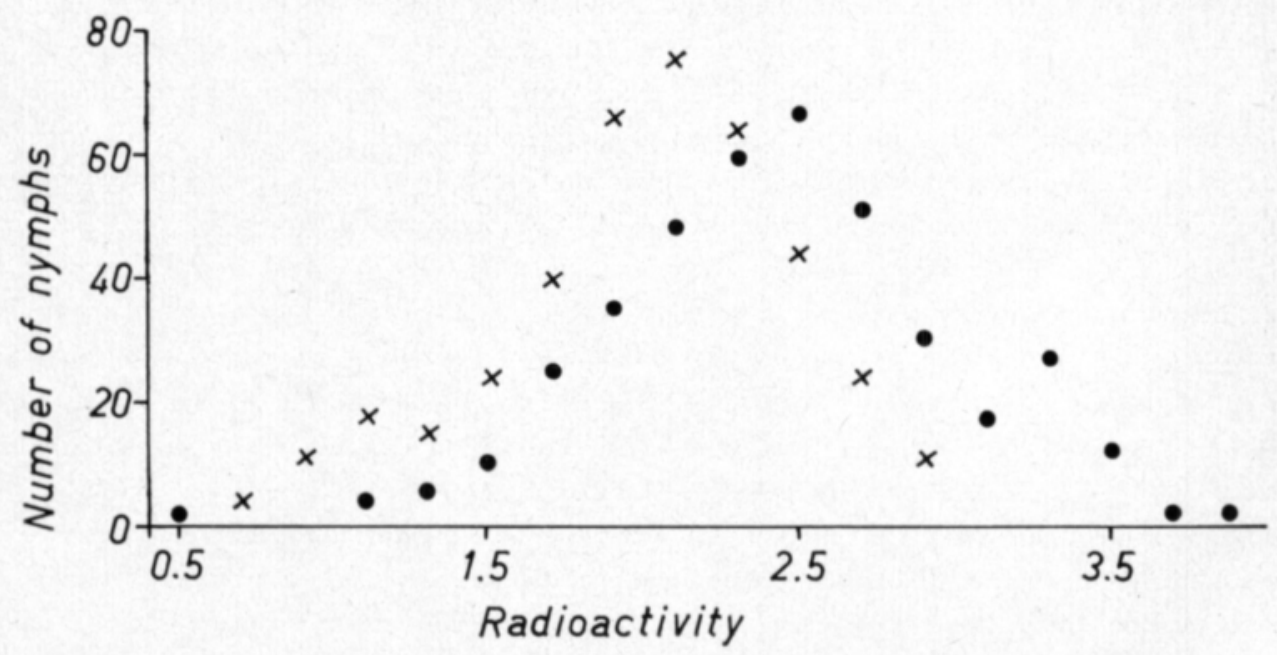

Fig. 19. Frequency distribution of radioactivity in nymphs of $P$. njalensis after feeding for five days on ${ }^{32} \mathrm{P}$-active $10 \%$ sucrose solution via a parafilm membrane $(\mathrm{x})$, or on ${ }^{32} \mathrm{P}$-active cocoa seedlings $(\bullet)$. Original count rates $\log (\mathrm{n}+1)$ transformed. 
eight seedlings but without ${ }^{32} \mathrm{P}$. After three days uptake in culture solution, nymphs of $P$. njalensis were put onto seedlings in feeding cages for an AAT of 96 hours, after which the nymphs were transferred on half bean test plants at a rate of three per bean for an IAT of one day. There were 400 test beans in each of the two treatments but some did not germinate. The final results were as follows:

$\begin{array}{lcc}\text { Treatment } & \text { Infection rate } & \text { Infection rate, } \% \\ \text { Source plants with }{ }^{32} \mathrm{P} \ldots \ldots \ldots \ldots \ldots \ldots \ldots & 170 / 383 & 44.4 \\ \text { Source plants without }{ }^{32} \mathrm{P} \ldots \ldots \ldots \ldots \ldots \ldots . \ldots \ldots \ldots \ldots & 167 / 394 & 42.4\end{array}$

Calculation of chi-square gives a value of 0.192 which is highly non-significant. Thus, beta radiation from ${ }^{32} \mathrm{P}$ did not affect the virus transmission efficiency of $P$. njalensis in this experiment.

\subsection{Preliminary fasting/feeding}

It can be expected that mealybugs settle down to feed more rapidly if they have starved for some time before access to food is given. It is likewise possible that for some time after fasting, the starved mealybugs actually feed more rapidly than mealybugs which are only transferred from one food source to another without delay. Also, it is possible that the final infection rate would be affected by increased settling of mealybugs or increased feeding or both, if any. Several experiments were carried out in growth chambers in standard conditions to find an answer to these questions.

Field collected female mealybugs of $P$. njalensis were allowed to reproduce in reproduction cages for two days after which the nymphs that were $0-2$ days old were collected. Half of the nymphs were put on healthy cocoa seedlings directly to feed for 48 hours in the feeding cages after which they were starved for 24 hours before the final feed. The other half of the nymphs were put in starvation cages for 24 hours and then on healthy cocoa seedlings to feed for 48 hours. Thus the two groups of mealybugs, starved and unstarved, were 3-5 days old before the final feeding which was done on $10 \%$ sucrose solution containing $230 \mu \mathrm{Ci} / \mathrm{ml}$ of ${ }^{32} \mathrm{P}$. Parafilm sachets mounted on glass tubes and replicated four times served as food containers and feeding cages. The length of feeding access time on the solution was $2,4,8,24$ and 48 hours.

There were considerable differences between the settling rates of the starved and unstarved nymphs (Table 11). The settling rate of the starved nymphs was $47-68 \%$ during the feeding periods of 2,4 and 8 hours but the settling rate of unstarved nymphs was only $7-20 \%$ during the same periods. With longer feeds of 24 and 48 hours, both starved and unstarved nymphs settled down to feed at a rate of above $90 \%$.

The food uptake of starved nymphs was so much higher than that of unstarved nymphs that it is difficult to explain it merely in terms of increased settling. After 24 hours almost all the starved and unstarved nymphs had settled. The amount of food uptake of the starved nymphs was $330 \mathrm{cp} 100 \mathrm{~s}$ after 24 hours of feeding, and the increase during the second 24 hour period was $1116-330=$ $786 \mathrm{cp} 100 \mathrm{~s}$. At the same time the unstarved nymphs could only reach 146 
Table 11. Rate of settling and amount of food uptake by starved and unstarved nymphs of $P$. njalensis fed on ${ }^{32} \mathrm{P}$-active $10 \%$ sucrose solution via a parafilm membrane.

\begin{tabular}{|c|c|c|c|c|c|c|}
\hline $\begin{array}{l}\text { Length of } \\
\text { feeding } \\
\text { access time, } \\
\text { hours } \\
\end{array}$ & $\begin{array}{l}\text { Settlin } \\
\text { Starved }\end{array}$ & $\begin{array}{l}\text { (gate } \text { ratarved }^{1} \\
\text { Unstaris }\end{array}$ & $\begin{array}{l}\text { Settlin } \\
\text { Starved }\end{array}$ & $\begin{array}{l}\text { g rate, } \% \\
\text { Unstarved }\end{array}$ & $\begin{array}{r}\text { Mean for } \\
\text { settled ny } \\
\text { Starved }\end{array}$ & $\begin{array}{l}\text { uptake of } \\
\text { mphs, cp100s } \\
\text { Unstarved }\end{array}$ \\
\hline 2 & $56 / 108$ & $11 / 54$ & 52 & 20 & 120 & 84 \\
\hline 4 & $44 / 65$ & $4 / 45$ & 68 & 9 & 164 & 56 \\
\hline 8 & $31 / 66$ & $1 / 15$ & 47 & 7 & 176 & 57 \\
\hline 24 & $96 / 98$ & $13 / 14$ & 98 & 93 & 330 & 146 \\
\hline 48 & $72 / 76$ & $28 / 29$ & 95 & 97 & 1116 & 259 \\
\hline
\end{tabular}

1) Numerator $=$ number of radioactive nymphs, denominator $=$ number of nymphs examined. Expression used in this and some other tables.

cp100s during the first 24 hour period and $259-146=113 \mathrm{cp} 100 \mathrm{~s}$ during the second 24 hour period. Even if the unstarved nymphs voluntarily starved during the first 24 hour period (which they did not do), they were not able to feed at the same rate as the starved nymphs; 259 against $330 \mathrm{cp} 100 \mathrm{~s}$.

Some of the data in this experiment was not representative enough for final conclusions. Particularly this was so with the number of unstarved nymphs that had settled to feed on the radioactive source. Consequently, the experiment was repeated in a slightly different way. The starved and unstarved nymphs were obtained as before with $P$. njalensis as the test insect. Also, the feeding was done on $10 \%$ sucrose solution via parafilm sachets mounted on glass tubes and replicated three times. The specific activity of the solution was $200 \mu \mathrm{Ci} / \mathrm{ml}$ of ${ }^{32} \mathrm{P}$. The length of feeding access time on the solution was 2,4 , 8,16 and 32 hours.

As in the previous experiment, the overall settling rate of starved nymphs was higher than that of unstarved nymphs during the short feeds of $2-8$ hours (Table 12). This difference evened out during the longer feeds of 16 and 32 hours. The amount of food uptake was consistently higher by the starved nymphs during all the feeding periods. After 16 hours feeding period $99 \%$ of the starved nymphs had settled down to feed, displaying a geometric mean feeding activity of 2.38 . The unstarved nymphs could attain the same settling rate after 32 hours of feeding with a mean feeding activity of 2.19 . The difference between the two geometric means is significant; $t=3.36^{* * *}$. This, and the fact that the mean food uptake is based on radioactive (settled) nymphs, proves without doubt that starved nymphs actually take up more food per time unit than unstarved nymphs during the early stages of feeding. Combining the food uptake data of the two experiments, the most satisfactory goodness of fit is given by a linear relationship between time and the amount of food uptake (Fig. 20).

The effect of preliminary fasting on the rate of virus transmission was also investigated. Starved nymphs of $P$. njalensis were obtained by putting them, at the age of $0-2$ days, from reproduction cages on healthy cocoa seedlings to feed for two days after which they were starved for one day before the AAT. 
Table 12. Rate of settling and amount of food uptake by starved and unstarved nymphs of $P$. njalensis fed on ${ }^{32} \mathrm{P}$-active $10 \%$ sucrose solution via a parafilm membrane.

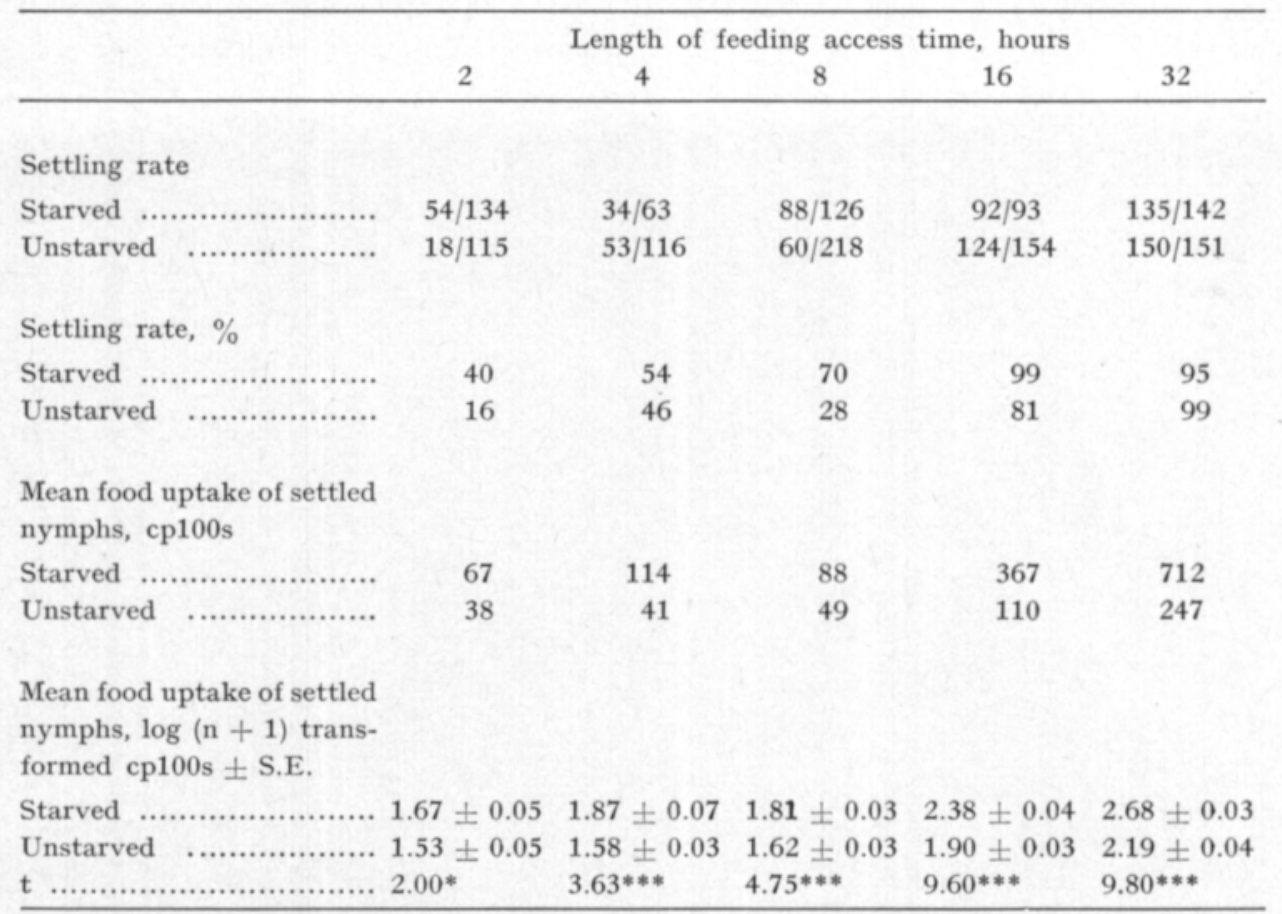

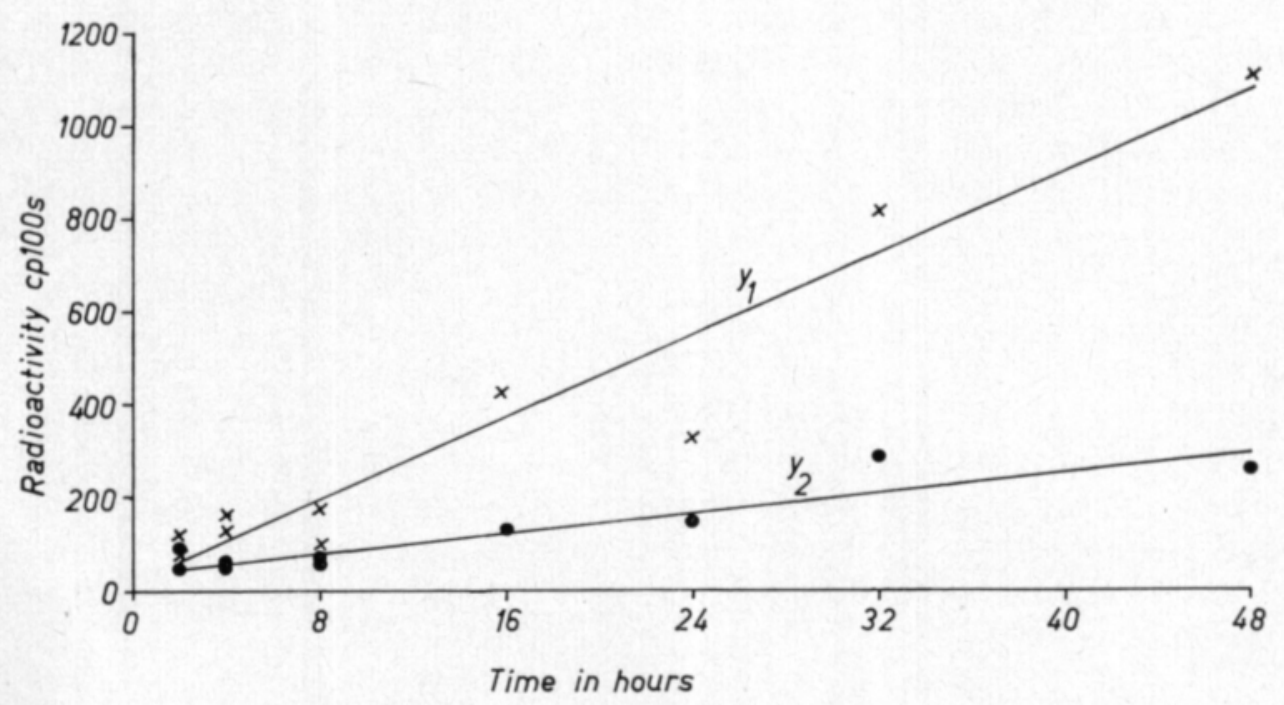

Fig. 20. Uptake of radioactivity by starved and unstarved nymphs of $P$. njalensis fed on ${ }^{32} \mathrm{P}$ active $10 \%$ sucrose solution via a parafilm membrane. Starved nymphs; $y_{1}=19.60+22.03 x$; $\mathrm{r}=+0.965^{* * *}$. Unstarved nymphs; $\mathrm{y}_{2}=36.70+5.36 \mathrm{x} ; \mathrm{r}=+0.928^{* * *}$. 
Table 13. Effect of preliminary fasting of $P$. njalensis nymphs on the rate of CSSV $1 \mathrm{~A}$ isolate transmission.

\begin{tabular}{rrrrr}
\hline $\begin{array}{c}\text { Length of } \\
\text { AAT, hours }\end{array}$ & \multicolumn{2}{c}{$\begin{array}{c}\text { Infection rate } \\
\text { Starved }\end{array}$} & $\begin{array}{c}\text { Infection rate, \% } \\
\text { Starved Unstarved }\end{array}$ \\
\hline 6 & $70 / 126$ & $45 / 184$ & 56 & 24 \\
18 & $109 / 117$ & $159 / 189$ & 93 & 84 \\
54 & $43 / 62$ & $136 / 176$ & 69 & 77 \\
\hline
\end{tabular}

1) Numerator $=$ number of infected test plants, denominator $=$ total number of test plants. Expression used in this and some other tables.

Unstarved nymphs were obtained by starving $0-2$ day old nymphs for one day and then allowing them to feed on healthy cocoa seedlings for two days prior to AAT. Both starved and unstarved nymphs were thus $\mathbf{3 - 5}$ days old and they had fed for two days, also they carried no infective virus. Eighteen CSSV 1A isolate infected Amelonado seedlings were used as source plants for virus and food, the length of AAT being 6, 18 and 54 hours. Five nymphs were put on each half bean test plant, and the length of IAT was 24 hours.

After 6 and also 18 hours of AAT the starved nymphs transmitted virus more efficiently than the unstarved nymphs; chi-squares $29.77 * * *$ and $4.58^{*}$, respectively (Table 13). At 54 hours there was no difference. Between the three treatments of starved nymphs there was a definite peak of infection rate at 18 hours, but with unstarved nymphs this phenomenon did not occur. Thus, due to preliminary fasting, the infectivity of starved nymphs increased more rapidly during short acquisition access times to reach a peak at 18 hours and then decreased to the same level of infectivity as with unstarved nymphs at 54 hours.

Finally, an attempt was made to combine the three previous tests to investigate the effect of preliminary fasting of $P$. njalensis on the settling rate, food uptake and rate of virus transmission by using ${ }^{32} \mathrm{P}$-active virus infected cocoa seedlings as source of virus and food in one single experiment.

Altogether there were 24 healthy cocoa seedlings and starvation cages which were used to produce starved and unstarved nymphs in the same manner as in the previous experiments. A total of $24 \mathrm{CSSV} 1 \mathrm{~A}$ isolate infected cocoa seedlings were used as source plants. These were grown for three days in culture solution containing $30 \mu \mathrm{Ci} / \mathrm{ml}$ of ${ }^{32} \mathrm{P}$. Both source and test plants were of the Amelonado-type cocoa. One nymph was put on each half bean test plant for an IAT of 24 hours.

The same pattern emerged as in the earlier tests (Table 14). Starved nymphs settled down to feed more readily at first than the unstarved nymphs during the short acquisition feeds, but after 72 hours of AAT the rate of settling was nearly equal in both cases. The amount of food uptake by starved nymphs was also higher during all the acquisition feeds, while again the starved nymphs displayed an infectivity peak at 24 hours of AAT. In this experiment the peak was more gentle because only one nymphs was used per test plant, which always results in an overall reduction of the infection rate. 
Table 14. Effect of preliminary fasting of $P$. njalensis nymphs on settling rate, food uptake and transmission of CSSV $1 \mathrm{~A}$ isolate.

\begin{tabular}{|c|c|c|c|}
\hline & \multicolumn{3}{|c|}{ Length of AAT, hours } \\
\hline & 6 & 24 & 72 \\
\hline \multicolumn{4}{|l|}{ Settling rate } \\
\hline 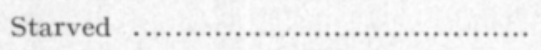 & $70 / 208$ & $196 / 236$ & $185 / 185$ \\
\hline 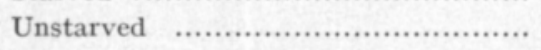 & $5 / 228$ & $176 / 245$ & $265 / 266$ \\
\hline \multicolumn{4}{|l|}{ Settling rate, $\%$} \\
\hline Starved & $34 \mathrm{a}$ & $83^{\mathrm{c}}$ & $100^{\mathrm{e}}$ \\
\hline Unstarved & $2^{b}$ & $72^{\mathrm{d}}$ & $100^{e}$ \\
\hline \multicolumn{4}{|l|}{ Infection rate } \\
\hline Starved & $9 / 203$ & $62 / 229$ & $27 / 185$ \\
\hline 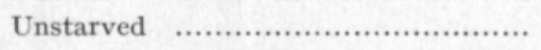 & $2 / 228$ & $57 / 244$ & $48 / 263$ \\
\hline \multicolumn{4}{|l|}{ Infection rate, $\%$} \\
\hline 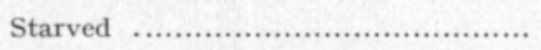 & $4^{\mathrm{a}}$ & $27 \mathrm{e}$ & $15^{e}$ \\
\hline 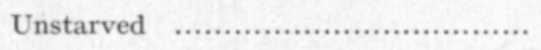 & $1^{b}$ & $23^{\mathrm{ed}}$ & $18^{\mathrm{de}}$ \\
\hline \multicolumn{4}{|l|}{$\begin{array}{l}\text { Mean food uptake of settled nymphs, } \\
\log (n+1) \text { transformed } c p 100 s \pm \text { S.E. }\end{array}$} \\
\hline 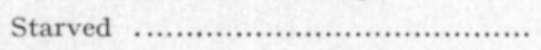 & $0.49 \pm 0.05$ & $1.46 \pm 0.05$ & $2.61 \pm 0.03$ \\
\hline 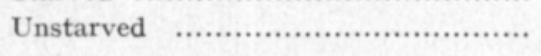 & $0.03 \pm 0.01$ & $1.18 \pm 0.05$ & $2.35 \pm 0.02$ \\
\hline t & $9.06^{* * *}$ & $3.98^{* * *}$ & $8.21 * * *$ \\
\hline
\end{tabular}

\subsection{Availability of virus in source plants}

The chance of a mealybug becoming infective depends on the availability of virus in the tissue in which it is feeding. The distribution of virus in source plants may not be completely systemic, and also the age of the source plant or the virus infection may contribute to the availability of transmissible virus for mealybugs. There can be also plant to plant differences in the availability of virus in plants of the same age.

The distribution of virus in the source plants and its effect on virus transmission was investigated with not more than four day old nymphs of P. njalensis. The nymphs were allowed to feed in feeding cages for two days (AAT) on five different feeding sites of $20 \mathrm{CSSV}$ 1A isolate infected cocoa seedlings. The feeding sites were upper surface of the leaf, lower surface of the leaf, upper part of the stem, middle part of the stem, and lower part of the stem below the cotyledons. After AAT the nymphs were transferred to half bean test plants at a rate of five per plant for an IAT of one day. The beans were sown in the ordinary way and the germinated seedlings were examined for symptoms of virus.

Virus was more often transmitted from stems than from leaves; infection rates $810 / 1893(42.8 \%$ ) and $237 / 849(27.9 \%$ ), respectively (chi-square $54.34 * * *$ ) (Table 15). However, this difference does not necessarily mean that there is more virus in the stems because $P$. njalensis can more frequently be found 
Table 15. Effect of feeding site during acquisition access time on the rate of CSSV 1A isolate transmission by nymphs of $P$. njalensis.

\begin{tabular}{lccccc}
\hline Feeding site & $\begin{array}{c}\text { Leaf } \\
\text { upper } \\
\text { side }\end{array}$ & $\begin{array}{c}\text { Leaf, } \\
\text { lower } \\
\text { side }\end{array}$ & $\begin{array}{c}\text { Stem, } \\
\text { upper } \\
\text { part }\end{array}$ & $\begin{array}{c}\text { Stem, } \\
\text { middle } \\
\text { part }\end{array}$ & $\begin{array}{c}\text { Stem, } \\
\text { lower } \\
\text { part }\end{array}$ \\
\hline Infection rate $\ldots \ldots \ldots \ldots \ldots \ldots$ & $96 / 386$ & $141 / 463$ & $321 / 676$ & $203 / 555$ & $286 / 662$ \\
Infection rate, $\% \ldots \ldots \ldots \ldots$ & 25 & 30 & 47 & 37 & 43 \\
\hline
\end{tabular}

feeding on stems than on leaves, and thus the difference between infection rates can be also explained by the feeding habits of the species.

The effect of age of young virus source plants on the rate of virus transmission was also investigated. CSSV 1A isolate infected cocoa beans were sown at different times to produce seedlings 29,39 and 48 days old at the beginning of the experiment. Six seedlings of each group were used at the beginning of the experiment and subsequently every second day up to six days as source plants for $0-2$ day old nymphs of $P$. njalensis. AAT was two days and IAT one day. Half beans were used as test plants in the usual way and three nymphs were put on each bean.

Although there were significant differences between the treatments, there was no relationship between the infection rate and the increasing age of the seedlings. The four different mealybug populations used in the experiment did not differ appreciably in their efficiency of virus transmission (Table 16). Thus the general practice to use seedlings $30-50$ days old as source plants can be considered acceptable.

Variation in the availability of virus between source plants of same age was investigated with CSSV $1 \mathrm{~A}$ isolate infected seedlings. The vectors were $0-2$ day old nymphs of $P$. njalensis which were allowed to feed on source plants for two days (AAT). Then the IAT of one day followed on half bean test plants

Table 16. Effect of age of virus source plant on the rate of CSSV 1A isolate transmission by nymphs of $P$. njalensis.

\begin{tabular}{cccc}
\hline $\begin{array}{c}\text { Age of source } \\
\text { plant, days }\end{array}$ & $\begin{array}{c}\text { Infection } \\
\text { rate }\end{array}$ & $\begin{array}{c}\text { Infection } \\
\text { rate, } \%\end{array}$ & $\begin{array}{c}\text { Mealybug } \\
\text { population No. }\end{array}$ \\
\hline 29 & $96 / 120$ & 80 & 1 \\
31 & $95 / 97$ & 98 & 2 \\
33 & $87 / 116$ & 75 & 3 \\
35 & $98 / 120$ & 82 & 4 \\
39 & $112 / 120$ & 93 & 1 \\
41 & $102 / 113$ & 90 & 2 \\
43 & $88 / 117$ & 75 & 3 \\
45 & $100 / 116$ & 86 & 4 \\
48 & $110 / 119$ & 92 & 1 \\
50 & $88 / 104$ & 85 & 2 \\
52 & $85 / 114$ & 75 & 3 \\
54 & $68 / 114$ & 60 & 4 \\
\hline
\end{tabular}


Table 17. Availability of virus in source plants of same age and its effect on the rate of CSSV $1 \mathrm{~A}$ isolate transmission by nymphs of $P$. njalensis.

\begin{tabular}{lrc}
\hline Source plants & Infection rate & Infection rate, $\%$ \\
\hline A & $17 / 25$ & 68 \\
B & $11 / 23$ & 48 \\
C & $21 / 27$ & 78 \\
ABC & $20 / 25$ & 80 \\
D & $12 / 30$ & 40 \\
E & $18 / 29$ & 62 \\
F & $6 / 22$ & 27 \\
DEF & $14 / 24$ & 58 \\
G & $21 / 27$ & 78 \\
H & $15 / 26$ & 58 \\
I & $17 / 25$ & 68 \\
GHI & $24 / 28$ & 86 \\
\hline
\end{tabular}

with three nymphs per bean. The nymphs on each test plant came from either one or three source plants thus making four treatments, and the whole experiment was replicated three times.

The infection rates varied more when the insects came from one source plant (range $27-78 \%$ ) than when the insects came from three different source plants (range 58-86\%) (Table 17). Therefore, due to differences between source plants, it is obvious that less variation can be expected if nymphs from different source plants are used during the IAT within the same treatment.

\subsection{Acquisition feed}

During acquisition feed virus is taken up by the vectors which may subsequently transmit the virus into other plants during the next feed. Several factors may influence virus acquisition, length of the feeding being one of the most obvious. Also viruses and virus isolates may differ in their characteristics of acquisition, there can be differences between vector species, and finally, the experimenter may use purified liquid extracts of virus as 'source plant' instead of virus infected seedlings, and again virus acquisition characteristics may be different. Acquisition feed was investigated in several experiments to find out some of the obvious factors involved.

\subsubsection{Removal of mealybugs from virus source plant}

At the end of acquisition feed the mealybugs must be removed from the source plant to test their infectivity or for other experimental purposes. The standard procedure of removal at the Cocoa Research Institute is to tap the source plant gently over a sheet of glass; some of the mealybugs probably not feeding will fall off the plant and those feeding will be disturbed to the extent that they will start to withdraw their stylets. Thus, in about fifteen minutes all the mealybugs can be removed. 
However, since it was not known whether tapping would damage the delicate mouthparts and affect infectivity, this was tested (Experiment 1). Also, there was a possibility that the mealybugs falling off the source plant with the first tapping would be those that did not feed at all and, therefore, would not be infective. This, too, called for some experimentation (Experiment 2). Finally, the normal duration of stylet withdrawal was studied (Experiment 3).

\section{Experiment 1}

The effect of tapping the nymphs off the source plant on the rate of virus transmission was studied with $0-3$ day old nymphs of $P$. njalensis in standard conditions. The length of AAT was 48 hours and IAT 24 hours. Four CSSV 1A infected source plants were used per treatment of which there were two, ordinary removal through tapping and removal by sunshine. Two nymphs were transferred per each test bean. The results were as follows:

\begin{tabular}{|c|c|c|}
\hline Treatment & Infection rate & Infection rate, $\%$ \\
\hline 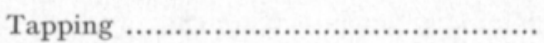 & $22 / 80$ & 27.5 \\
\hline Sunshine & $24 / 80$ & 30.0 \\
\hline
\end{tabular}

Calculation of chi-square results in a value of 0.03 which is highly nonsignificant. It is obvious, therefore, that tapping did not affect adversely the transmission efficiency of the nymphs if compared with the removal by heat of sunshine outside the laboratory.

Experiment 2

Three CSSV 1A isolate infected seedlings were grown in laboratory conditions in conical flasks containing $45 \mathrm{ml}$ of culture solution with a specific activity of $37.2 \mu \mathrm{Ci} / \mathrm{ml}$ of ${ }^{32} \mathrm{P}$. After six days of uptake, each seedling was infested twice on consecutive days with adults and nymphs of $P$. njalensis by using the paper cone technique. For each infestation a feeding access period of 24 hours was allowed after which the nymphs were sorted out into three different categories. The first consisted of nymphs that were attached to the paper cone when it was removed from the seedling. The second group consisted of nymphs that fell off the seedling immediately after the removal of the cone with the first tapping. The third group was obtained when the seedling was tapped again after five minutes. The settling rate and radioactivity of the nymphs was as follows:

\begin{tabular}{|c|c|c|c|}
\hline Group & $\begin{array}{l}\text { Settling } \\
\text { rate }\end{array}$ & $\begin{array}{l}\text { Settling } \\
\text { rate, } \%\end{array}$ & $\begin{array}{l}\text { Mean radioactivity of the } \\
\text { settled nymphs, cpm }\end{array}$ \\
\hline 1 (...................................... & $1 / 69$ & $1.4^{\mathrm{a}}$ & 19 \\
\hline 2 (n............................... & $3 / 36$ & $8.3^{\mathrm{a}}$ & 50 \\
\hline $3 \ldots \ldots \ldots \ldots \ldots$ & $21 / 47$ & $44.7^{b}$ & 86 \\
\hline
\end{tabular}

The proportion of radioactive nymphs was significantly larger in the third group and it is, therefore, justifiable to discard the nymphs that fall off with the paper cone and with the first tapping, and use nymphs that are dislodged during later tappings. 
Experiment 3

Up to three day old nymphs of $P$. njalensis were fed on young cocoa seedlings in feeding cages and standard conditions for two days. Then the cages were opened and the nymphs were touched gently one at a time with a brush on the back in order to know how rapidly the stylets would be withdrawn by the nymphs. Care was taken not to lift up the nymphs to avoid pulling the stylets from the plant tissues by the operator, and that only one nymph was disturbed at a time. Disturbance was indicated by the movement of the legs and body, and the time was counted from this reaction till the nymphs started to walk. A total of 36 nymphs was studied and the mean duration of stylet withdrawal was found to be $240 \pm 37 \mathrm{~s}$ (S. E.), with a range of $42 \mathrm{~s}-21 \mathrm{~min} 12 \mathrm{~s}$. It is obvious that the standard procedure of tapping does not speed up the withdrawal of stylets by force or otherwise because usually about 15 minutes is required to tap all the nymphs off the seedling.

\subsubsection{Length of acquisition feed with CSSV $1 A$ and P. nj a le $n$ s is}

When mealybugs settle down to feed on virus infected cocoa, the length of feeding may influence the amount of virus uptake or the infectivity of the mealybugs which can affect the subsequent transmission to a healthy plant during the next feed. Thus, the effect of acquisition access time was studied in the following experiments.

Experiments 1 and 2

These two experiments were replicas of each other with $201 \mathrm{~A}$ isolate of CSSV infected Amelonado seedlings as source plants. The seedlings were made radioactive by placing the roots into complete culture solution containing 29 $\mu \mathrm{Ci} / \mathrm{ml}$ of ${ }^{32} \mathrm{P}$. After four days of uptake in an insectary the seedlings were brought into air-conditioned laboratory and field collected adults and nymphs of $P$. njalensis starved for two days were then put on the seedlings to feed and acquire virus by using the paper cone technique. The length of the AAT was $8,16,24,48$ and 120 hours, and four source plants were used for each AAT. After AAT the mealybugs were counted for radioactivity and then put on half bean test plants for an IAT of $\mathbf{2 4}$ hours. Five mealybugs of about the same level of radioactivity were put on each half bean. After IAT the mealybugs were killed with nicotine sulphate solution and the beans were planted into ordinary soil in wooden boxes. The germinated seedlings were examined for virus symptoms during three months or up to the stage of the third leaf flush which is sufficient for revealing practically all the infected seedlings.

Experiment 3

This experiment was similar to 1 and 2 described above but there were 16 source plants and the length of the AAT was $24,48,72$ and 96 hours.

In all three experiments, with an increasing length of AAT, the mealybugs obtained more and more food as described by the count rates of radioactivity (Tables 18-20). The infection rate of test plants increased with the length 
Table 18. Effect of length of acquisition access time on the rate of CSSV 1A isolate transmission by $P$. njalensis.

\begin{tabular}{|c|c|c|c|c|c|c|}
\hline \multirow{2}{*}{$\begin{array}{c}\text { Length } \\
\text { of AAT, } \\
\text { hours } \\
\\
8\end{array}$} & \multicolumn{2}{|c|}{$\begin{array}{c}\text { Infection rate } \\
\text { and } \%\end{array}$} & \multicolumn{3}{|c|}{$\begin{array}{l}\text { Mean food uptake of transmitters (A), non- } \\
\text { transmitters (B), and all the mealybugs (C), } \\
\begin{array}{ccc}\log (n+1) & \text { transformed cp } 100 \text { s } \pm \text { S.E. } \\
\text { A } & \text { B }\end{array}\end{array}$} & \multirow{2}{*}{$\begin{array}{c}\mathrm{t} \\
\mathrm{A}-\mathrm{B} \\
3.16^{* * *}\end{array}$} \\
\hline & $3 / 49$ & $6^{a}$ & $2.33 \pm 0.44$ & $0.91 \pm 0.08$ & $0.99 \pm 0.09 \mathrm{ab}$ & \\
\hline 16 & $5 / 49$ & $10^{\mathrm{a}}$ & $1.18 \pm 0.34$ & $0.83 \pm 0.08$ & $0.86 \pm 0.08^{a}$ & 1.03 \\
\hline 24 & $16 / 54$ & $30^{\mathrm{be}}$ & $1.62 \pm 0.21$ & $0.94 \pm 0.11$ & $1.14 \pm 0.11^{b}$ & $2.81 * *$ \\
\hline 48 & $22 / 55$ & $40^{\mathrm{e}}$ & $1.91 \pm 0.11$ & $1.24 \pm 0.13$ & $1.51 \pm 0.10^{\mathrm{e}}$ & $3.98^{* * *}$ \\
\hline 120 & $8 / 51$ & $16^{\mathrm{ab}}$ & $2.26 \pm 0.26$ & $2.07 \pm 0.13$ & $2.10 \pm 0.12^{\mathrm{d}}$ & 0.68 \\
\hline
\end{tabular}

Table 19. Effect of length of acquisition access time on the rate of CSSV 1A isolate transmission by $P$. njalensis.

\begin{tabular}{|c|c|c|c|c|c|c|}
\hline \multirow{2}{*}{$\begin{array}{c}\begin{array}{c}\text { Length } \\
\text { of AAT, } \\
\text { hours }\end{array} \\
8\end{array}$} & \multicolumn{2}{|c|}{$\begin{array}{c}\text { Infection rate } \\
\text { and } \%\end{array}$} & \multicolumn{3}{|c|}{$\begin{array}{l}\text { Mean food uptake of transmitters (A), non- } \\
\text { transmitters (B), and all the mealybugs (C), } \\
\begin{array}{c}\log (n+1) \text { transformed cp100s } \pm \text { S.E. } \\
\text { A }\end{array}\end{array}$} & \multirow{2}{*}{$\begin{array}{c}\mathbf{t} \\
A-B \\
-\end{array}$} \\
\hline & $0 / 33$ & $0^{\mathrm{a}}$ & - & $0.97 \pm 0.11$ & $0.97 \pm 0.11 \mathrm{a}$ & \\
\hline 16 & $9 / 47$ & $19^{b}$ & $1.78 \pm 0.19$ & $1.07 \pm 0.10$ & $1.21 \pm 0.10^{\mathrm{a}}$ & $3.23 * *$ \\
\hline 24 & $11 / 38$ & $29 \mathrm{bed}$ & $2.30 \pm 0.19$ & $1.39 \pm 0.14$ & $1.65 \pm 0.13^{b}$ & $3.81 * * *$ \\
\hline 48 & $20 / 40$ & $50^{\mathrm{c}}$ & $2.90 \pm 0.16$ & $1.67 \pm 0.24$ & $2.28 \pm 0.17 \mathrm{e}$ & $4.23 * * *$ \\
\hline 120 & $8 / 47$ & $17^{b d}$ & $3.09 \pm 0.16$ & $2.39 \pm 0.17$ & $2.51 \pm 0.15^{c}$ & $2.92^{* *}$ \\
\hline
\end{tabular}

Table 20. Effect of length of acquisition access time on the rate of CSSV $1 \mathrm{~A}$ isolate transmission by $P$. njalensis.

$\begin{array}{lcc}\text { Length } & \text { Mean food uptake of the } \\ \text { of AAT, } & \text { Infection rate } & \text { mealybugs, } \log (\mathrm{n}+1) \\ \text { hours } & \text { and } \% & \text { transformed cp } 100 \mathrm{~s} \pm \\ & \text { S.E. } x \mathrm{t} 95 \%\end{array}$

\begin{tabular}{llll}
\hline 24 & $20 / 69$ & $29^{\mathrm{a}}$ & $1.52 \pm 0.19^{\mathrm{a}}$ \\
48 & $41 / 73$ & $56^{\mathrm{b}}$ & $2.00 \pm 0.22^{\mathrm{b}}$ \\
72 & $36 / 57$ & $63^{\mathrm{b}}$ & $2.51 \pm 0.19^{\mathrm{c}}$ \\
96 & $20 / 46$ & $43^{\mathrm{ab}}$ & $2.41 \pm 0.28^{\mathrm{c}}$ \\
\hline
\end{tabular}

of the AAT, and an AAT of 48 to 72 hours gave the highest percentage of infected plants. However, an AAT of 120 hours resulted in a low infection rate which is probably due to preliminary fasting as described under 3.5 , pages $236-$ 240. The food uptake of transmitters, in terms of radioactivity, was higher than that of non-transmitters. 
Experiment 4

This experiment was carried out to study whether CSSV 1A isolate can be transmitted by $P$. njalensis after very short access to virus source. The experiment was done under microscope in an air-conditioned laboratory, except the test feed which occurred in an insectary. 0-14 days old nymphs were used and they were allowed to probe between a few to 30 seconds (AAT) on'infected Amelonado-type young cocoa leaves. The length of IAT was 24 hours, and 3-4 nymphs were put on each half bean test plant. After killing the nymphs, the beans were planted and the germinated seedlings were examined for virus symptoms. There were eight virus source leaves from different seedlings and 73 nymphs which were put on 21 test beans, however, none of these became infected.

In this experiment the nymphs were confined to a small area on cocoa leaf in transparent cages where they could be seen walking around at first for some time. Suddenly the walking stopped and they made slight movements with the front part of the body towards the surface of the leaf. If the nymphs were left undisturbed, most of them settled down to feed. The movements of the front part of the body continued and the stylets were pushed gradually deeper and deeper into the leaf tissue. The stylets could be seen when the nymphs were observed laterally under a microscope. Other evidence was obtained by touching the nymphs gently with a brush. If the stylets are not embedded in the leaf tissue, the touch of the brush will cause the nymphs to move away immediately. In the reverse case, the stylets will anchor the nymphs and it takes some time to withdraw the stylets as described under 3.7.1, pages $242-244$. From numerous observations it appears that if the nymphs are not moulting, they will either walk, attempt to feed (prcbe), or feed. Feeding does not necessarily mean food uptake but rather that the stylets are embedded in plant tissue.

Experiment 5

An AAT of one hour was tested in this experiment with $0-2$ day old nymphs of $P$. njalensis in standard conditions and on CSSV $1 \mathrm{~A}$ isolate infected cocoa seedlings. After the short AAT the nymphs were starved for $0,1,2,3$ and 4 hours in starvation cages after which an IAT of one hour was allowed. Ten nymphs were put on each test bean and the number of test beans was 20 in each treatment. No transmissions occurred which indicates that transmission of CSSV by $P$. njalensis may be rare with short acquisition feeds, or with short transmission cycles which were from 2 to 6 hours in this experiment.

\subsubsection{Length of acquisition feed with other isolates and $P$. n $j$ a l e $n s$ is}

The rate of transmission of two isolates, $1 \mathrm{M}$ and $1 \mathrm{~A}$ of CSSV, by P. njalensis was investigated in ordinary laboratory conditions with infected Amelonado cocoa seedlings as source plants. The seedlings were made radioactive with ${ }^{32} \mathrm{P}$ in the normal way and field collected mealybugs starved for two days were put on them for an AAT of 24 and 48 hours to feed and acquire virus by using the paper cone technique. Each treatment was replicated six times. After 
Table 21. Effect of length of acquisition access time on the rate of CSSV $1 \mathrm{~A}$ and $1 \mathrm{M}$ isolate transmission by $P$. njalensis.

\begin{tabular}{|c|c|c|c|c|}
\hline $\begin{array}{c}\text { Length } \\
\text { of AAT, } \\
\text { hours }\end{array}$ & $\begin{array}{r}\text { Virus } \\
\text { isolate }\end{array}$ & \multicolumn{2}{|c|}{$\begin{array}{c}\text { Infection rate } \\
\text { and } \%\end{array}$} & $\begin{array}{c}\text { Mean food uptake of the } \\
\text { mealybugs, } \log (\mathrm{n}+1) \\
\text { transformed cp100s } \pm \\
\text { S.E.x t } 95 \%\end{array}$ \\
\hline 24 & $\operatorname{cssv} 1 \mathrm{~A}$ & $35 / 75$ & $47^{a}$ & $1.50 \pm 0.10^{\mathrm{a}}$ \\
\hline 24 & $\operatorname{Cssv} 1 \mathrm{M}$ & $27 / 78$ & $35^{a}$ & $1.54 \pm 0.12^{\mathrm{a}}$ \\
\hline 48 & $\operatorname{cssv} 1 \mathrm{~A}$ & $40 / 58$ & $69^{b}$ & $2.58 \pm 0.11^{b}$ \\
\hline 48 & $\operatorname{CSSV} 1 \mathrm{M}$ & $52 / 79$ & $66^{b}$ & $2.19 \pm 0.09^{c}$ \\
\hline
\end{tabular}

AAT the mealybugs were counted for radioactivity and five bugs of about equal count rate were put on each of the half bean test plants for an IAT of 24 hours. Then the beans were planted into ordinary soil and the germinated seedlings were examined for virus symptoms.

According to radioactivity figures the feeding of mealybugs during AAT was quite normal (Table 21). There was no difference in the rate of virus transmission between the two isolates, however, both isolates were more efficiently transmitted after the longer AAT.

In another experiment the effect of AAT on transmission of CSSV $1 \mathrm{M}$ isolate by $P$. njalensis was studied with ${ }^{32} \mathrm{P}$-active infected Amelonado cocoa seedlings as source plants of virus. The experiment was carried out in ordinary laboratory conditions, and field collected mealybugs starved for two days were put on the source seedlings in paper cones for an AAT of 8, 16, 24, 48, 72 and 96 hours. Each AAT was replicated with eight source plants. After AAT the radioactivity of the mealybugs was measured and they were put on half beans at a rate of one per bean for an IAT of $\mathbf{2 4}$ hours. Following IAT the mealybugs were killed, the beans were planted and the germinated seedlings were inspected for symptoms of virus.

The mealybugs acquired radioactivity in the typical way, in increasing amounts with the increased length of AAT (Table 22). The rate of virus transmission increased with the length of the AAT, and the highest infection rates were obtained with an AAT of 48 to 96 hours.

Table 22. Effect of length of acquisition access time on the rate of CSSV $1 \mathrm{M}$ isolate transmission by $P$. njalensis.

\begin{tabular}{crrr}
\hline $\begin{array}{c}\text { Length } \\
\text { of AAT, } \\
\text { hours }\end{array}$ & $\begin{array}{c}\text { Infection rate } \\
\text { and } \%\end{array}$ & $\begin{array}{c}\text { Mean food uptake of } \\
\text { the mealybugs, log } \\
(\mathrm{n}+1) \text { transformed } \\
\text { cp100s } \pm \text { S.E. }\end{array}$ \\
\hline 8 & $6 / 322$ & $2^{\mathrm{a}}$ & $0.68 \pm 0.03^{\mathrm{a}}$ \\
16 & $3 / 291$ & $1^{\mathrm{a}}$ & $1.13 \pm 0.05^{\mathrm{b}}$ \\
24 & $17 / 333$ & $5^{\mathrm{b}}$ & $1.21 \pm 0.04^{\mathrm{b}}$ \\
48 & $39 / 403$ & $10^{\mathrm{e}}$ & $1.62 \pm 0.04^{\mathrm{c}}$ \\
72 & $48 / 395$ & $12^{\mathrm{e}}$ & $2.01 \pm 0.03^{\mathrm{d}}$ \\
96 & $69 / 371$ & $19^{\mathrm{d}}$ & $2.23 \pm 0.04^{\mathrm{e}}$ \\
\hline
\end{tabular}


Besides comparing two isolates of CSSV, one experiment was carried out to investigate possible differences between CSSV 1A isolate and CMLV 1C (Kpeve) isolate. In general, this experiment was similar to the one described above, however, only nymphs of $P$. njalensis were used as vectors and the length of the AAT was 8, 24 and 72 hours, and each treatment was replicated with four source plants.

There were no great differences between the food uptake of nymphs feeding either on CSSV or CMLV infected seedlings and the transmission characteristics of the two viruses were similar (Table 23).

Table 23. Effect of length of acquisition access time on the rate of CSSV $1 \mathrm{~A}$ and CMLV 1C isolate transmission by nymphs of $P$. njalensis.

\begin{tabular}{rlrcc}
\hline $\begin{array}{c}\text { Length } \\
\text { of AAT, } \\
\text { hours }\end{array}$ & $\begin{array}{c}\text { Virus and } \\
\text { isolate }\end{array}$ & $\begin{array}{c}\text { Infection rate } \\
\text { and } \%\end{array}$ & $\begin{array}{c}\text { Mean food uptake of the } \\
\text { nymphs, log(n }+1) \\
\text { transformed cp100s } \pm \text { S.E. }\end{array}$ \\
\hline & CMLV 1C & $13 / 184$ & $7^{\mathrm{a}}$ & $0.23 \pm 0.02^{\mathrm{a}}$ \\
8 & CSSV 1A & $17 / 192$ & $9^{\mathrm{ab}}$ & $0.32 \pm 0.03^{\mathrm{b}}$ \\
8 & CMLV 1C & $19 / 199$ & $10^{\mathrm{ab}}$ & $0.52 \pm 0.05^{\mathrm{c}}$ \\
24 & CSSV 1A & $28 / 198$ & $14^{\mathrm{b}}$ & $0.60 \pm 0.04^{\mathrm{e}}$ \\
24 & CMLV 1C & $103 / 198$ & $52^{\mathrm{e}}$ & $2.23 \pm 0.05^{\mathrm{d}}$ \\
72 & CSSV 1A & $68 / 161$ & $42^{\mathrm{e}}$ & $2.23 \pm 0.06^{\mathrm{a}}$ \\
\hline 72 & & & & \\
\hline
\end{tabular}

\subsubsection{Length of acquisition feed with CSSV $1 A$ and F. virg a t a}

Eighteen ${ }^{32} \mathrm{P}$-active CSSV 1A isolate infected Amelonado seedlings were used as virus source plants to investigate the effect of length of AAT on the rate of virus transmission by nymphs of $F$. virgata. This experiment was carried out in a growth chamber at $24-27^{\circ} \mathrm{C}$. and $55-75 \% \mathrm{RH}$. The length of the AAT was 6,24 and 72 hours, and the age of nymphs was $0-3$ days when taken from the reproduction cages in the beginning of the AAT. The length of the IAT was 24 hours as usual and three nymphs were put on each half bean test plant. After the IAT the nymphs were destroyed, the beans were planted and the germinated seedlings were examined for symptoms of virus.

The nymphs settled down to feed slowly at first, with about $35 \%$ of them indicating some feeding activity after 24 hours feeding access time (Table 24), however, after 72 hours about $93 \%$ of the nymphs had settled down to feed. With increasing length of feeding access time the amount of food uptake also increased. The rate of virus transmission increased with the length of AAT and the increasing amount of food uptake. Thus the highest infection rate was obtained with an AAT of 72 hours. The food uptake by transmitters was higher than by non-transmitters.

\subsubsection{Acquisition of virus from liquid leaf extract}

No doubt it would be very useful if virus could be acquired, and subsequently transmitted, by mealybugs while feeding via a membrane on labelled virus 
Table 24. Effect of length of acquisition access time on settling rate, food uptake, and rate of CSSV $1 \mathrm{~A}$ isolate transmission by nymphs of $F$. virgata.

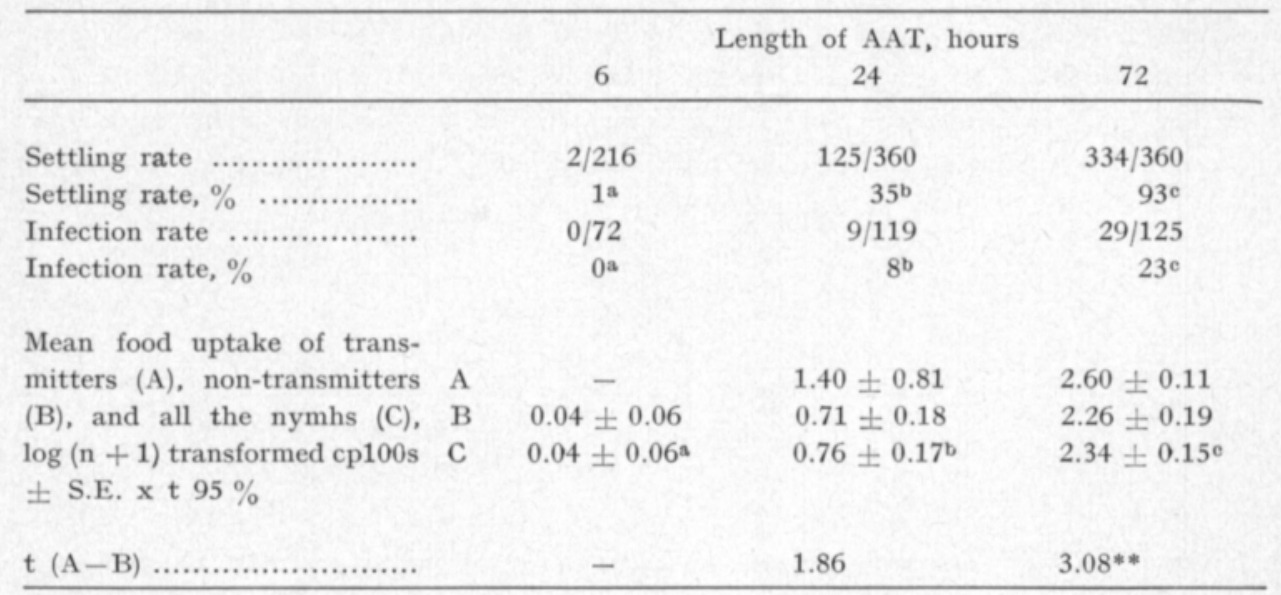

preparations. Radioactivity would be an exact measure of the amount of virus taken up by mealybugs because radioactive chemical and virus would be evenly distributed in the preparation, whereas in radioactive virus infected seedlings the pattern of distribution of the radioactivity and virus is unknown. Several experiments were carried out to investigate this approach.

At first it had to be established that mealybugs can feed via a membrane on a liquid diet. Twelve $250 \mathrm{ml}$ conical flasks were used in the experiment as feeding cages. The flasks had a cloth covered hole in the neck for aeration. Forty adult females of $P$. njalensis with adhering nymphs, were put into each flask which was then sealed with parafilm (Parafilm M, Marathon Co., U.S.A.). The parafilm was slightly pressed down the mouth to form a basin for the liquid diet. One $\mathrm{ml}$ of diet was applied into each basin which was then covered by another layer of parafilm. The diet contained $10 \%$ sucrose in distilled rain water and $37.2 \mu \mathrm{Ci} / \mathrm{ml}$ of ${ }^{32} \mathrm{P}$. Radioactivity of nymphs was determined after $2,5,7$ and 9 days by opening three flasks at random and dislodging the nymphs attached to the parafilm. The experiment was carried out in an air-conditioned laboratory.

After moving around in the flasks for a few hours some of the nymphs settled down on the parafilm and, as tabulated below, also fed on the diet.

$\begin{array}{ccccc}\text { Mean food uptake of } & 2 & 5 & 7 & 9 \\ \text { nymphs } \log (\mathrm{n}+1) & 0.44 \pm 0.16^{\mathrm{a}} & 1.58 \pm 0.24^{\mathrm{b}} & 1.91 \pm 0.17 \mathrm{e} & 1.90 \pm 0.16^{\mathrm{e}} \\ \text { cp100s } \pm \text { S.E. } \mathrm{x} \text { t } 95 \% & \mathrm{n}=63 & \mathrm{n}=54 & \mathrm{n}=68 & \mathrm{n}=70\end{array}$

To obtain evidence that $P$. njalensis would also feed on virus preserving solution, $11.5 \%$ of sucrose was added into the solution originally containing $0.01 \mathrm{M}$ thioglycolate, $0.02 \mathrm{M}$ citrate and a trace of carbontetrachloride, $\mathrm{pH} 6$. The control was $11.5 \%$ sucrose in distilled rain water. Specific activity of ${ }^{32} \mathrm{P}$ in both solutions was $57.5 \mu \mathrm{Ci} / \mathrm{ml}$. Nymphs of $0-7$ days old obtained from 
reproduction cages were put into four feeding cages co itaining the two solutions in parafilm sachets. At the end of a feeding access time of 2 and 3 days in airconditioned laboratory, the radioactivity of the nymphs attached to the parafilm was determined. As given below, the nymphs fed more readily on the control solution than on the virus preserving solution, but the amount of uptake from preserving solution was considered high enough to justify experimentation with the virus itself.

Length of feeding access time, days

2

3

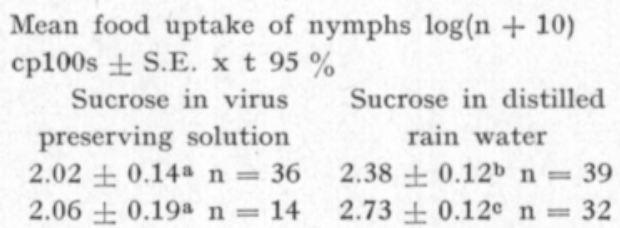

Before major experiments with the virus, the effect of parafilm on the rate of virus transmission was investigated with $14 \mathrm{CSSV} 1 \mathrm{~A}$ infected cocoa seedlings. Pieces of parafilm about $3 \mathrm{~cm}$ wide were used to coat the stems of these seedlings in such a way that there was only one layer of $3 \mathrm{~cm}$ wide stretched parafilm on the stem. The thickness of extended parafilm was found to be about 70 microns and the stylets of young nymphs of $P$. njalensis measure about $\mathbf{5 0 0}$ microns if fully extended. Thus the stylets could possibly reach the phloem which was considered to be the source of virus. Two feeding cages were fixed around the stem of each seedling, one on the parafilm covered portion and the other where there was no parafilm. Nymphs of $0-2$ days were put into the feeding cages for an AAT of 48 hours. The length of IAT was 24 hours on half beans with five nymphs per each half bean. The beans were planted in the ordinary way and the germinated seedlings were examined for virus symptoms. The experiment was carried out in a growth chamber in $24-27^{\circ} \mathrm{C}$. and $55-75 \% \mathrm{RH}$.

The nymphs that fed via parafilm infected 36 out of 235 test plants (15\%) and the control insects 64 out of $224(29 \%$ ) (chi-square 12.61***). Thus the nymphs could acquire virus while feeding via a parafilm during the AAT and subsequently transmit the virus into beans. The difference of infection rates may indicate that nymphs did not feed readily via parafilm or that the parafilm made it more difficult for the nymphs to reach the phloem.

Three experiments were carried out to investigate whether nymphs of $P$. njalensis could acquire virus from liquid leaf extract in preserving solution via parafilm. The length of AAT in these experiments was 24 and 48 hours, length of IAT was 24 hours on half bean test plants and, prestarved $\mathbf{0 - 5}$ day old nymphs were used. The experiments were carried out in growth chambers at $24-27^{\circ} \mathrm{C}$. and $55-75 \% \mathrm{RH}$. ${ }^{32} \mathrm{P}$ was also used to check the food uptake.

Two experiments, with a total of 536 nymphs on 84 test beans, gave negative results. The third experiment, however, with an AAT at 48 hours and 172 $0-2$ day old nymphs on 35 test plants, gave two infections and also two other seedlings with transient symptoms of virus. There is very little chance that the infections were caused by infective mealybugs from outside because the insectary was sprayed regularly and also other precautions were taken during the experiment. 


\subsection{Persistence of virus in mealybugs after acquisition feed}

After cessation of acquisition feed, infective mealybugs may carry over virus into other feeding sites. However, there are factors that may influence the fate of virus during the period between cessation of acquisition feed and commencement of the next feed. Time is the most obvious among these factors, but postacquisition fasting or feeding and also moulting of vectors may influence the resulting retention of virus or loss of infectivity. Several experiments were carried out to investigate persistence of cocoa viruses in mealybugs.

\subsubsection{Persistence of CSSV $1 \mathrm{~A}$ in fasting P. njalens $i \mathrm{~s}$}

An experiment was carried out on virus retention by fasting mealybugs in ordinary laboratory conditions with field collected $P$. njalensis adults and nymphs which were starved for two days before an AAT of 48 hours was given on $52 \mathrm{CSSV} 1 \mathrm{~A}$ isolate infected cocoa seedlings. After AAT only nymphs from source plants were put into small covered cages for a postacquisition fasting of either $0,24,48$ or 72 hours. After fasting, nymphs were put on half bean test plants at a rate of one per bean for an IAT of 24 hours. At the end of IAT the nymphs were killed, the beans were planted and germinated seedlings were examined for virus symptoms.

As tabulated below, infectivity of the nymphs decreased rapidly but in one case out of 371 virus persisted in the nymphs up to $48-72$ hours. Because it is not known when the virus was actually injected into the test bean during the IAT of 24 hours, the minimum and maximum length of virus retention is given here $(48-72$ hours).

\begin{tabular}{lllll} 
& \multicolumn{4}{c}{ Length of post-AAT fasting, hours } \\
& $0-24$ & $24-48$ & $48-72$ & $72-96$ \\
Infection rate $\ldots \ldots \ldots \ldots \ldots \ldots \ldots \ldots \ldots \ldots \ldots$ & $78 / 419$ & $9 / 419$ & $1 / 371$ & $0 / 156$ \\
Infection rate, $\% \ldots \ldots \ldots \ldots \ldots \ldots \ldots \ldots \ldots \ldots$ & 18.6 & 2.1 & 0.3 & 0.0
\end{tabular}

\subsubsection{Persistence of CSSV $1 \mathrm{~A}$ in feeding P. n jalens $i$ s}

A similar experiment as the one described under 3.8.1 above was carried out in standard conditions in the growth chambers with $0-3$ day old nymphs obtained from reproduction cages, and four virus source plants. The only differences were that, after the AAT, the nymphs were transferred on healthy Amelonado seedlings for a postacquisition feeding rather than fasting, and the number of nymphs during IAT on test beans varied from one to five.

Loss of infectivity in the nymphs followed the same pattern as in the previous experiment and again virus persisted in the nymphs up to $48-72$ hours as indicated by one test plant out of 100 (Table 25). Also quite a number of nymphs were observed with their stylets embedded in tissues of the healthy seedlings during postacquisition feeding which gives indirect evidence of actual feeding by mealybugs on the healthy seedlings.

To obtain direct evidence on postacquisition feeding on healthy seedlings and its effect on subsequent transmission of virus by mealybugs, nymphs of $P$. njalensis were allowed an AAT of 48 hours on non-radioactive CSSV $1 \mathrm{~A}$ isolate 
infected Amelonado seedlings. The experiment was carried out in ordinary laboratory conditions, and after the AAT the nymphs were transferred on 24 ${ }^{32} \mathrm{P}$-active healthy seedlings where the nymphs had an access to feed for 24 hours. At the end of this period the radioactive (postacquisition feeding) and the non-radioactive (postacquisition fasting) nymphs were put on cocoa half bean test plants at a rate of one per bean for an IAT of 24 hours. Then the nymphs were killed and the beans were planted as usual, and the germinated seedlings were examined for symptoms of virus.

A total of 1648 seedlings germinated and 37 of them showed symptoms of virus. The mean radioactivity of nymphs that successfully transmitted the virus, and the ones that did not, was 83.7 and $33.4 \mathrm{cp} 100 \mathrm{~s}$, respectively. Frequency distribution of radioactivity in the nymphs indicated that 34 nymphs, out of the 37 that transmitted the virus, had also fed during the postacquisition period of 24 hours (Fig. 21). $\log (n+1)$ transformation and statistical processing gave the means \pm S.E. $x$ t $95 \%$ of $1.92 \pm 0.11$ and $1.62 \pm 0.014$ for the transmitters and non-transmitters, respectively $\left(t=5.46^{* * *}\right)$ (Fig. 22), thus indicating that in this experiment the virus was transmitted more often by nymphs after postacquisition feeding than after fasting.

Table 25. Effect of feeding (access to feed) after acquisition access time on the rate of CSSV $1 \mathrm{~A}$ isolate transmission by nymphs of $P$. njalensis.

\begin{tabular}{|c|c|c|c|c|c|}
\hline $\begin{array}{l}\text { Number of } \\
\text { nymphs per } \\
\text { test plant }\end{array}$ & & \multicolumn{4}{|c|}{ Length of post-AAT feeding, hours } \\
\hline \multirow{3}{*}{1} & Infection rate...$\ldots \ldots \ldots \ldots$ & $4 / 20$ & $0 / 20$ & $0 / 20$ & $0 / 20$ \\
\hline & Infection rate, $\%$............ & 20 & 0 & 0 & 0 \\
\hline & $\left.\mathrm{p}^{*}, \mathrm{o}^{1}\right)$ & 20 & 0 & 0 & 0 \\
\hline \multirow{3}{*}{2} & Infection rate $\ldots \ldots \ldots \ldots \ldots \ldots$ & $8 / 20$ & $0 / 20$ & $0 / 20$ & $0 / 20$ \\
\hline & Infection rate, $\%$............ & 40 & 0 & 0 & 0 \\
\hline & 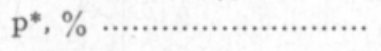 & 23 & 0 & 0 & 0 \\
\hline \multirow{3}{*}{3} & Infection rate $\ldots \ldots \ldots \ldots \ldots . .$. & $10 / 20$ & $2 / 20$ & $0 / 20$ & $0 / 20$ \\
\hline & Infection rate, $\%$............ & 50 & 10 & 0 & 0 \\
\hline & 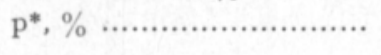 & 21 & 3.4 & 0 & 0 \\
\hline \multirow{3}{*}{4} & Infection rate $\ldots \ldots \ldots \ldots \ldots$ & $10 / 20$ & $4 / 20$ & $0 / 20$ & $0 / 20$ \\
\hline & Infection rate, $\%$............ & 50 & 20 & 0 & 0 \\
\hline & $\mathrm{p}^{*}, \%$......................... & 16 & 5.5 & 0 & 0 \\
\hline \multirow{3}{*}{5} & Infection rate $. . . \ldots \ldots \ldots \ldots . . .$. & $13 / 20$ & $4 / 20$ & $1 / 20$ & $0 / 20$ \\
\hline & Infection rate, $\%$.............. & 65 & 20 & 5 & 0 \\
\hline & 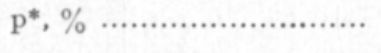 & 19 & 4.3 & 1 & 0 \\
\hline \multirow{3}{*}{$1-5$} & Infection rate $\ldots \ldots \ldots \ldots \ldots \ldots$ & $45 / 100$ & $10 / 100$ & $1 / 100$ & $0 / 100$ \\
\hline & Infection rate, $\%$.............. & 45 & 10 & 1 & 0 \\
\hline & 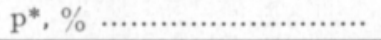 & 19.8 & 2.6 & 0.2 & 0 \\
\hline
\end{tabular}

1) $\mathrm{p}^{*}=$ maximum likelihood estimator of infection rate for one nymph per test plant. Expression used in this and some other tables to compare results whenever the number of mealybugs during IAT has varied. 


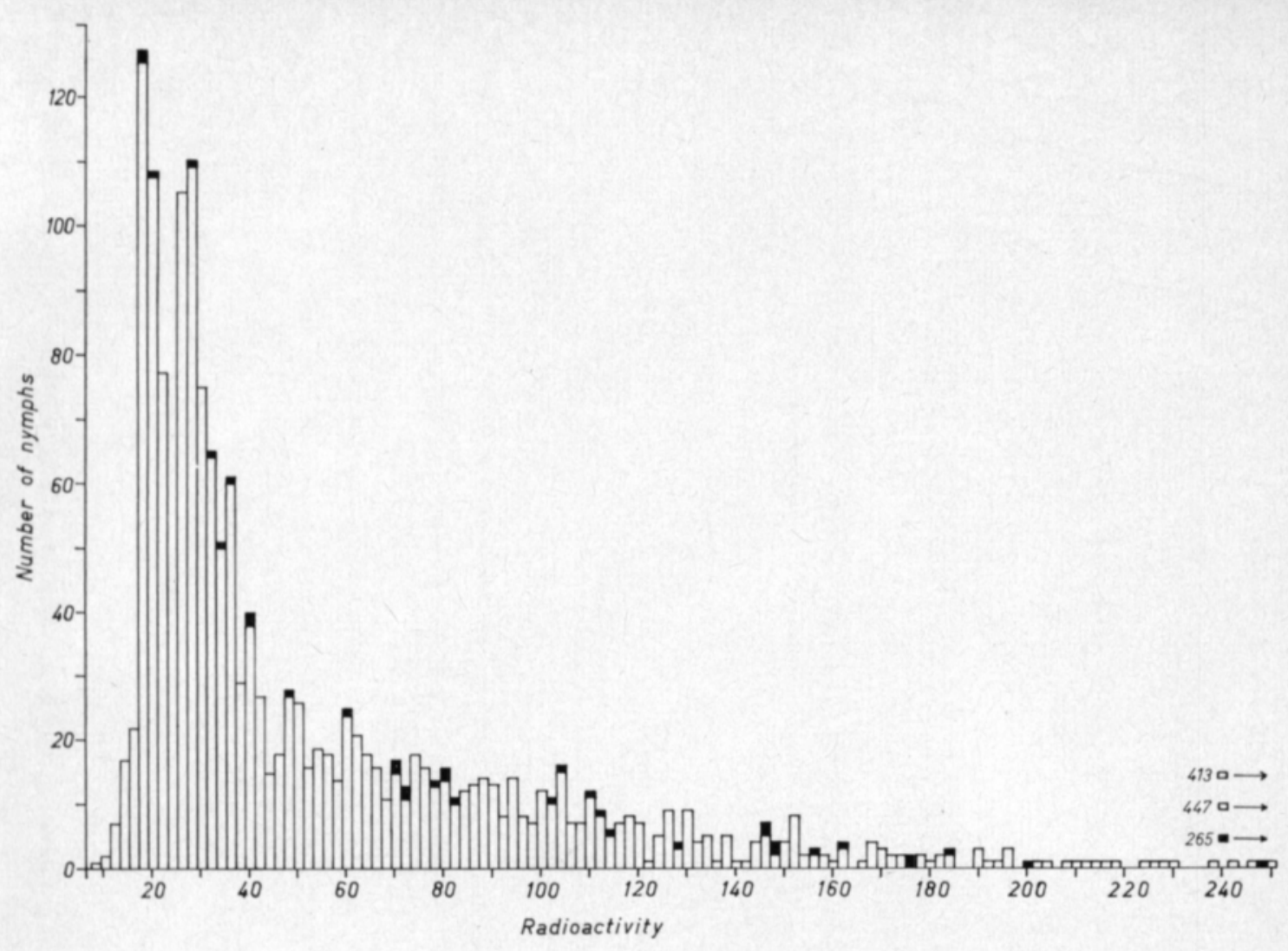

Fig. 21. Frequency distribution of radioactivity in nymphs of $P$. njalensis after a feeding access time of 24 hours on ${ }^{32} \mathrm{P}$-active cocoa seedlings. Solid parts of histogram indicate transmitters, and open parts non-transmitters.

The experiment described above was repeated in a modified way with 14 CSSV isolate infected seedlings as source plants. To get data on mealybug feeding during AAT, these seedlings were made radioactive by growing them in culture solution containing $52.4 \mu \mathrm{Ci} / \mathrm{ml}$ of ${ }^{35} \mathrm{~S}$ for four days. Then $0-2$ day old nymphs of $P$. njalensis were put, in air-conditioned laboratory, on the seedlings for an AAT of 48 hours by using the paper cone technique. After AAT the nymphs were removed from the plants and put on six healthy seedlings which had been made radioactive in culture solution containing $31 \mu \mathrm{Ci} / \mathrm{ml}$ of ${ }^{32} \mathrm{P}$. The nymphs were allowed to stay on these seedlings for a postacquisition feed of 24 hours after which they were removed and put on half beans at a rate of one per bean. As usual, the beans were planted and infections recorded in the germinated seedlings.

Radioactivity recordings were taken immediately after AAT for ${ }^{35} \mathrm{~S}$ and, after the 24 hour postacquisition feed on healthy seedlings for ${ }^{32} \mathrm{P} .{ }^{35} \mathrm{~S}$ counts were taken from nymphs that were on a planchet under a thin film (Saran Wrap) cover weighing $1.87 \mathrm{mg} / \mathrm{cm}^{2}$. The film absorbed $43.5 \%$ of the weak ${ }^{35} \mathrm{~S}$ beta radiation, but the film was necessary to keep the nymphs on a planchet during the counting. ${ }^{32} \mathrm{P}$ counting after postacquisition feed was also done on 


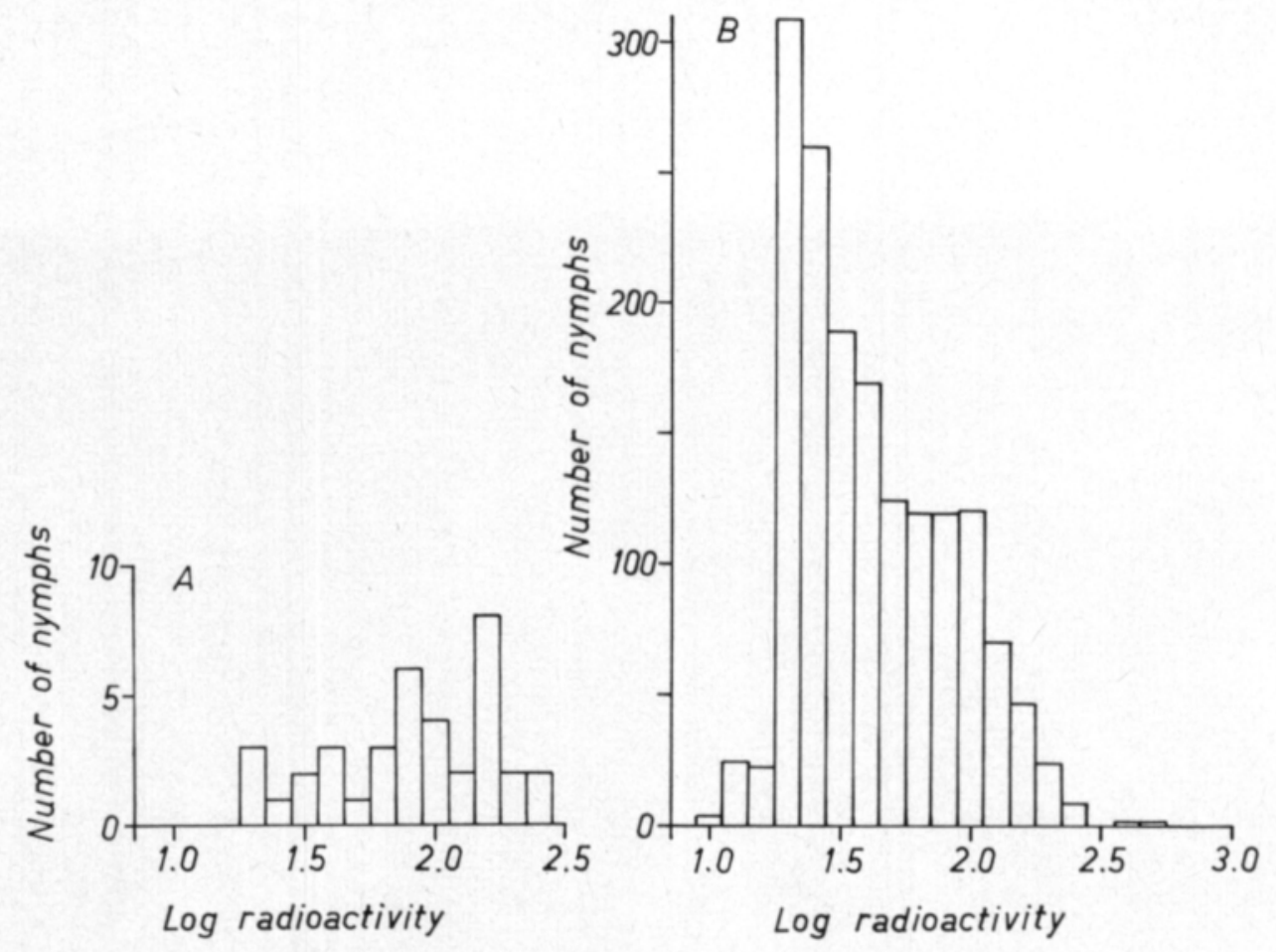

Fig. 22. Frequency distribution of radioactivity in nymphs of $P$. njalensis after a feeding acces time of 24 hours on ${ }^{32}$ P-active cocoa seedlings. Same data as in Fig. 21., but $\log (\mathrm{n}+1)$ transformed. A and B, frequency distribution of transmitters and non-transmitters, respectively.

planchets but these were now covered with a thicker film (Saran Wrap + Scotch Tape) which weighed $10.41 \mathrm{mg} / \mathrm{cm}^{2}$. The film absorbed $96.7 \%$ of ${ }^{35} \mathrm{~S}$ radiation but only $1.68 \%$ of the strong radiation of ${ }^{32} \mathrm{P}$. This technique made it possible to differentiate the two beta rays of different energies in order to record the feeding during the AAT and during the 24 hour postacquisition feed. Self absorption of ${ }^{35} \mathrm{~S}$ in the nymphs was not considered because of the nature of the experiment.

A total of 505 nymphs were obtained from virus source plants and they were sorted out into three different levels of ${ }^{35}$ S-activity; $0-10,11-70$ and $71-$, cp100s. Nymphs of different levels were put on separate ${ }^{32} \mathrm{P}$-active healthy seedlings for the postacquisition feed after which they were removed and counted for ${ }^{32} \mathrm{P}$. Knowing the level of ${ }^{35} \mathrm{~S}$ and the effect of the absorber, the amount of ${ }^{32} \mathrm{P}$ radiation could be calculated from the total count rate of combined ${ }^{35} \mathrm{~S}$ and ${ }^{32} \mathrm{P}$. The number of nymphs obtained from the ${ }^{32} \mathrm{P}$-active seedlings was 131 , and the number of test plants was the same.

The feeding of nymphs during the AAT was similar to feeding data cbtained in other experiments with ${ }^{32} \mathrm{P}$-active seedlings as source plants. Five of the 131 test plants became infected. Count rate recordings of the five nymphs that caused infection are tabulated as follows in cp100s. 


\begin{tabular}{|c|c|c|c|c|c|}
\hline $\begin{array}{c}\text { Observed count rate of }{ }^{35} \mathrm{~S} \\
\text { via Saran Wrap }\end{array}$ & $\begin{array}{c}1 \\
71-266\end{array}$ & $\stackrel{2}{11-70}^{2}$ & $\begin{array}{l}\text { Nymph No. } \\
\quad 3 \\
71-245\end{array}$ & $\begin{array}{c}4 \\
11-70\end{array}$ & $\begin{array}{c}5 \\
11-70\end{array}$ \\
\hline $\begin{array}{r}\text { Count rate of }{ }^{35} \text { S, corrected } \\
\text { for absorption by Saran } \\
\text { Wrap }\end{array}$ & $126-471$ & $19-124$ & $126-433$ & $19-124$ & $19-124$ \\
\hline $\begin{array}{l}\text { Observed count rate of }{ }^{35} \mathrm{~S} \\
+{ }^{32} \mathrm{P} \text { via Saran Wrap } \\
+ \text { Scotch Tape }\end{array}$ & 84 & 117 & 5 & 84 & 109 \\
\hline $\begin{array}{c}\text { Amount of penetrating }{ }^{35} \mathrm{~S} \\
\text { via Saran Wrap }+ \\
\text { Scotch Tape .................. }\end{array}$ & $4-16$ & $1-4$ & $4-14$ & $1-4$ & $1-4$ \\
\hline Amount of penetrating ${ }^{32} \mathrm{P}$ & $68-80$ & $113-116$ & $0-1$ & $80-83$ & $105-108$ \\
\hline
\end{tabular}

Nymphs Nos. 1, 2, 4 and 5 fed during AAT and during postacquisition time, and transmitted the virus into test plants during IAT. Nymph No. 3 fed during AAT but not with certainty during the postacquisition time, and transmitted the virus into test plant.

\subsubsection{Consecutive transmission of virus by a single mealybug}

Another way to approach the loss of infectivity in mealybugs was to ascertain whether the same nymphs of $P$. njalensis could transmit CSSV $1 \mathrm{~A}$ isolate after AAT twice or more often into test plants. This experiment was carried out in a growth chamber at $25-26^{\circ} \mathrm{C}$. and $55-75 \% \mathrm{RH}$. Nymphs $0-3$ days old were given an AAT of 72 hours on young source plants in feeding cages, and then transferred on half beans at a rate of one per bean. After IAT of three hours on the beans all the 348 beans were examined and 17 nymphs were found feeding. These 17 nymphs were transferred on another lot of beans (17) and allowed to feed during a three hour IAT after which the beans were examined and only one nymphs was found feeding. This single nymphs was transferred again to a half bean for a new 3 hour IAT. After IAT the bean was examined but the nymph was not feeding.

Infection rate of the first lot of test beans was $55 / 348$, the second lot gave $2 / 17$, and the third $0 / 1$. Only one bug that transmitted virus during the first IAT also transmitted during the second IAT. This experiment was repeated but no further consecutive transmissions were obtained. The combined results were as follows:

1st IAT, infection rate 70/698, 48 nymphs found feeding out of 698 .

2nd IAT, infection rate 2/48, 9 nymphs found feeding out of 48 .

3rd IAT, infection rate $0 / 9$, none found feeding out of 9 nymphs.

Only one nymph infected a plant during the first and the second IAT. The other nymph that caused infection during the second IAT did not do so during the first IAT although the nymph was found feeding.

\subsubsection{Persistence of CMLV $1 C$ in fasting $P$. n j a le $n$ s is}

In the previous experiments retention of CSSV $1 \mathrm{~A}$ isolate was studied. Retention of CMLV 1C isolate was also investigated by using $0-1$ day old nymphs 
of $P$. njalensis as vectors. These were put on infected source plants for an AAT of 48 hours in standard conditions of the growth chamber. After AAT a postacquisition fasting of 24 and 48 hours followed in the starvation cages before the nymphs were put on test beans for an IAT of 24 hours. The control insects were transferred to test plants immediately after AAT. Number of nymphs per test plant was $1,3,6$ or 12 . After IAT the beans were planted and the germinated seedlings were examined for virus symptoms.

As with CSSV $1 \mathrm{~A}$ isolate, CMLV $1 \mathrm{C}$ isolate persisted in the nymphs up to 48-72 hours after AAT (Table 26).

Table 26. Effect of fasting after acquisition access time on the rate of CMLV 1C isolate transmission by nymphs of $P$. njalensis.

\begin{tabular}{|c|c|c|c|c|}
\hline $\begin{array}{l}\text { Number of } \\
\text { nymphs per } \\
\text { test plant }\end{array}$ & & \multicolumn{3}{|c|}{ Length of post-AAT fasting, hours } \\
\hline \multirow{3}{*}{1} & Infection rate & $4 / 240$ & $1 / 115$ & $0 / 80$ \\
\hline & 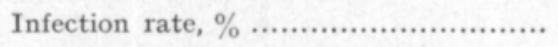 & 1.7 & 0.9 & 0.0 \\
\hline & 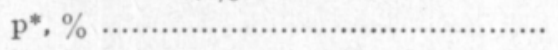 & 1.7 & 0.9 & 0.0 \\
\hline \multirow{3}{*}{3} & 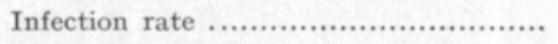 & $24 / 119$ & $3 / 49$ & $0 / 40$ \\
\hline & Infection rate, $\%$.............................. & 20.2 & 6.1 & 0.0 \\
\hline & 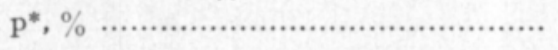 & 7.2 & 2.1 & 0.0 \\
\hline \multirow{3}{*}{6} & Infection rate & $13 / 56$ & $1 / 30$ & $0 / 20$ \\
\hline & Infection rate, $\%$ & 23.2 & 3.3 & 0.0 \\
\hline & 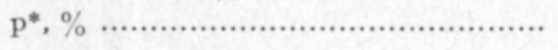 & 4.3 & 0.6 & 0.0 \\
\hline \multirow{3}{*}{12} & Infection rate & $14 / 29$ & $1 / 15$ & $1 / 10$ \\
\hline & Infection rate, $\%$ & 48.3 & 6.7 & 10.0 \\
\hline & 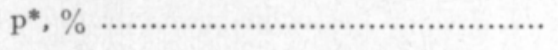 & 5.3 & 0.6 & 0.9 \\
\hline \multirow{3}{*}{$1-12$} & 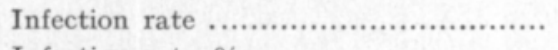 & $55 / 444$ & $6 / 209$ & $1 / 150$ \\
\hline & 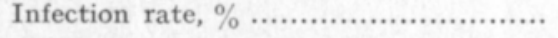 & 12.4 & 2.9 & 0.7 \\
\hline & 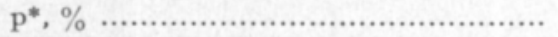 & 4.6 & 1.0 & 0.2 \\
\hline
\end{tabular}

\subsubsection{Persistence of CSSV $1 \mathrm{~A}$ in fasting $F$. virg a $t$ a}

An experiment was carried out to find whether there are any differences in retention of virus between $P$. njalensis and $F$. virgata. Nymphs $0-1$ day old of the two mealybug species were put on different CSSV $1 \mathrm{~A}$ isolate infected virus source plants for an AAT of 48 hours in standard conditions. This was followed by a postacquisition fasting of 6,24 and 48 hours in starvation cages before the nymphs were put on half bean test plants at a rate of five per bean for an IAT of 24 hours. Control insects were transferred to test beans immediately after the AAT. Beans were planted and the germinated seedlings were examined for virus symptoms as usual.

There was a shortage of $F$. virgata nymphs, however, it could be shown that CSSV $1 \mathrm{~A}$ is retained in $F$. virgata as in $P$. njalensis (Table 27). $F$. virgata 
Table 27. Effect of fasting after acquisition access time on the rate of CSSV $1 \mathrm{~A}$ isolate transmission by nymphs of $F$. virgata and $P$. njalensis.

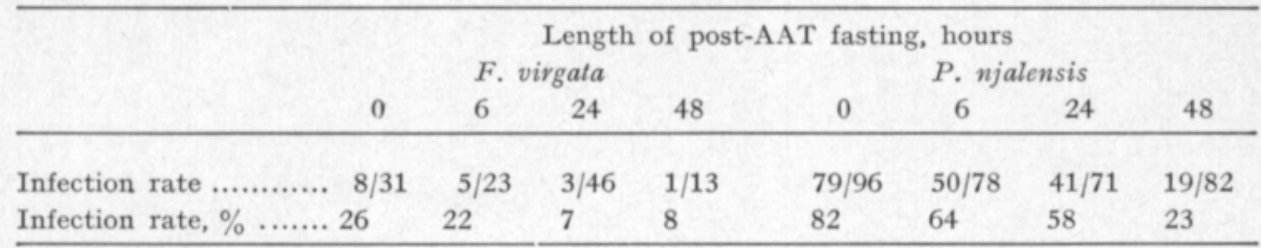

was a less efficient vector than $P$. njalensis when virus was acquired from the stems of source plants as in this experiment.

\subsubsection{Relationship between virus persistence and time}

A large scale experiment was carried out to establish a mathematical relationship between retention of virus in mealybugs and time. 14 CSSV 1A isolate infected Amelonado seedlings were used as virus source plants. The experiment was carried out in growth chambers at $25-27^{\circ} \mathrm{C}$. and $50-75 \% \mathrm{RH}$. The nymphs of $P$. njalensis, from seven reproduction cages, were $0-2$ day old when they were put on virus source plants. The length of AAT was 48 hours after which the nymphs were transferred into 28 starvation cages for a postacquisition fasting of $12,24,36,48,60$ and 72 hours. The control insects were transferred directly from source plants to test plants $(0$ hours postacquisition fasting). After fasting, the nymphs were put on test plants at a rate of 2,4 and 8 per half bean for an IAT of 24 hours. The beans were planted and the germinated seedlings were examined for virus symptoms.

In general, infectivity of the nymphs decreased rapidly and in a similar way as in the experiments described earlier (Table 28). However, it was estab-

Table 28. Effect of fasting after acquisition access time on the rate of CSSV $1 \mathrm{~A}$ isolate transmission by nymphs of $P$. njalensis.

\begin{tabular}{|c|c|c|c|c|c|c|c|}
\hline \multirow{2}{*}{$\begin{array}{l}\text { Number of } \\
\text { nymphs per } \\
\text { test plant }\end{array}$} & \multirow{2}{*}{ 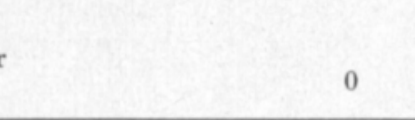 } & \multicolumn{5}{|c|}{ Length of post-AAT fasting, hours } & \multirow[b]{2}{*}{72} \\
\hline & & 12 & 24 & 36 & 48 & 60 & \\
\hline \multirow{3}{*}{2} & Infection rate ......... $74 / 139$ & $6 / 68$ & $3 / 127$ & $2 / 48$ & $1 / 88$ & $0 / 69$ & $0 / 149$ \\
\hline & Infection rate, $\% \quad \ldots . \quad 53.2$ & 8.8 & 2.4 & 4.2 & 1.1 & 0.0 & 0.0 \\
\hline & $\mathrm{p}^{*}, \%$ & 4.5 & 1.2 & 2.1 & 0.6 & 0.0 & 0.0 \\
\hline \multirow{3}{*}{4} & Infection rate $\ldots \ldots \ldots . .104 / 137$ & $11 / 67$ & $17 / 130$ & $2 / 49$ & $2 / 90$ & $3 / 78$ & $1 / 149$ \\
\hline & Infection rate, $\% \quad \ldots .75 .9$ & 16.4 & 13.1 & 4.1 & 2.2 & 3.8 & 0.7 \\
\hline & $\mathrm{p}^{*}, \%$ & 4.4 & 3.5 & 1.1 & 0.6 & 1.0 & 0.2 \\
\hline \multirow{3}{*}{8} & Infection rate $\ldots \ldots \ldots . . .121 / 138$ & $15 / 69$ & $23 / 129$ & $7 / 46$ & $7 / 86$ & $4 / 80$ & $0 / 146$ \\
\hline & Infection rate, $\% \quad \ldots \quad 87.7$ & 21.7 & 17.8 & 15.2 & 8.1 & 5.0 & 0.0 \\
\hline & $\mathrm{p}^{*}, \% \ldots \ldots \ldots \ldots \ldots \ldots \ldots \ldots$ & 3.0 & 2.4 & 2.0 & 1.1 & 0.7 & 0.0 \\
\hline \multirow{3}{*}{$2-8$} & Infection rate ......... 299/414 & $32 / 204$ & $43 / 386$ & $11 / 143$ & $10 / 264$ & $7 / 227$ & $1 / 444$ \\
\hline & Infection rate, $\% \quad \ldots \quad 72.2$ & 15.7 & 11.1 & 7.7 & 3.8 & 3.1 & 0.2 \\
\hline & $\mathrm{p}^{*}, \% \quad \ldots \ldots \ldots \ldots \ldots \ldots \ldots \ldots \ldots . . .28$ & 4.0 & 2.4 & 1.7 & 0.8 & 0.6 & 0.1 \\
\hline
\end{tabular}




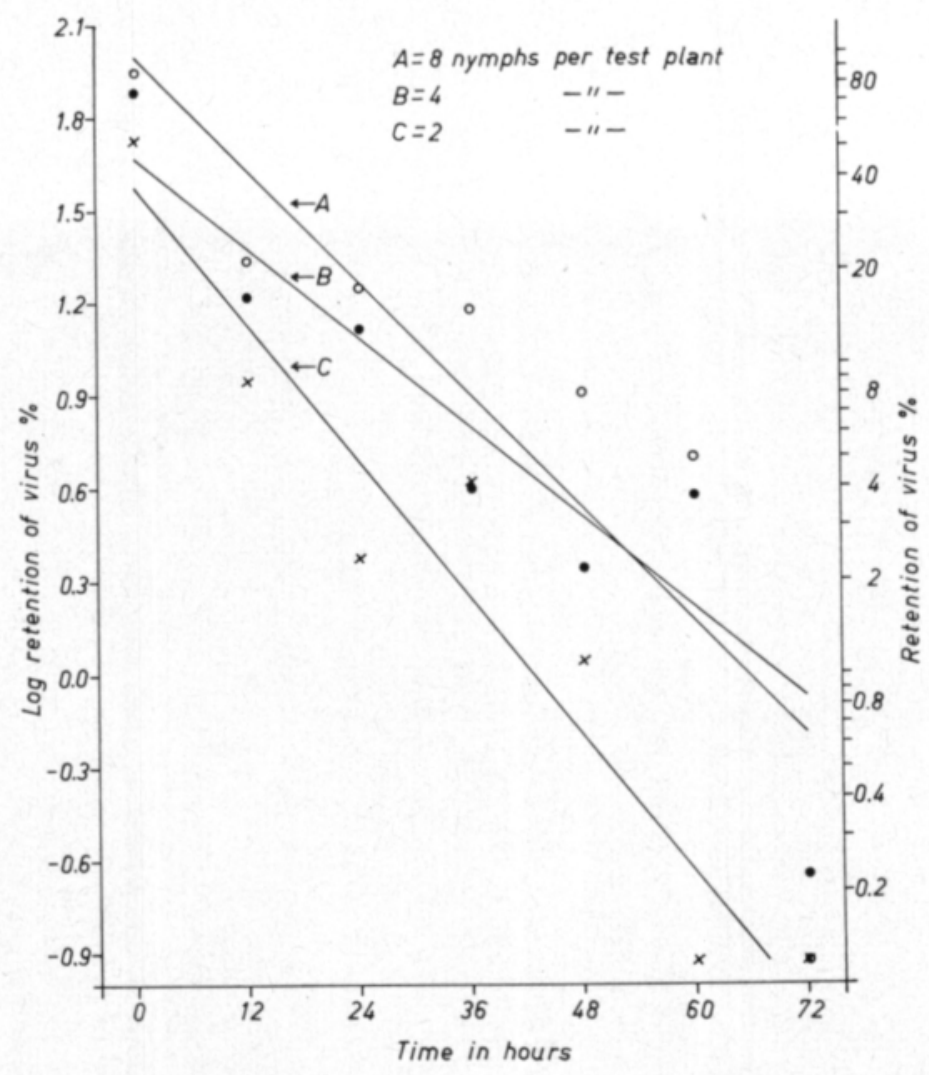

Fig. 23. Persistence of infectivity in starving nymphs of $P$. njalensis after acquisition access time. $\mathrm{A}(\mathrm{o}) ; \mathrm{y}=2.022-0.0311 \mathrm{x} ; \mathrm{r}=-0.872^{*} ; \mathrm{T}_{\frac{1}{2}}$ persistence $=9.7$ hours. $\mathrm{B}(\bullet) ; \mathrm{y}=1.672-$ $0.0242 \mathrm{x} ; \mathrm{r}=-0.947^{* *} ; \mathrm{T}_{\frac{1}{2} \text { persistence }}=12.4$ hours. $\mathrm{C}(\mathrm{x}) ; \mathrm{y}=1.574-0.0369 \mathrm{x} ; \mathrm{r}=$ $-0.958^{* * * ;} \mathrm{T}_{\frac{1}{2} \text { persistence }}=8.2$ hours.

lished that virus may persist in the nymphs during a postacquisition fasting of 72-96 hours. Mathematical relationship between length of postacquisition fasting and infectivity of the nymphs is best described by equations where loss of infectivity is exponential with time (Figs. 23 and 24). According to such a relationship, half of the nymphs lost their ability to transmit virus about every $12-13$ hours, or the half-life, $\mathrm{T} \frac{1}{2}$ persistence $=12-13$ hours. (Fig. $24 \mathrm{~A}, \mathrm{~B}$ ).

\subsubsection{Persistence of virus through postacquisition moulting}

The effect of postacquisition moulting on CSSV 1A isolate transmission by nymphs of $P$. njalensis has been reported before (Rorvarnen 1971). According to that report, first instar nymphs, fed on virus infected cocoa seedlings (AAT), transmitted the virus to cocoa half bean test plants even if moulting had taken place during postacquisition fasting. Also, there was no significant difference between the infection rates of moulted and unmoulted control insects. 


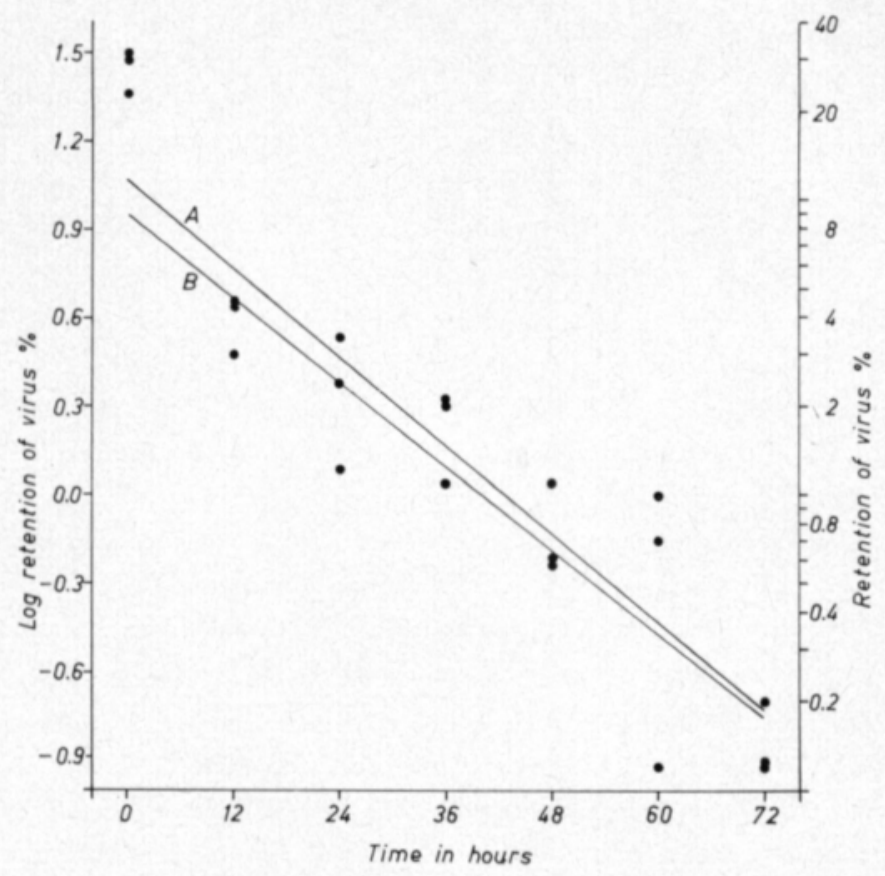

Fig. 24. Persistence of infectivity in starving nymphs of $P$. njalensis after acquisition access time. Infection rate values after calculation of $\mathrm{p}^{*}$ (maximum likelihood estimator) from Table 28. A (all the values); $\mathrm{y}=1.068-0.0249 \mathrm{x} ; \mathrm{r}=-0.867^{* * *} ; \mathrm{T}_{\frac{1}{2}}$ persistence $=12.1$ hours. $\mathrm{B}$ (omitting 3 values at 0 hours); $\mathrm{y}=0.949-0.0237 \mathrm{x} ; \mathrm{r}=-0.897^{* * *} ; \mathrm{T}_{\frac{1}{2} \text { persistence }}=12.7$ hours.

Similar experiments described above were carried out also with CMLV 1C isolate and $P$. njalensis. The length of AAT at 120 hours and IAT at 24 hours, the nymphs were allowed a postacquisition fasting of 20 hours in moulting cages. Moulted and unmoulted nymphs were put on different test beans at a rate of $4-5$ per bean for an IAT of 24 hours. Then the beans were planted and the germinated seedlings were examined for symptoms of virus.

Moulted nymphs transmitted virus into one test plant out of 65 , while unmoulted control nymphs transmitted it into six out of 65 test beans.

\subsection{Inoculation feed}

The final stage, the transmission of virus by mealybugs into a healthy plant or test bean, takes place when an infective mealybug settles down to feed on the test plant at the same time inoculating the virus. Several factors may contribute to the final observed infection rate, e.g. length of IAT, length of latent period of virus in the test plants, number of infective mealybugs per test plant during the IAT, degree of resistance to virus of different cocoa types used as test plants, and feeding site on the test plant. No specific expriments were carried out on the length of the IAT, however, the available data is analyzed in the discussion part of this paper. 


\subsubsection{Latent period of virus in the test plant}

Normally test plants are kept and examined for virus symptoms up to three months after sowing the test beans, however, in some experiments, particularly in the early stage of this work, test plants were examined for virus symptoms up to four months before they were discarded. Appearance of virus symptoms was studied in 929 test seedlings extracted from these early experiments. All these seedlings were of Amelonado-type cocoa, and virus was transmitted into them while the plants were half beans by $P$. njalensis during an IAT of 24 hours. After IAT the mealybugs were killed with nicotine sulphate solution and the beans were planted into ordinary soil in wooden boxes and kept in an insectary.

Usually it takes about a week before the young seedling emerges from the soil after the bean has been planted. Thus symptom spotting cannot start before the seedling is one week old or older. In the material under study, the shortest time interval from planting the bean to the first appearance of virus symptoms was 13 days, while the longest was 118 days (Fig. 25). During 2140 days after planting the beans, symptoms appeared in $72.1 \%$ of the seedlings, and 50,70 and 90 days after planting, 88.6, 96.5 and $98.6 \%$ of the seedlings had developed symptoms of virus, respectively. The remaining $1.4 \%$ of the seedlings produced virus symptoms at $91-120$ days after planting of the half beans.

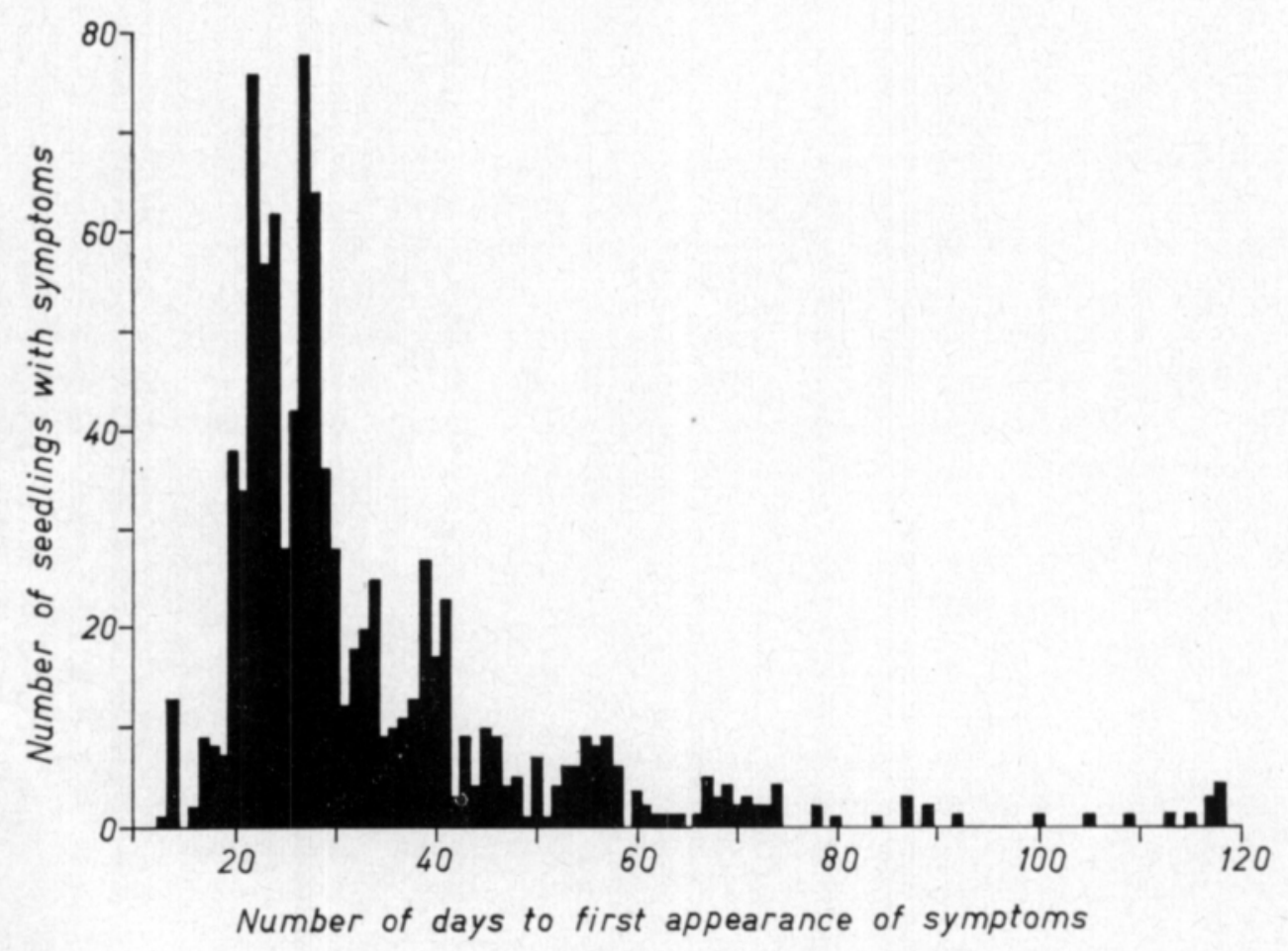

Fig. 25. Relationship between time and appearance of CSSV $1 \mathrm{~A}$ isolate symptoms in Amelonado cocoa test plants. 


\subsubsection{Number of mealybugs on test plants during inoculation feed}

In transmission tests with cocoa viruses the infection rate generally increases with the number of mealybugs used on individual test beans during the IAT (e.g. Tables 25, 26, 28 and 30). One specific experiment was carried out with the aim of proving that the transfer of several mealybugs to one test plant is essentially a multiple-transfer method and the maximum likelihood estimator is the most satisfactory method of estimating the frequency of transmission by individual mealybugs. According to GIBBs and Gower (1960), the maximum likelihood estimator is calculated as follows:

$$
\mathrm{p}^{*}=1-\left(1-\frac{\mathrm{R}}{\mathrm{N}}\right)^{\frac{1}{\mathrm{i}}}
$$

where, $\mathrm{N}=$ the number of test plants used,

$\mathrm{i}=$ the number of mealybugs transferred to each test plant,

$\mathrm{R}=$ the number of test plants that become infected, and

$\mathrm{p}^{*}=$ the maximum likelihood estimator of the proportion $(\mathrm{p})$ of transmitting mealybugs in the population being studied.

$24 \mathrm{CSSV} 1 \mathrm{~A}$ isolate infected Amelonado seedlings were used as virus source plants. All experimental stages up to the planting of the half beans were carried out in growth chambers at $24-27^{\circ} \mathrm{C}$. and $55-75 \% \mathrm{RH}$. The length of the AAT was 48 hours and $0-3$ day old nymphs of $P$. njalensis were used as vectors. The length of the IAT was 24 hours and 1-10 nymphs were put on each half bean. After IAT the beans were planted and the germinated seedlings were examined for virus symptoms.

The infection rate increased gradually with the insect number (Table 29, Fig. 26). The rate of increase was in accordance with the mathematical expectation.

Table 29. Effect of number of nymphs during inoculation access time on the rate of CSSV 1A isolate transmission by nymphs of $P$. njalensis.

\begin{tabular}{cccc}
\hline $\begin{array}{c}\text { Number of nymphs } \\
\text { per test plant }\end{array}$ & $\begin{array}{c}\text { Infection } \\
\text { rate }\end{array}$ & $\begin{array}{c}\text { Infection rate, } \\
\left.\% \pm \text { error }^{1}\right)\end{array}$ & $\mathrm{p}^{*}, \%$ \\
\hline 1 & $55 / 230$ & $23.9 \pm 5.7$ & 23.9 \\
2 & $39 / 168$ & $36.1 \pm 9.5$ & 20.1 \\
3 & $38 / 65$ & $58.5 \pm 12.7$ & 25.4 \\
4 & $44 / 82$ & $53.7 \pm 11.4$ & 17.5 \\
5 & $33 / 52$ & $63.5 \pm 14.0$ & 18.3 \\
6 & $37 / 50$ & $74.0 \pm 13.2$ & 20.1 \\
7 & $41 / 56$ & $73.2 \pm 12.5$ & 17.2 \\
8 & $27 / 36$ & $75.0 \pm 15.5$ & 15.9 \\
9 & $17 / 21$ & $81.0 \pm 17.0$ & 16.8 \\
10 & $17 / 19$ & $89.5 \pm 16.4$ & 20.2 \\
\hline
\end{tabular}

1) $95 \%$ confidence limits for a proportion corrected for continuity.

\subsubsection{Inoculation feed on different cocoa types as test plants}

Possibilities were investigated to use nymphs of $P$. njalensis while testing virus resistant/tolerant cocoa types against a susceptible standard. Accord- 


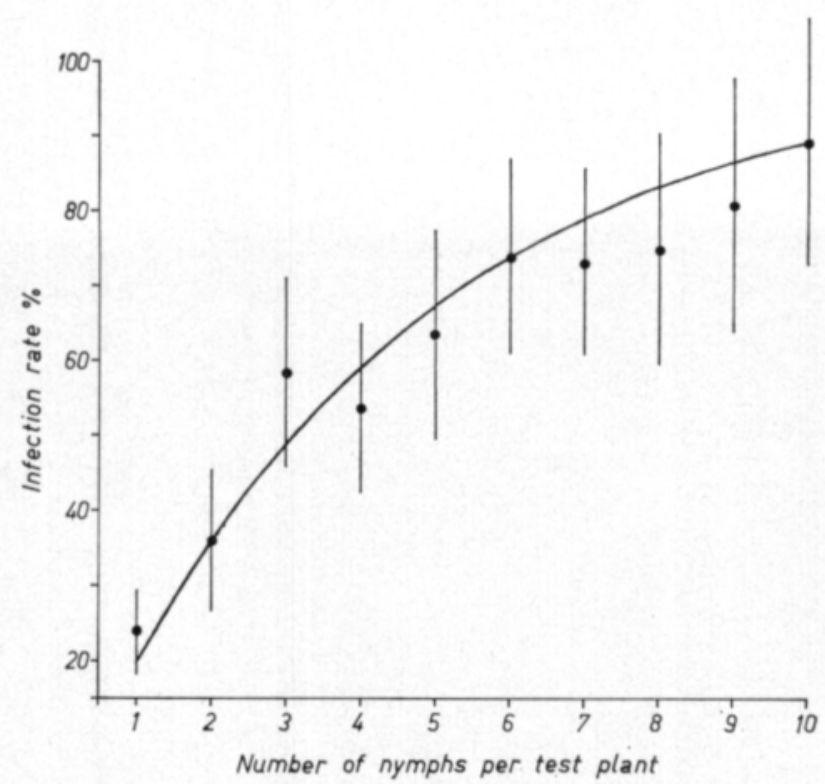

Fig. 26. Effect of number of nymphs during inoculation access time on the rate of CSSV $1 \mathrm{~A}$ isolate transmission by nymphs of $P$. njalensis. Black circles (•) indicate infection rates (\%) with $95 \%$ confidence limits for a proportion corrected for continuity. The curve describes mathematical expectation of infection rates if one nymph per test plant gives an infection rate of $20 \%$.

ing to the formula for maximum likelihood estimator, when $\mathrm{p}^{*}$ is low (resistant/ tolerant) i should be high, and when $\mathrm{p}^{*}$ is high (susceptible) i should be low to avoid high bias and error in the infection rates obtained, while the infection rates can still be statistically compared by calculating the value of $\mathrm{p}^{*}$ for both cases. If the same number of nymphs (i) is used on the test beans of resistant/ tolerant and susceptible cocoa there is a tendency that the infection rates run out of scale; the infection rate is either too low with the resistant/tolerant cocoa or too high with the susceptible cocoa depending on the number of nymphs used during the IAT.

Four CSSV 1A isolate infected Amelonado seedlings were used as virus source plants and the length of the AAT was 48 hours. The experiment was done in a growth chamber at $25-27^{\circ} \mathrm{C}$. and $50-70 \% \mathrm{RH}$. The age of the nymphs in the beginning of AAT was $0-2$ days. The length of the IAT was 24 hours and 1, 2, 4 and 8 nymphs were put on each half bean test plant. The test plants were different resistant/tolerant crosses of Na33/564 $\times \mathrm{Na34/807}$, T63/967/59 $\times$ TF20/24 and, TF16/76 $\times$ Sca6. TF20/68 was used as susceptible control. The beans were planted after IAT and the germinated seedlings were examined for virus symptoms as usual.

Unfortunately, cocoa beans were in very short supply when this experiment was carried out, however, despite these material limitations, there were significant differences between the infection rates of the four cocoa types tested (Table 30 ). The infection rate also increased with the numbers of insects used during the IAT.

The results of this experiment give rise to interesting theoretical considerations about the sensitivity of testing resistance/tolerance of different cocoa types with mealybugs. True, sensitivity can be increased by increasing the number of test plants, but it can be improved also if the number of nymphs per test bean is selected in such a way that the infection rates do not come too close 
to zero or 100 . The ideal, in fact, seems to be that the mean of all the infection rates is about $50 \%$.

The values of $\mathrm{p}^{*}$ in Table 30 are estimates of infection rates that would have been obtained if one nymph per bean had been used all through the experiment. Using each mean value of $\mathrm{p}^{*}$ (Table $\left.30,1 \mathrm{~A}-8 \mathrm{D}\right)$, infection rate estimates were calculated for $1,2,3,4,5$ and 8 nymphs per test plant as follows:

Number of nymphs per test plant

1
2
3
4
5
8

\begin{tabular}{rccc}
\multicolumn{5}{c}{ Infection rate $(\%)$} & according to $\mathrm{p}^{*}$ \\
A & B & C & D \\
9.9 & 14.7 & 23.5 & 43.6 \\
18.7 & 27.1 & 41.2 & 63.9 \\
26.7 & 37.5 & 54.8 & 74.5 \\
33.9 & 46.2 & 65.1 & 80.9 \\
40.3 & 53.5 & 73.0 & 85.1 \\
56.0 & 69.4 & 87.3 & 91.7
\end{tabular}

Range of
A-D
33.7
45.2
47.8
47.0
44.8
35.7

Assuming that 100 test plants were used in each treatment $(1 \mathrm{~A}-8 \mathrm{D})$, and rounding off the decimals, the following infection rates and chi-squares can be obtained (Table 31). If the judgement is based on chi-square values and the ranges of infection rates, it is obvious that the sensitivity of the test is highest when 3-4 nymphs are used per test plant, and the sensitivity decreases when more or less nymphs are used.

Table 30. Rate of CSSV $1 \mathrm{~A}$ isolate transmission by nymphs of $P$. njalensis into four different cocoa types with different degree of resistance to virus.

\begin{tabular}{|c|c|c|c|c|c|}
\hline \multirow{3}{*}{$\begin{array}{l}\text { Number of } \\
\text { nymphs per } \\
\text { test plant }\end{array}$} & & \multicolumn{4}{|c|}{ Cocoa type } \\
\hline & & $\mathrm{Na} 33 / 564 \mathrm{x}$ & T63/967/59 & TF16/76 & TF20/68 \\
\hline & & Na34/807 (A) & x TF $20 / 24$ (B) & x Sca6 $(\mathrm{C})$ & (D) \\
\hline \multirow{3}{*}{1} & Infection rate ............ & $1 / 12$ & $3 / 20$ & $6 / 20$ & $4 / 7$ \\
\hline & Infection rate, $\%$........ & 8.3 & 15.0 & 30.0 & 57.1 \\
\hline & $\mathrm{p}^{*}, \%$ & 8.3 & 15.0 & 30.0 & 57.1 \\
\hline \multirow{3}{*}{2} & Infection rate ............ & $2 / 12$ & $6 / 20$ & $8 / 20$ & $4 / 7$ \\
\hline & Infection rate, $\%$........ & 16.7 & 30.0 & 40.0 & 57.1 \\
\hline & $\mathrm{p}^{*}, \mathrm{\%}, \ldots \ldots \ldots \ldots \ldots \ldots \ldots$ & 8.7 & 16.3 & 22.5 & 34.4 \\
\hline \multirow{3}{*}{4} & Infection rate ............ & $4 / 12$ & $12 / 20$ & $13 / 20$ & $7 / 7$ \\
\hline & Infection rate, $\%$....... & 33.3 & 60.0 & 65.0 & 100.0 \\
\hline & $\mathrm{p}^{*}, \%$ & 9.6 & 20.5 & 23.1 & $\left.68.4^{1}\right)$ \\
\hline \multirow{3}{*}{8} & Infection rate ............. & $8 / 12$ & $9 / 20$ & $16 / 20$ & $5 / 7$ \\
\hline & Infection rate, $\%$........ & 66.7 & 45.0 & 80.0 & 71.4 \\
\hline & $\mathrm{p}^{*}, \mathrm{\%}, \ldots \ldots \ldots \ldots \ldots \ldots$ & 12.8 & 7.2 & 18.2 & 14.5 \\
\hline \multirow{3}{*}{$1-8$} & Infection rate ............. & $15 / 48$ & $30 / 80$ & $43 / 80$ & $20 / 28$ \\
\hline & Infection rate, $\%$....... & 31.3 & 37.5 & 53.8 & 71.4 \\
\hline & $p^{*}, \%$...................... & 9.9 & 14.7 & 23.5 & 43.6 \\
\hline
\end{tabular}

1) Instead of using the true infection rate $7 / 7=100 \%$, an infection rate of $99 \%$ has been used to calculate $\mathrm{p}^{*}$ because $\frac{\mathrm{R}}{\mathrm{N}}=1$ will always give $\mathrm{p}^{*}=1$ with any number of nymphs. 
Table 31. Probable variation of chi-square while testing resistance to CSSV 1A isolate of different cocoa types with different numbers of nymphs of $P$. njalensis.

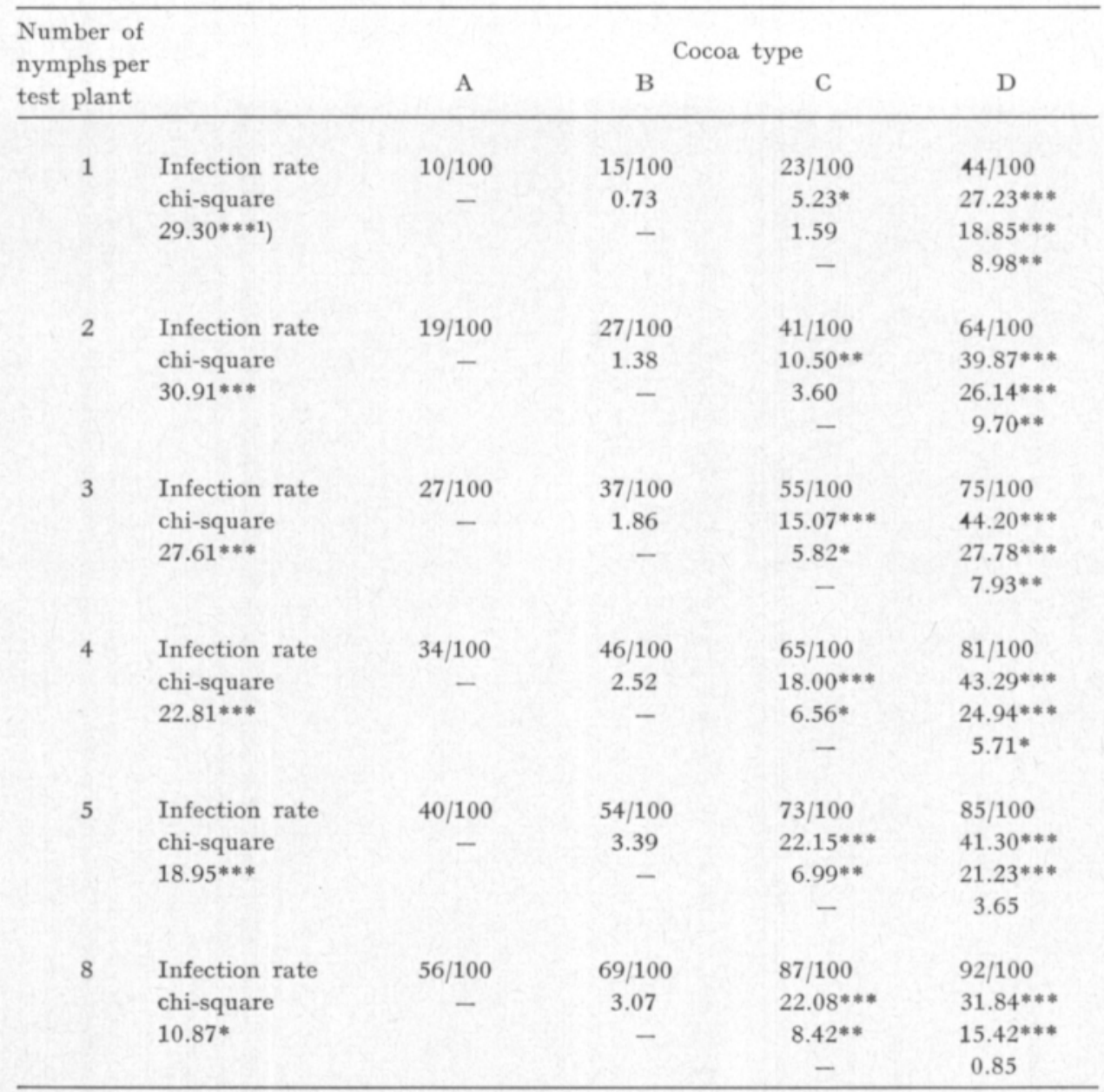

1) overall chi-square for $\mathrm{A}-\mathrm{D}$ with expected infection rates equal as null hypothesis.

Comparison between different cocoa types can be carried out also through a study of different numbers of nymphs required to cause the same infection rate in the cocoa types. Thus, one nymph per test bean may cause an infection rate of $44 \%$ in susceptible cocoa, while five nymphs are required per test bean to cause an almost similar infection rate of $40 \%$ in resistant/tolerant cocoa (Table $31,1 \mathrm{D}$ and $5 \mathrm{~A}$ ).

\subsubsection{Location of feeding on test beans}

Nymphs of $P$. njalensis, $0-2$ days old, were given an AAT of 48 hours on CSSV 1A isolate infected virus source plants. After AAT they were put on half bean test plants at a rate of one per bean for an IAT of 24 hours. At the end of the IAT the feeding of each nymph was checked on the beans by inspecting whether the stylets were embedded in the bean tissue. Location on the bean 
of those feeding was recorded. The nymphs were then destroyed, and the beans were planted in the ordinary way and the germinated seedlings were examined for virus symptoms. The experiment was carried out in a growth chamber at $25-26^{\circ} \mathrm{C}$. and $60-80 \% \mathrm{RH}$ until planting of the half beans.

A total of 202 nymphs were found feeding and 174 of them on the inside surface of the cotyledon. The nymphs obviously preferred the inside to the outside (chi-square $62.36^{* * *}$ ), where the only obvious difference is that the inside is uneven with involutions and crevices in the cotyledon tissue whereas the outside is smooth. The rate of virus transmission by nymphs feeding on either side of the bean was similar; nymphs feeding on the inside and the outside surfaces gave infection rates of $57 / 174(33 \%)$ and $8 / 28(29 \%)$, respectively. Location of the nymphs during feeding on either side of the bean had no influence on virus transmission (Fig. 27).
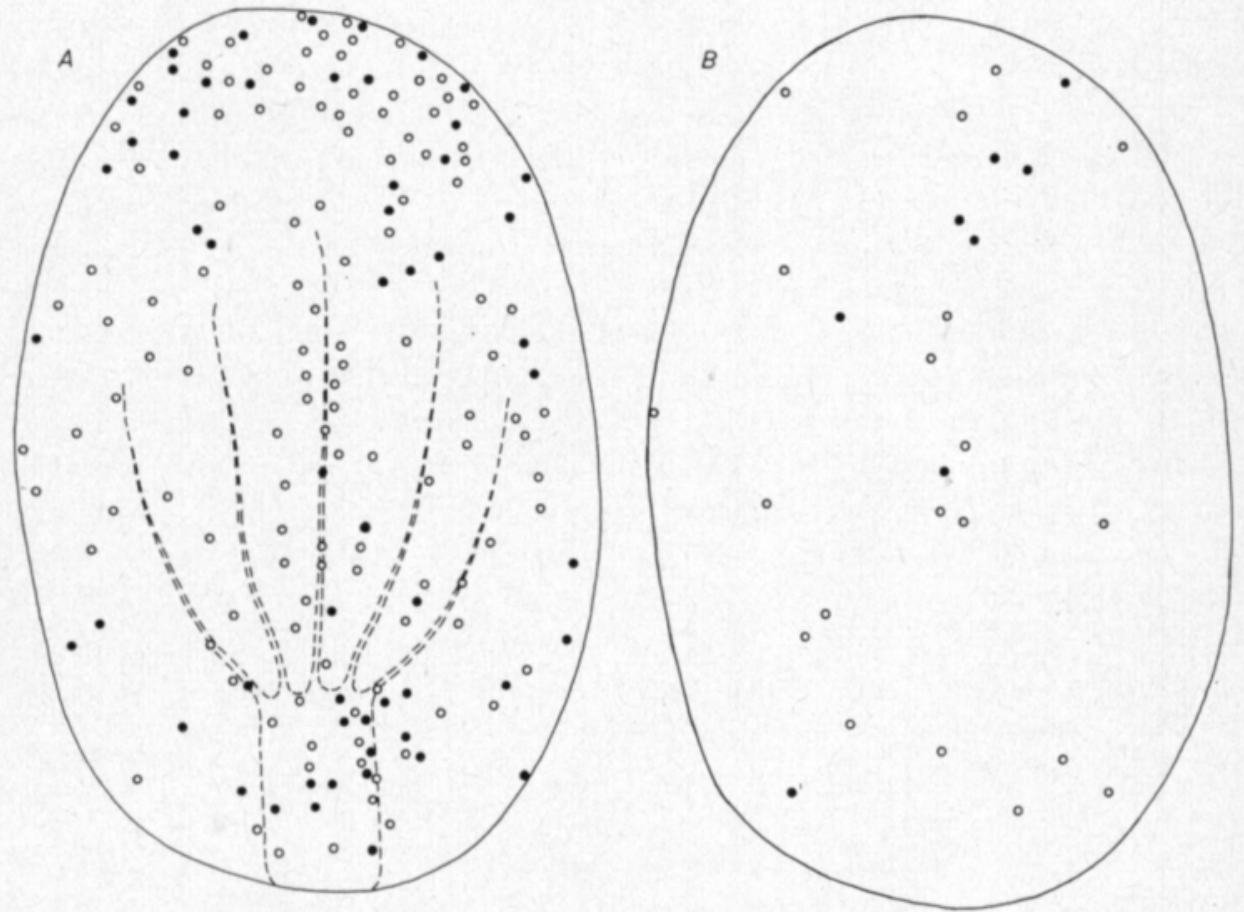

Fig. 27. Effect of feeding site on cocoa half bean test plant on transmission of CSSV $1 \mathrm{~A}$ isolate by nymphs of $P$. njalensis. A and B, inside and outside of the half bean, respectively. Black circles (•) indicate feeding sites of single nymphs that transferred the virus into half beans. Open circles (o) indicate feeding sites of single nymphs that did not transfer the virus into half beans.

\subsection{Effect of physical factors on virus transmission}

Reactions and orientation of mealybugs in different light and temperature conditions was discussed earlier under 2.5 in this paper. However, some specific experiments were carried out also to investigate the effect of these physical factors on transmission of CSSV 1A isolate by nymphs of $P$. njalensis. 


\subsubsection{Effect of light on virus transmission}

Nine replicate CSSV $1 \mathrm{~A}$ isolate infected cocoa seedlings were made ${ }^{32} \mathrm{P}$-active and then kept in dark under a thick black cloth. Another set of nine seedlings was prepared similarly but kept without cover. All the seedlings were in an ordinary laboratory room in daylight conditions and fluorescent lights were kept on during the night. The mealybugs were allowed to feed on these seedlings for 24 hours (AAT) before their radioactivity was measured and they were put on half bean test plants at a rate of five per bean for an IAT of 24 hours. Then the beans were planted an the germinated seedlings were examined for virus symptoms as usual.

There was no difference in the rate of virus transmission or in the amount of food uptake by mealybugs kept in darkness or in the light conditions of the laboratory room; the infection rates were $63 / 109(58 \%)$ and 55/103 (53 \%) (chi-square 0.26), and the mean amounts of food uptake of the mealybugs were $2.04 \pm 0.08$ (S.E.) and $2.18 \pm 0.09$ (S.E.) $\log (\mathrm{n}+1) \mathrm{cp} 100 \mathrm{~s}(\mathrm{t}=1.23)$, respectively.

In another experiment the effect of light periodicity on the rate of virus transmission was investigated. There were eight different combinations of light and dark arranged in the two growth chambers in $27-29^{\circ} \mathrm{C}$. and $55-80 \%$ $\mathrm{RH}$ (Table 32). A total of $32 \mathrm{CSSV}$ 1A isolate infected seedlings were used as virus source plants. Field collected females of $P$. njalensis were allowed to reproduce in the growth chambers either in the dark or with all the lights on (about 2000 foot candles) during a preacquisition period of 46 hours. After this the newly-borne nymphs were given an AAT of 24 hours in different conditions of light and dark. Finally the nymphs were transferred on half beans for an IAT of 24 hours in the dark. Five nymphs were put on each half bean, and after the IAT the beans were planted and the germinated seedlings were examined for symptoms of virus.

All the eight treatments gave almost similar infection rates suggesting that light periodicity does not influence the mealybug behaviour as far as infectivity of mealybugs is concerned (Table 32).

Table 32. Effect of light periodicity on the rate of CSSV $1 \mathrm{~A}$ isolate transmission by nymphs of P. njalensis.

\begin{tabular}{|c|c|c|c|c|c|c|}
\hline \multirow{2}{*}{$\begin{array}{c}\text { Treatment } \\
1\end{array}$} & \multicolumn{4}{|c|}{\begin{tabular}{cccc}
\multicolumn{4}{c}{ Period, time of onset and duration } \\
pre-AAT & AAT & AAT & IAT \\
8 am & 6 am & $6 \mathrm{pm}$ & 6 am \\
46 hours & 12 hours & 12 hours & 24 hours
\end{tabular}} & \multicolumn{2}{|c|}{$\begin{array}{c}\text { Infection } \\
\text { rate and \% }\end{array}$} \\
\hline & dark & dark & dark & dark & $60 / 84$ & 71 \\
\hline 2 & dark & light & light & dark & $57 / 83$ & 69 \\
\hline 3 & light & dark & dark & dark & $62 / 94$ & 66 \\
\hline 4 & light & light & light & dark & $75 / 95$ & 79 \\
\hline 5 & dark & dark & light & dark & $62 / 99$ & 63 \\
\hline 6 & dark & light & dark & dark & $83 / 98$ & 85 \\
\hline 7 & light & dark & light & dark & $66 / 94$ & 70 \\
\hline 8 & light & light & dark & dark & $74 / 93$ & 80 \\
\hline
\end{tabular}




\subsubsection{Effect of temperature on virus transmission}

Sixteen CSSV $1 \mathrm{~A}$ isolate infected seedlings were made ${ }^{32} \mathrm{P}$-active and taken into a growth chamber which was consecutively programmed to produce four different temperature regimes with the lights off. Using the paper cone technique, all stages of $P$. njalensis were put on the seedlings for an AAT of 24 hours. After AAT the radioactivity of the nymphs was measured and they were put on half beans at a rate of five per bean for an IAT of 24 hours. After IAT the beans were planted and the germinated seedlings were examined for virus symptoms.

The amount of food uptake increased with the temperature (Table 33). Also virus was transmitted more frequently in the higher temperature regimes.

Table 33. Effect of temperature on transmission of CSSV $1 \mathrm{~A}$ isolate by nymphs of P. njalensis.

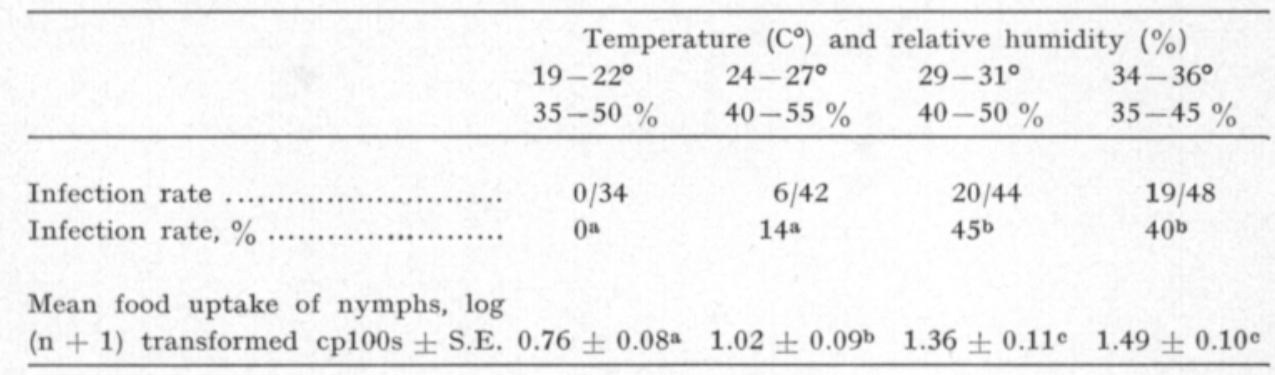

\subsection{Relationship between virus uptake, persistence and infectivity of mealybugs}

It has been shown earlier in this paper that the amount of food uptake by mealybugs from virus infected source plant is positively related to the infectivity of these mealybugs (e.g. 3.1, 3.5). Various experiments have described also how the infectivity of mealybugs increases with the length of AAT (e.g. 3.7.2). Finally, loss of infectivity was best described as exponential with time (3.8.6). In the following a plausible mathematical solution is given for virus acquisition or infectivity increase by mealybugs with the length of AAT.

To collect more data for the final mathematical analysis the amount of food uptake by nymphs of $P$. njalensis was investigated at three hour intervals. The food source was $10 \%$ sucrose containing $100 \mu \mathrm{Ci} / \mathrm{ml}$ of ${ }^{32} \mathrm{P}$. Parafilm sachets were used as food containers. Age of nymphs was $0-3$ days in the beginning of the feeding access time. The experiment was carried out in growth chambers at $25-27^{\circ} \mathrm{C}$. and $50-70 \%$ RH. After feeding access time the nymphs were removed one at a time from food source and the count rate was determined.

The nymphs settled down to feed at a rate increasing with time (Table 34, Fig. 28). After 12 hours of feeding access time the settling rate was about $50 \%$. After feeding access time of 21 hours the settling rate was about $80 \%$, and there was no further increase of the settling rate with longer feeding access times. 
Table 34. Rate of settling and amount of food uptake by nymphs of $P$. njalensis feeding on ${ }^{32}$ P-active $10 \%$ sucrose solution via parafilm membrane.

\begin{tabular}{|c|c|c|c|c|}
\hline $\begin{array}{c}\text { Length of } \\
\text { feeding access } \\
\text { time, hours }\end{array}$ & $\begin{array}{l}\text { Settling } \\
\text { rate }\end{array}$ & $\begin{array}{l}\text { Settling } \\
\left.\text { rate, } \%^{1}\right)\end{array}$ & $\begin{array}{r}\text { Mean food uptake, } \\
\text { cp100s } \pm \mathrm{S} \\
\text { Settled nymphs }\end{array}$ & $\begin{array}{l}\text { og } n \text { transformed } \\
x \text { t } 95 \% \\
\text { All the nymphs }\end{array}$ \\
\hline 3 & $46 / 140$ & $33 \pm 8$ & $1.63 \pm 0.09$ & $0.54 \pm 0.13$ \\
\hline 6 & $63 / 145$ & $43 \pm 8$ & $1.71 \pm 0.09$ & $0.74 \pm 0.14$ \\
\hline 9 & $66 / 125$ & $53 \pm 9$ & $1.82 \pm 0.10$ & $0.96 \pm 0.17$ \\
\hline 12 & $138 / 287$ & $48 \pm 6$ & $1.71 \pm 0.07$ & $0.82 \pm 0.10$ \\
\hline 15 & $126 / 210$ & $60 \pm 7$ & $1.66 \pm 0.09$ & $1.00 \pm 0.12$ \\
\hline 18 & $78 / 129$ & $60 \pm 9$ & $1.95 \pm 0.08$ & $1.18 \pm 0.17$ \\
\hline 21 & $165 / 198$ & $83 \pm 5$ & $2.06 \pm 0.07$ & $1.72 \pm 0.12$ \\
\hline 24 & $141 / 161$ & $88 \pm 5$ & $2.00 \pm 0.07$ & $1.75 \pm 0.12$ \\
\hline 27 & $123 / 153$ & $80 \pm 7$ & $1.79 \pm 0.08$ & $1.44 \pm 0.13$ \\
\hline 30 & $108 / 126$ & $86 \pm 7$ & $1.87 \pm 0.09$ & $1.60 \pm 0.14$ \\
\hline 33 & $83 / 116$ & $72 \pm 9$ & $1.77 \pm 0.10$ & $1.27 \pm 0.16$ \\
\hline 36 & $168 / 195$ & $86 \pm 5$ & $2.08 \pm 0.07$ & $1.80 \pm 0.12$ \\
\hline 39 & $66 / 84$ & $79 \pm 9$ & $2.13 \pm 0.13$ & $1.67 \pm 0.22$ \\
\hline 42 & $116 / 130$ & $89 \pm 6$ & $2.19 \pm 0.10$ & $1.96 \pm 0.15$ \\
\hline 45 & $107 / 131$ & $82 \pm 7$ & $2.24 \pm 0.09$ & $1.83 \pm 0.17$ \\
\hline
\end{tabular}

1) Percentage radioactive of all the nymphs $\pm 95 \%$ confidence limits for a proportion corrected for continuity.

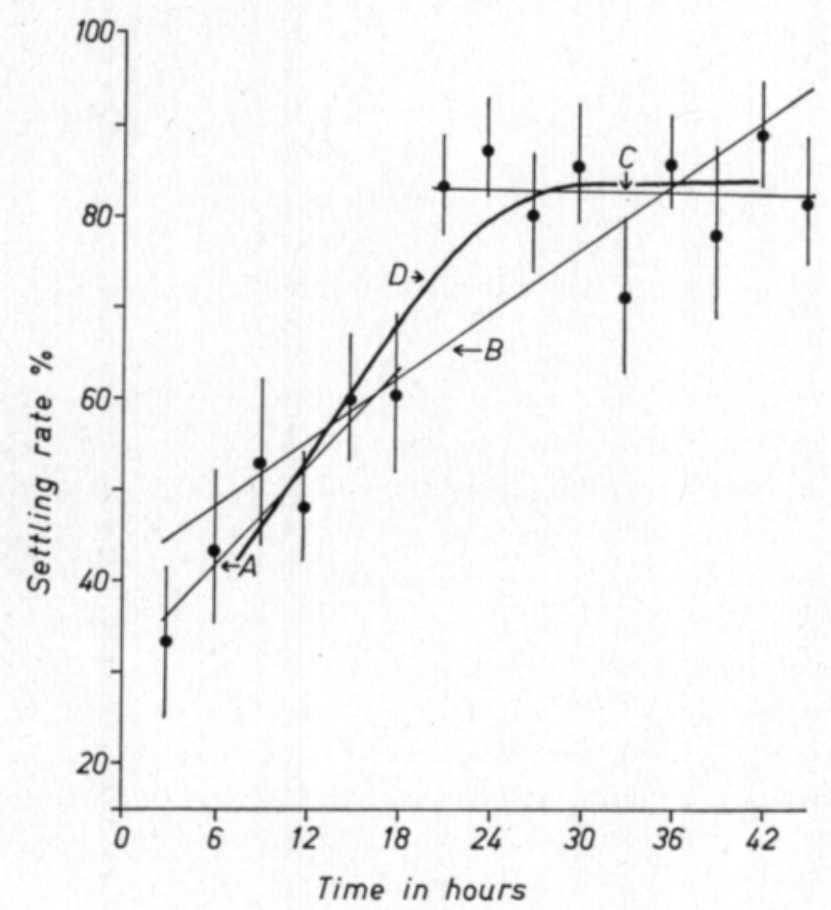

Fig. 28. Rate of settling to feed by nymphs of $P$. njalensis on ${ }^{32} \mathrm{P}$-active $10 \%$ sucrose solution via a parafilm membrane. A; $\mathrm{y}=31.10+5.31 \mathrm{x}$; $\mathrm{r}=+0.930^{* *}$. B; $\mathrm{y}=41.39$ $+3.51 \mathrm{x} ; \mathrm{r}=+0.854 * * *$. C; $\mathrm{y}=83.55-0.0167 \mathrm{x} ; \mathrm{r}=-$ 0.026. D; probable curvilinear increase of settling rate with time.

In general, the settling rate appeared to be curvilinear with the time (Fig. 28). The amount of food uptake increased with time in a linear manner (Table 34, Fig. 29).

For the derivation of a mathematical formula to describe the increase of infectivity with time during AAT, a short time interval dt $\left(t_{2}-t_{1}\right)$ has to be 


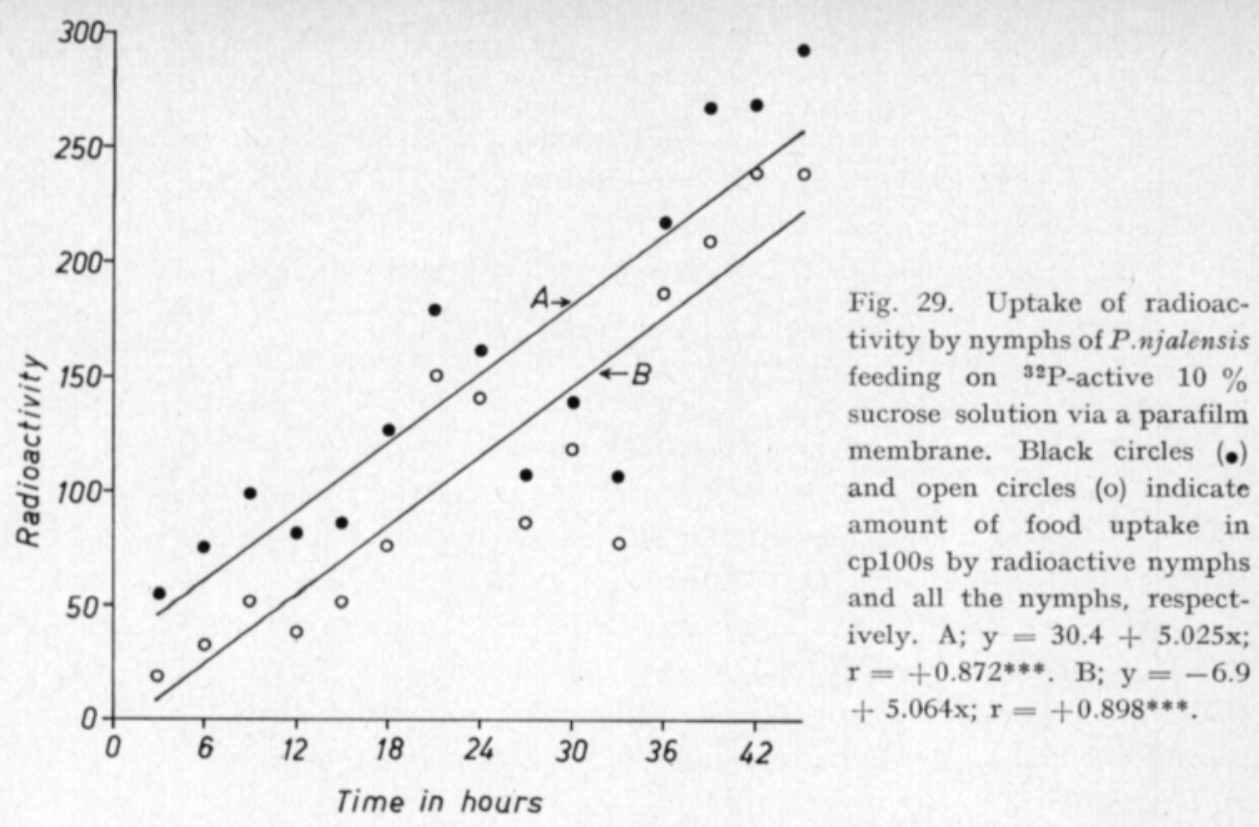

considered. The change in the amount of infectivity (I) during this time interval is dI. Assuming that the amount of food (virus) uptake (F) is linear and loss of infectivity $(\mathrm{L})$ is exponential, then the following differential equation can be made:

$$
\mathrm{dI}=\mathrm{F} d \mathrm{t}-\mathrm{L} \mathrm{I} d \mathrm{t}
$$

which is solved by integration as follows:

$$
\int \frac{d I}{1-\frac{L}{F} I}=\int F d t+c
$$

where $\mathrm{c}$ is constant. This gives:

$$
-\frac{F}{L} \ln \left(1-\frac{L}{F} \quad I\right)=F t+c .
$$

When $t=0$ and $I=I_{0}$ (infectivity at $t_{0}$ ), then the value of $c$ can be calculated from (3). When this value is used instead of $c$ in (3), the final formula is given by:

$$
I=\left[1-\left(1-L \frac{I_{0}}{F}\right) e^{-L t}\right] \frac{F}{L}
$$

From (4) formulae for special cases can be derived:

$$
\begin{aligned}
& \text { when } t=0 \text {, then } I=\frac{F}{L}, \\
& \text { when } I_{0}=\frac{F}{L} \text {, then } I=\frac{F}{L}, \\
& \text { when } F=0, \text { then } I=I_{0} e^{-L t} .
\end{aligned}
$$

To facilitate calculation of constant L, T can be the half-life of L. Thus from (7) we obtain:

$$
\frac{1}{2} \mathrm{I}_{0} \mathrm{e}^{-\mathrm{Lt}}=\mathrm{I}_{0} \mathrm{e}^{-\mathrm{L}(\mathrm{t}+\mathrm{T})}
$$

which gives results:

$$
\mathrm{L}=\frac{(\ln 2)}{\mathrm{T}}, \text { or } \mathrm{L}=\frac{(\log 2)}{\mathrm{T} \log \mathrm{e}}
$$

If $\log 2=0.30103$, and $\log \mathrm{e}=0.43429$ and, $\mathrm{T}=12$ hours, then $\mathrm{L}=0.0578 /$ hour. If $\mathrm{I}_{\max }=$ 100 then, $100=\frac{F}{L}$ and, $F=5.78 /$ hour. When these values are fitted into $(4)$, then:

$$
I=100\left[1-\left(1-0.578 I_{0}\right) e^{-0.0578 t}\right]
$$


From formulae (7) and (10) it follows that when mealybugs have stopped feeding on virus source plant, then after 48 hours only $6.24 \%$ of the infectivity remains. Also, when originally non-infective mealybugs have fed on virus source plant for 48 hours, then their infectivity is $93.8 \%$ of the maximum infectivity.

One specific experiment was carried out in a growth chamber at $25-27^{\circ} \mathrm{C}$. and $50-75 \% \mathrm{RH}$ to obtain empirical data on validity of the formula (10). CSSV 1A isolate infected seedlings were used as virus source plants. Length of AAT varied from one to 120 hours and the age of the nymphs of $P$. njalensis was $0-3$ days at the beginning of AAT. The length of IAT was 24 hours and three nymphs were put on each half bean test plant.

Virus was not transmitted after a short AAT of $1-6$ hours but from 12 hours onwards the infection rate increased rapidly to reach a maximum at $48-72$ hours (Table 35). A decrease in infection rate was noticed after an AAT of 96 and 120 hours. The experimental data are given with mathematical formulae in Fig. 30 .

In order to get a more general picture of the relationship between the linear food uptake and the exponential loss of infectivity, results were compiled from several experiments dealing with the length of the AAT and the infection rate (Tables 13, 14, 18-24 and 35). In each experiment, infection rate at 24 hours AAT was calculated close to $50 \%$ by using the maximum likelihood estimator, and infection rates for other lengths of AAT were calculated accordingly. Thus the level of adjustment of infection rates remained the same within each experiment, but may have varied between different experiments. Finally, infection rate means were calculated for $1-6,7-12,13-18,19-24,25-36$, $37-60,61-84,85-108$ and, $109-120$ hours of AAT, and the infection rate means were plotted against time (length of AAT).

Table 35. Effect of length of acquisition access time on the rate of CSSV 1A isolate transmission by nymphs of $P$. njalensis.

\begin{tabular}{|c|c|c|c|}
\hline $\begin{array}{l}\text { Length of } \\
\text { AAT, hours }\end{array}$ & $\begin{array}{c}\text { Infection } \\
\text { rate }\end{array}$ & $\begin{array}{c}\text { Infection rate, } \\
\% \pm \text { error }^{1} \text { ) }\end{array}$ & $\mathrm{p}^{*}, \%$ \\
\hline 1 & $0 / 70$ & 0 & 0 \\
\hline 2 & $0 / 70$ & 0 & 0 \\
\hline 4 & $0 / 70$ & 0 & 0 \\
\hline 6 & $0 / 69$ & 0 & 0 \\
\hline 12 & $1 / 70$ & $1 \pm 4$ & 0.5 \\
\hline 18 & $25 / 70$ & $36 \pm 12$ & 9 \\
\hline 24 & $55 / 70$ & $79 \pm 10$ & 40 \\
\hline 30 & $45 / 70$ & $64 \pm 12$ & 29 \\
\hline 36 & \multicolumn{2}{|c|}{ accidentally destroyed } & \\
\hline 42 & $45 / 70$ & $64 \pm 12$ & 29 \\
\hline 48 & $59 / 67$ & $88 \pm 9$ & 51 \\
\hline 72 & $58 / 63$ & $92 \pm 8$ & 58 \\
\hline 96 & $47 / 70$ & $67 \pm 12$ & 34 \\
\hline 120 & $47 / 68$ & $69 \pm 12$ & 35 \\
\hline
\end{tabular}

1) $95 \%$ confidence limits for a proportion corrected for continuity. 


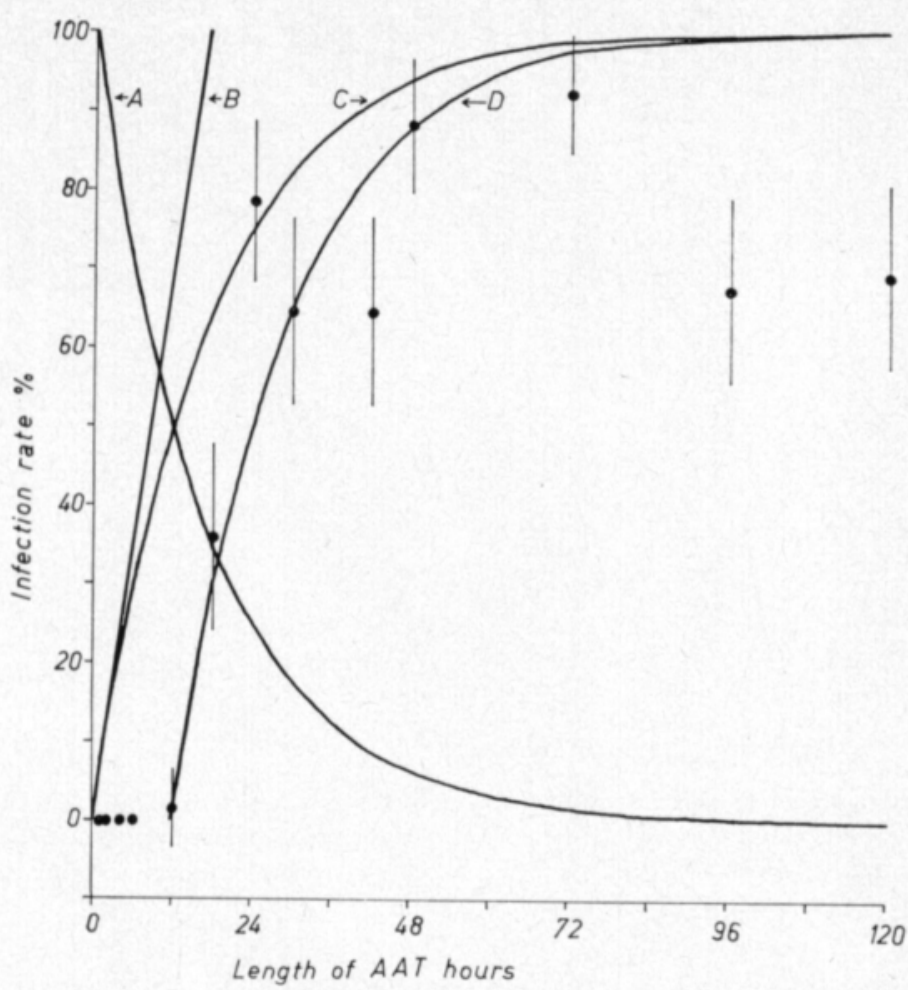

Fig. 30. The effect of length of acquisition access time (AAT) on the rate of CSSV 1A isolate transmission by nymphs of $P$. njalensis. Relationship (C, D) between linear uptake of food (B) and exponential loss of infectivity (A) with time. Black circles (•) indicate infection rates obtained after different length of AAT with $95 \%$ confidence limits for a proportion corrected for continuity.

A; exponential loss of infectivity with time; $I=100 \mathrm{e}^{-0.0578 t} ; \mathrm{F}=0 / \mathrm{h} ; \mathrm{I}_{\mathrm{o}}=100$.

$\mathrm{B}$; linear uptake of food with time; $\mathrm{F}=5.78 \mathrm{t}$.

C; increase of infectivity with time during AAT, a theoretical case with settling rate of $100 \%$ at $\mathrm{t}_{\mathrm{o}} ; \mathrm{I}=100\left(1-\mathrm{e}^{-0.0578 \mathrm{t}}\right) ; \mathrm{F}=5.78 / \mathrm{h} ; \mathrm{I}_{\mathrm{o}}=0$.

D; increase of infectivity with time during AAT, a case with observed settling rate of $50 \%$ at $t_{12} ; I=100\left[1-\mathrm{e}^{-0.0578 \mathrm{t}(\mathrm{t}-12)}\right] ; \quad \mathrm{F}=5.78 / \mathrm{h} ; \mathrm{I}_{12}=0$.

The infection rate means were in accordance with the mathematical expectation up to $72(61-84)$ hours AAT (Fig. 31). However, with 96 and 120 hours AAT there was a significant decrease in the infection rate, which is considered to be due to the decreased amount of food uptake by prestarved mealybugs at later stages of prolonged feeding, or in other words, the disappearance of increased amount of food uptake caused by preliminary fasting (see 3.5). 


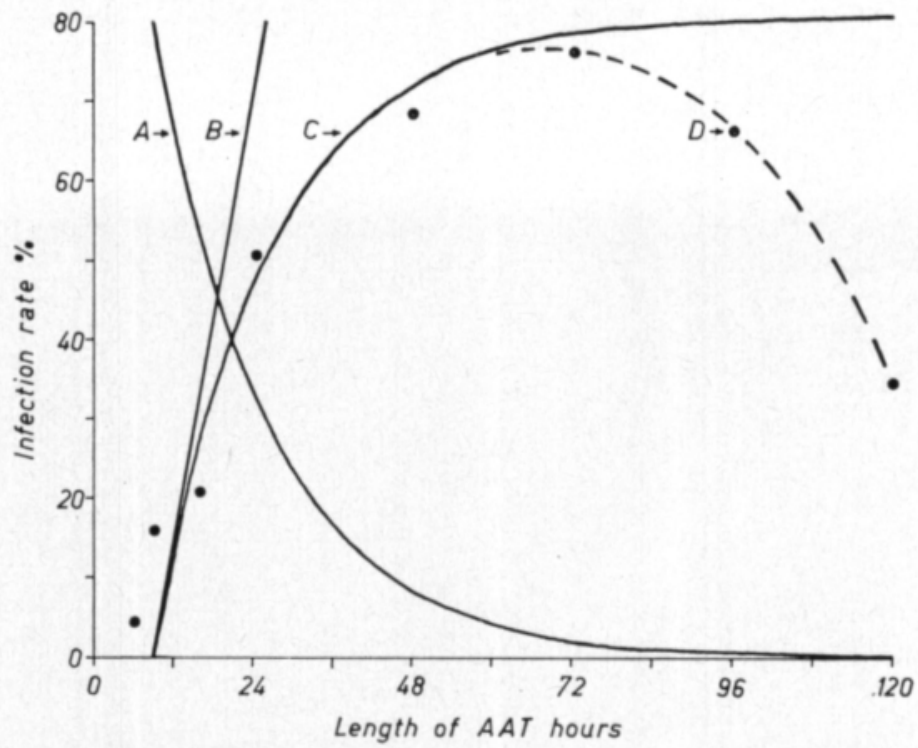

Fig. 31. Relationship between linear uptake of food (virus) by mealybugs and exponentia loss of infectivity (virus) in mealybugs. Black circles (•) indicate infection rate means calculated from results of several experiments.

A; exponential loss of infectivity with time; $I=80 e^{-0.0578(t-9)}: F=0 / h ; I_{0}=80$.

$\mathrm{B}$; linear uptake of food with time; $\mathrm{F}=-41.62+4.62 \mathrm{t}$.

$\mathrm{C}$; increase of infectivity with time during AAT, a case with $\mathrm{I}_{9}=0 ; \mathrm{I}=80\left[1-\mathrm{e}^{-0.0578(\mathrm{t}-9)}\right]$; $\mathrm{F}=4.62 / \mathrm{h}$.

D; suggested decrease of infection rate with long AAT due to starvation before AAT.

\section{Discussion and conclusions}

\subsection{General}

Among the 15 families of Coccoidea (IMMS 1957), only the family Pseudococcidae, the mealybugs, have been shown to transmit plant viruses, although the general ecology and feeding behaviour is similar in all the families. P. citri was the first mealybug species reported to be a vector of the tobacco mosaic virus (TMV) (OLitsky 1925), further confirmed by Newton (1953). Pseudococcus maritimus (Ehrhorn) was recorded as a vector of an unspecified mosaic disease (ELMER 1922, 1925). An unidentified mealybug species was reported to be a vector of a bean mosaic disease (FAJARDo 1930). Hughes and Lister (1953) noted that lime dieback was transmitted by $F$. virgata.

Mealybug wilt of pineapple was long considered to be caused by wilt inducing toxic secretions of Dysmicoccus brevipes (Cockerell) and D. neobrevipes Beardsley, however, in a recent reappraisal CARTER (1963) has concluded that a transmissible latent factor is also involved which 'is presumed to be a latent virus'.

Some of the above reports have not been confirmed, while in others there is not enough evidence to sustain virus entity, or no information is given on 
virus-vector relationships. Consequently, virus transmission by other homopterous insects, notably aphids, is the nearest parallel of mealybug transmission of cocoa viruses.

It has not always been generally agreed that mealybugs are the sole vectors of cocoa viruses. During the search for vectors of cocoa viruses all other insects, particularly aphids and psyllids, which were at first claimed to be vectors of cocoa viruses (COTTERELL 1943), failed to transmit virus in confirmatory tests (Box 1945, Posnette and Strickland 1948, Lister 1953) (see Appendix III). Recently, MARTINI $(1961,1962)$ repeatedly reported successful transmission of two isolates of CSSV by Aphis gossypii Glover in tests where 250 aphids were confined on $20 \mathrm{~mm}$ diameter areas on symptom bearing flush leaves for an AAT of 18 hours, and then transferred on half beans at a rate of $\mathbf{5 0}$ aphids per half bean; infection rates of 5-12\% were obtained. LongworTH (1964 c, communication by letter 24 Jan. 1969) repeated these tests with the same technique but no transmissions were recorded out of 376 tests. More recently, EgUAGIE (1970) used about 28050 individual aphids with the same technique, with 18-36 hours AAT and 12-30 hours IAT. Virus symptoms developed in one out of 1038 test plants and the single transmission in the experiment was attributed to mealybug contamination of test seedlings in the insectary. The conclussion thus seems evident that only mealybugs are the vectors of cocoa viruses.

Relationships between mealybugs and cocoa viruses are analyzed in the following and, as much as possible, in the same sequence as different stages of virus transmission occur in nature.

\subsection{Preliminary fasting/feeding}

According to KIRKPATRICK $(1950,1953$ a) fasting prior to AAT does not in itself increase the ability of $P$. citri to transmit CTV, but if the mealybugs are starved for some $6-24$ hours, they tend to settle down to feed more readily on the source plant. Posnetre and Robertson (1950), however, suggested that fasting before AAT increases temporarily the infection rate as well. They investigated the effect of 12 hours of preliminary fasting on the settling and infection rate with $P$. njalensis and an AAT of 2-12 hours on leaves of CSSV $1 \mathrm{M}$ isolate infected source seedlings. The settling and infection rates rose with the increasing length of the AAT and apparently more rapidly with starved than with unstarved mealybugs. Knowing that a high proportion of unstarved mealybugs would settle down to feed on cotyledons within 30 minutes, infected cotyledons were used as source plants in another similar experiment with AAT of $2-18$ hours. The same but less noticeable difference was observed between the starved and the unstarved mealybugs. The infection rate was largely independent of the settling rate when the two sets of mealybugs were compared, e.g. $48 \%$ of the starved mealybugs settled at 10 hours AAT and gave an infection rate of $30 \%, 47 \%$ of the unstarved mealybugs settled at 12 hours AAT gave only an infection rate of $18 \%$. Thus in these experiments the infection rate increased through preliminary fasting but only part of the increase could be related to increased settling. 
DALE (1954 d, 1955 a) tested the effect of preliminary fasting on the infection rate with CSSV $1 \mathrm{~A}$ isolate infected source plants and single young adults of $P$. njalensis on test plants. The mealybugs were starved for $0-48$ hours and then given an AAT of 16 hours. There were no appreciable differences between the treatments; unstarved mealybugs infected $43 \%$ of the test plants and mealybugs starved for various periods infected $25-43 \%$ of the test plants. MARTINI (1959 b, 1961) also used a constant length of AAT (2 hours) and various fasting periods of 15-120 minutes with $P$. njalensis and $F$. virgata. The starved and unstarved mealybugs gave similar infection rates from source plants that were infected with Balogun and Offa-Igbo isolates of CSSV.

According to the present study, preliminary fasting increases the settling rate of $P$. njalensis during the first $6-8$ hours and probably up to 16 hours of feeding (see 3.5, Tables 11-14). Preliminary fasting also increased the rate of food uptake of the settled mealybugs. Starved mealybugs transmitted the virus more efficiently than the unstarved ones. All these findings are in accordance with results reported by Posnette and Robertson (1950), but not with those of Dale (1954 d, $1955 \mathrm{a})$ and Martini (1959 b, 1961). However, experimental details, e.g. number of test plants in each treatment, are lacking in these contradictory reports and, therefore, the right evaluation is impossible.

It is concluded that preliminary fasting increases the settling rate and amount of food uptake of $P$. njalensis, and also that these two factors contribute to the increase of infectivity of the mealybugs; both increased settling and food uptake make it more probable that the vectors acquire virus.

\subsection{Availability of virus in source plants}

Posnette and Strickland (1948) showed that 1A isolate of CSSV can be transmitted by $P$. njalensis while feeding on leaves, shoots or bark during the AAT. Young flush leaves appeared to be the best source of virus. Virus could be acquired by mealybugs also from pods on naturally infected trees. DALE (1958) found that the maturity of pods had little influence on the infection rate. The 1A isolate of CSSV was present in flowers of infected plants (DALE 1954 a, Anon. 1963). The same virus isolate could be transmitted from the testae of beans as well (ANON. 1950), but in numerous tests seed transmission was not obtained (Posnette 1947 a).

Posnette and Robertson (1950) investigated the effect of symptom pattern and leaf age on the infection rate with $1 \mathrm{M}$ isolate of CSSV. Immature leaves with the red-veining symptoms provided the best source of virus for mealybugs, and slight differences in the maturity of leaves of the source plants could lead to considerable variation in the infection rate. Uniform infection rates were usually obtained when young seedlings were used as source plants but from older plants the results were often variable. The availability of virus appeared to decline as the plants became older. This might be expected with viruses which cause dissimilar acute and chronic phases like CSSV, but it was also noticed with CMLV 1C isolate, which does not (Posnetre 1947 a). Few transmissions with mealybugs were obtained from mature trees or from seedlings which had been infected with the $1 \mathrm{C}$ isolate for over a year, but once the virus 
had been transferred into seedlings, subsequent transmissions were readily obtained from them.

The availability of virus in different parts of source plant was investigated by Posnette and Robertson (1950). Separate parts of plants infected with $1 \mathrm{M}$ isolate of CSSV were colonized by mealybugs and comparable tests were done. Although normal infection rates were obtained from 22 feeding sites, no transmission was obtained from four sites. Three of these were petioles and the fourth was a stem. The probability that the lack of transmission by these colonies was due to chance was 0.005 for each of them and this suggests that systemic infection was incomplete.

The relative transmissibility of mild and virulent isolate of CSSV $1 \mathrm{~A}$ isolate by $P$. njalensis was investigated by Posnette and Todd (1955). In contrast to the virulent isolate, which was transmitted usually to over $30 \%$ of the test plants, the mild isolate was transmitted at widely varying rates according to the site at which the virus was acquired, but never was the mild isolate more readily transmitted than the virulent. From newly infected seedlings, the two isolates were transmitted almost equally at first, but the mild isolate became much less readily transmitted as the symptoms became less conspicuous in the second and later flushes.

Substantiated by detailed studies THRESH (1958 c) indicated that CSSV is more extensively distributed in available form in infected trees with symptoms than in trees without them. When mealybugs were allowed to feed on samples collected from obviously infected trees, they later infected 170 of the 381 test beans $(44.6 \%)$ which were colonized, whereas mealybugs which had fed on the samples from latently infected trees, infected only 76 out of $332(22.9 \%)$ beans infested.

In an experiment using $1 \mathrm{~A}$ isolate of CSSV and two year old Iquitos type seedlings with symptoms of varying intensity as virus source plants and $P$. njalensis as the vector, the following infection rates were obtained: severe symptoms $38 / 215(17.7 \%)$, intermediate symptoms $30 / 282(10.6 \%)$, regular mild symptoms $21 / 145(14.5 \%)$, very mild sporadic symptoms $1 / 248(0.4 \%)$ (DALE 1958).

IGWEGBE (1966 a) compared infection rates using CSSV infected seedlings in acute and chronic phases of infection and $P$. njalensis and $F$. virgata as vectors. Regardless of the feeding site, considerably higher infection rates were obtained from source seedlings in the acute phase of infection with both vectors.

Owusu (1972) studied the availability of CSSV 1A isolate in recently infected Amelonado cocoa seedlings and mature trees with $P$. njalensis. It was established that soon after inoculation and throughout the greater part of the latent period, both seedlings and mature trees were potential sources of virus to mealybugs. Two mature trees yielded virus without ever producing disease symptoms, while two other plants which produced symptoms, never yielded virus.

In the present study, higher infection rates were obtained with $P$. njalensis while feeding on stems than on leaves of young infected cocoa seedlings (Table 15). However, this may reflect feeding behaviour of the species rather than actual differences of virus availability as discussed in more detail under 4.8 . 
There was no relationship between the age of the source seedlings (29-54 days) and the infection rate (Table 16). Significant random variation was observed between young source seedlings of the same age (Table 17).

The chance of mealybugs becoming infective depends on the availability of virus in the tissues on which the mealybugs are feeding. It is concluded that in general mealybugs can pick up virus from any part of plant except the seed in untouched pod. There is evidence that virus is not always fully systemic in the host. Recently infected plants in the acute phase of infection and with severe symptoms are good sources of virus while availability decreases with age of infection when the infection turns into the chronic phase. Availability of virus is not always indicated by the presence of visible symptoms.

\subsubsection{Availability of virus in different cocoa types}

It is generally known that tolerance to virus exists among certain types of cocoa. A tolerant plant produces mild and often transient symptoms of infection and this would render detection of infection with CSSV very difficult.Implicit in their use, therefore, is that the control of virus by eradication methods would be almost impossible. It would be of value if virus was less readily available in tolerant cocoa types, as this would tend to restrict spread of infection in a tolerant population and from it to a susceptible population.

DALE (1958) used virus tolerant Iquitos-type cocoa seedlings infected with 1C isolate of CMLV and similarly infected Amelonado-type cuttings as contrels to investigate the availability of virus for $P$. njalensis. The infection rate from tolerant Iquitos was $44 \%$ and from susceptible Amelonado $76 \%$.

BRUNT (personal communication reported by Blencowe 1962) found that when batches of 25 nymphs were transferred to test plants after feeding on twigs of infected Amelonado trees, relatively intolerant Amazon trees, and tolerant Amazon trees, the infection rates were $43 / 89(48.3 \%), 28 / 95(29.4 \%)$ and $16 / 93(17.2 \%)$, respectively.

Availability of Egbeda isolate of CSSV was examined by LONGWORTH (1964 b) in seven populations of Amazon hybrids with two known to be tolerant and with Amelonado-type cocoa as control. P. njalensis crawlers were used as vectors and beans as test plants. The infection rates varied from 0 to $70 \%$, and the results were considered inconclusive. In a repeated test the availability of virus was highest in the Amelonado control and one of the hybrids not tolerant of infection. Otherwise the results were variable; even high availability of virus in some replicates of tolerant cocoa was observed and sometimes virus was less available in sensitive cocoa. No transmissions whatever were recorded from three trees, although the trees had shown symptoms of virus and quite a large number of mealybugs had been used. In another test the availability of Offa-Igbo and Egbeda isolates of CSSV was followed in three cocoa hybrids and with Amelonado-type cocoa as control. No general pattern emerged, except that in many plants availability was high only during two months after the date of infection and fluctuated in subsequent tests, often widely.

TINSLEY (personal communication reported by LONGWORTH $1964 \mathrm{~b}$ ) followed the availability of two isolates of CSSV in seven different cocoa types in seedlings 
derived from open pollinations which were infected as beans. Availability in the first nine months after germination was high in all types (86-99\%), presumably as the virus was completely systemic and the seedlings were in the acute phase of infection. At 12 months, when the seedlings were in the chronic phase of infection, availability was greatly reduced $(1-40 \%)$.

IGWEGBE (1966 b) studied the availability of Egbeda isolate in two susceptible and four tolerant or suspected tolerant cocoa types with $P$. njalensis. There were no consistent differences between the cocoa types in virus availability, however, it was noted that two types of cocoa in the chronic phase of infection after 22 weeks gave very low infection rates, 0 and $5 \%$, whereas the other four types not yet in the chronic phase gave infection rates of $15-79 \%$.

Five tolerant and sensitive cocoa trees were used by LEGG and BonNeY (1968 b) to investigate the availability of 1A isolate of CSSV for P. njalensis. The tolerant Amazon-type trees had good canopies and showed only mild leaf symptoms, while the sensitive Amelonado trees had severe leaf symptoms and extensive dieback. The infection rate from tolerant trees ranged from $4-$ $44 \%$ (mean $17.2 \%$ ) and from sensitive trees from 4-72\% (mean $24.9 \%$ ) however, the mean differences for all tests were not significant.

Owusu $(1969,1970,1971 \mathrm{~b}, 1973)$ reported a series of trials to investigate the availability of virulent $1 \mathrm{~A}$ isolate of CSSV to the mealybug vector $P$. njalensis in virus tolerant and virus sensitive cocoa. Acquisition feeds were given directly on young plants in the greenhouse and on mature trees in the field without severing the branch. In the first trial with mature cocoa of 7-17 years there were five tolerant Amazon trees with five Amelonado trees as controls. Availability of virus was investigated five times in these trees at about monthly intervals over a period of six months. The infection rate from the sensitive trees was 1040/1963 (53\%) and from tolerant trees 603/1967 (31\%). In the second similar trial, but with eight replicate trees of each sensitive and tolerant type, the infection rates from sensitive and tolerant trees were 996/2223 (45\%) and $627 / 2297(27 \%)$, respectively. In another trial with six replicate young seedlings of each sensitive and tolerant type there was no difference between the infection rates; $227 / 774(36 \%)$ and $253 / 731(35 \%)$, respectively. In a repeated trial with cocoa about two years old an infection rate of 744/1985 (37\%) was obtained from sensitive cocoa and $540 / 2137(25 \%)$ from tolerant cocoa.

It can be concluded that virus is more easily available or more readily transmitted by mealybugs from sensitive than tolerant cocoa, however, the difference in availability is relatively small. At most the difference appears to be the same as that between infection rates obtained by using one or two mealybugs per test plant.

\subsection{Acquisition feed}

\subsubsection{General conditions during acquisition feed}

Despite all efforts to standardize conditions during AAT, or during the experiments, there were sometimes significant differences between the infection rates of individual virus source plants in the same treatment (e.g. Table 17). 
From time to time such differences occurred even though standard conditions of temperature, humidity and light were maintained during the experiment, the source plants were of the same age and displayed similar acuteness of symptoms, and radioisotopes were used to verify the uniform feeding of mealybugs. Although this 'innate' difference between replicates could be overcome by increasing the number of source and test plants, it still remained an unnecessary nuisance in the experimental work of the present study.

KEnTEN (in the press) has recently investigated conditions during AAT and shown that source plants grown in sand and watered with nutrient solution may differ less than plants grown in soil with tap water. The range of infection rate of Amelonado test beans from 11 randomly selected source plants grown in soil was $24.5-84.8 \%$ and from those in sand $40.3-72.7 \%$, with coefficients of variation of $23.5 \%$ and $13.1 \%$, respectively. The difference between the two groups was significant. Occasionally, owing to shortages, source plants have to be used twice or more often for an AAT. No significant difference was found in the infectivity of mealybugs fed on source plants which were used once, twice or thrice for an acquisition feed; the infection rates were 58.3, 57.6 and $63.0 \%$, respectively.

During acquisition feed the nymphs are kept in feeding cages (see 2.4) close to the stem of infected seedlings and are buffered to some extent against the effects of low humidity. KEnTEN (in the press) found no difference in the infectivity of nymphs fed at an external humidity of $35 \%$ or $90 \%$, the infection rates were $74 \%$ and $65 \%$, respectively.

As described under 3.7.1, mealybugs are removed from source plants by tapping the plants repeatedly, however, the mealybugs that first fall off the plants may not have fed at all and batches of nymphs obtained through later tappings contain a higher proportion of mealybugs that have settled down to feed during the AAT. This was indicated by a higher proportion of radioactive mealybugs in later tappings.

KENTEN (in the press) has now obtained evidence that there is also a difference in infectivity between batches of mealybugs obtained through repeated tapping. The mean percent transmission to Amelonado test beans, after angular transformation, was $38.0 \%$ with the first batch, with the second $44.9 \%$ and the third $49.7 \%$ (L.S.D. 5.2 at $\mathrm{P}=0.05$ ). Such variation was avoided by tapping the nymphs off the plants repeatedly into a pool of nymphs on a large clock glass. Using these clock glasses and pools of nymphs in closely similar conditions in four tests, standard errors of the mean percentage transmission were satisfactorily low for all the five persons manipulating the mealybugs, yet the number of transmissions in one test was less than half of those obtained in the other three but the source of this variation could not be identified.

\subsubsection{Length of acquisition feed}

With different cocoa viruses the infection rate generally rises with the increasing length of AAT. Posnette and Strickland (1948) used 1A isolate of CSSV and P. njalensis to test the effect of an AAT of $4-48$ hours on the rate of virus transmission. The infection rate increased with the length of the AAT and the highest rate of transmission was obtained with an AAT of 48 hours. 
Posnette and Robertson (1950) tested starved and unstarved populations of $P$. njalensis and $1 \mathrm{M}$ isolate of $\mathrm{CSSV}$ in two experiments. The length of the AAT was $2-12$ hours in the first and $2-18$ hours in the second experiment, and an overall increase of infection rates was recorded with increasing length of the AAT.

DALE (1954 c, d) used P. njalensis starved for 18 hours before the AAT and CSSV isolate 1A in one experiment where the length of the AAT was 264 hours, and in another with an AAT of 8-32 hours. The infection rate rose with an AAT up to 16-32 hours but apparently decreased with long AAT of 64 hours. In a subsequent experiment with starved individuals of the same species the length of the AAT was 1-6 days at one day intervals and the infection rates were $80-90 \%$ in all the treatments (DALE 1954 d). Dale (1958) also reported infection rates of $43-55 \%$ with the length of AAT at 1, 2 and 3 days.

After a short AAT of one hour P. njalensis did not transmit the 1A isolate of CSSV (DALE 1958), and only few transmissions occurred after an AAT of 90 minutes (DALE 1957).

Posnette and Strickland (1948) experimented with 1A isolate of CSSV and $F$. virgata. The length of the AAT was 4 and 48 hours and the infection rates were $1 / 29$ and $6 / 27$, respectively.

With virus CTV and $P$. citri as the vector, the minimum length of the AAT required for transmission was 33 minutes. An AAT longer than one hour did not substantially increase the infection rate (KIRKPATRICK 1950).

In the present study the effect of the length of the acquisition feed was studied in several experiments (see Tables $13-14,18-24,35)$. A steady improvement in terms of higher infection rates was experienced during the five year experimental work of this study. This was largely due to increased knowledge of favourable transmission conditions and material improvements, e.g. optimum temperature and humidity, arrival of two growth chambers, more skilled handling of mealybugs and other improvements related to the experimental technique. A direct comparison of results is therefore difficult. However, through the use of maximum likelihood estimator such a comparison can be made because infecton rates in different experiments are brought to the same level without altering the trends of results.

In general, the results of the present study are in agreement with those reported by other authors, and there is enough accumulated evidence to conclude that with CSSV 1A isolate and $P$. njalensis as the vector, the infectivity of mealybugs increases with the length of the AAT and maximum infectivity is reached with an AAT of $48-72$ hours. The settling rate of mealybugs causes a delay in the actual commencement of feeding and thus the optimum length of the acquisition feed proper must be shorter. With a longer AAT of 96 hours or more the infectivity decreases with mealybugs that have gone through a preliminary fasting period long enough to cause considerable increase of settling and feeding in the beginning of the AAT (see Fig. 31, D). The contradictory evidence reported by DALE (1954 d), namely that equal and high infection rates were obtained with an AAT of 1-6 days, is explained by the excessively high level of the infection rate which obscured differences between treatments. 
Although there is less information on other West African virus isolates or other mealybug species, no controversial evidence has been obtained in this paper or elsewhere to the general statement given for CSSV 1A isolate and $P$. njalensis. The single report of KIRKPATRICK (1950) indicates that the effect of the length of the AAT on virus transmission by mealybugs may differ between the West African viruses and the CTV.

\subsubsection{Acquisition of virus from liquid leaf extract}

Although no conclusive evidence was obtained in the present study to the effect that virus can be acquired by mealybugs while feeding on liquid leaf extracts via a parafilm membrane (see 3.7.5), some space is devoted to discussing this approach and the conditions involved. It is a well established fact that CSSV and CMLV can be transmitted mechanically (BRUNT and Kenten 1960, 1962). As an example in this process about $0.5 \mathrm{~kg}$ of fresh virus infected leaves are required to produce $1 \mathrm{ml}$ of infective virus preparation. With suitable abrasives this $1 \mathrm{ml}$ is applied on 20 cocoa test beans and usually about half of the beans become infected. Thus, a relatively large volume of $0.1 \mathrm{ml}$ of virus preparation is needed to infect one bean.

Young nymphs of $P$. njalensis, $0-2$ days old, are minute creatures weighing only $0.0094 \mathrm{mg}$ each (mean of 266 nymphs). Such a young nymph is able to take up food at a rate of about $0.005 \mu \mathrm{l} /$ day while feeding on $10 \%$ sucrose solution (see Tables 11, 12). On cocoa seedlings the amount of food uptake may be higher but not so much as to cause relevant errors in this calculation. Assuming that a normal infection rate of $20 \%$ is obtained with an AAT of 24 hours and single nymphs are used on test beans during IAT, it follows that mealybug nymphs require about $0.025 \mu \mathrm{l}$ of infected plant sap to infect one bean, and the actual volume injected into the bean must be only a fraction of this. It is evident, therefore, that by volume the 'mealybug technique' of virus transmission is at least 4000 times more efficient than the technique of mechanical transmission. The reasons for such a difference should be investigated. It is possible and plausible that either, (1) the mealybug inoculation of virus with mouthparts into the beans is more efficient than the mechanical inoculation of brushing with abrasives, or (2) the inoculum injected by mealybugs and the liquid leaf extract used in mechanical transmission are not comparable as regards the infective virus titer. That mealybugs did not transmit the virus into beans with ease after feeding on the liquid leaf extract indicates that the low titer of infective virus in the extract may be one of the possible reason, however, it is not excluded that the chemicals in the extract may have had an adverse effect on the mealybugs and their transmission efficiency.

OKUSANYA (1969) reported recently that $P$. njalensis fed via parafilm on liquid leaf extracts failed to transmit CSSV. None of the 230 test beans became infected. OKusanya $(1969,1970)$ also reported two tests on successful transmission of cocoa virus from liquid leaf extracts by $P$. njalensis. Three different liquid leaf extracts were prepared from CSSV Ife, Ikire or Offa-Igbo isolate infected cocoa leaves and the extracts were mixed with $4 \%$ agar at $40^{\circ} \mathrm{C}$. The mealybugs were given an AAT of 16-24 hours on the agar and an IAT 
of $18-24$ hours on beans with $15-20$ crawlers on each bean. In the first test infected plants were obtained from two isolates, Ikire and Offa-Igbo, which gave infection rates of $76 / 112(68 \%)$ and $36 / 74(49 \%)$, respectively. In the second test Ikire and Offa-Igbo isolates were used again and the infection rates obtained were $363 / 621(58 \%)$ and $390 / 614(64 \%)$, respectively. However, none of the infected test plants in these tests showed the typical CSSV symptoms and threrefore OKusanya $(1969,1970)$ suggested that a new virus, the cocoa chlorotic mottle virus, was involved and that the new virus was an isolate of CSSV.

It appears to be too early to decide upon the right status of these new research findings before further evidence from confirmatory tests is available.

\subsection{Persistence of virus in mealybugs after acquisition feed}

\subsubsection{Persistence of virus in fasting/feeding mealybugs}

Posnette and Robertson (1950) used a mixture of all stages of 'fully fed' $P$. njalensis to test the persistence of CSSV $1 \mathrm{M}$ isolate after AAT by starving mealybugs. The infectivity declined gradually up to 20 hours of fasting and then more rapidly, and the mealybugs infected one test plant after 34 hours of fasting. With the same virus isolate and P. citri as the vector, there was no decline in the infection rate up to $\mathbf{1 8}$ hours of fasting, but after this infectivity declined and the virus did not persist longer than 36 hours in the fasting mealybugs.

LISTER (1953) found that the 1A isolate of CSSV persisted in starving adults of $P$. njalensis up to 49 hours and in first instar nymphs up to 23 hours. In Trinidad the CTV persisted in $P$. citri up to 23 hours and in $D$. brevipes up to eight hours after leaving the infected plant (KIRKPATRICK 1950).

MARTINI (1961) reported that mealybugs bred on infected plants retained their infectivity unchanged up to 17 hours if starved on glass. After 24 hours of fasting, infectivity declined to about $50 \%$ and was lost entirely after $30-40$ hours. However, the infectivity of insects was lost after 17 hours on glass when a short AAT of four hours was given. If postacquisition fasting was done on filter paper, the infectivity was lost more rapidly than on glass.

CARTER (1961) kept $P$. njalensis after an AAT of 48 hours on $3 \%$ agar for various periods before IAT. Infectivity of the mealybugs persisted up to 24 hours, but it is not known whether the mealybugs actually fed or voluntarily starved on the agar.

LONGWORTH and ENTWISTLE (1965) allowed infective mealybugs to probe into agar, subsequently as the stylets were withdrawn they were passed through tannic acid solution; no transmissions were obtained. In another experiment infective young adults of $F$. virgata were confined in special agar cells and the stylets were observed as they probed the agar. After probing continuously in agar for up to three hours the mealybugs were still infective.

Posnette and Strickland (1948), transferred infective P. njalensis on test plants for an IAT of 3-192 hours, after which the insects were transferred 
to a second series of test plants for an IAT of seven days. None of the plants in the second series became infected.

Posnette and Robertson (1950), using CSSV 1M isolate and P. njalensis, transferred single infective mealybugs to fresh test plants at intervals of 30 minutes. On only three occasions did an insect infect two plants in a series. One of the insects infected the first test plant, failed to infect the second, but again infected the third test plant in the series. The other two insects infected the first and the second plants in series.

Also, in the present study, the infectivity of mealybugs declined gradually after AAT (3.8). This decline was best described as exponential with time. In terms of a maximum the virus did not persist longer than up to 96 hours. Persistence of CMLV in $P$. njalensis and CSSV in $F$. virgata were closely similar to persistence of CSSV in $P$. njalensis. These results agree largely with those reported by other authors, however, infectivity did not remain unchanged up to 17-18 hours of postacquisition fasting as reported by PosNETTE and RoBERTSON (1950) and MARTINi (1961), but rather started to decline earlier. Evidence was obtained in the present study that feeding after AAT increases virus persistence rather than decreases as reported by MARTINI (1961). It is unfortunate that details of experimental procedure are not described in that report.

It is certain that the infectivity of mealybugs declines gradually with time after leaving the virus infected plant, and after about three days there is little infective virus left in the mealybugs. It is doubtful whether postacquisition feeding on healthy plants has any effect different from postacquisition fasting on virus persistence as such, yet postacquisition feeding may cause a delay in the settling to feed on test plants and thus reduce the infection rate.

\subsubsection{Persistence of virus through postacquisition moulting}

The critical test of whether a virus is transmitted after a moult is considered to give conclusive evidence on the mechanism of virus transmission. If virus is transmitted after a moult the mechanism is circulative, if not, the virus is stylet-borne, for during a moult the stylets with any virus contamination are cast.

MARTINi (1959 a) used Nigerian isolates of CSSV and nymphs of $F$. virgata and $P$. njalensis taken from infected plants during moulting, but no transmissions were obtained with these insects.

LONGWORTH and ENTwistle (1965) placed single infective nymphs of $F$. virgata in watch glasses and examined them for absence of exuvial skins before they were left for 12 hours to moult. After this period the bugs were examined again and moulted nymphs were transferred singly to cocoa half beans for an IAT. Double the number of unmoulted nymphs were used on beans as controls. Altogether some 100 moulted nymphs were obtained, but none was infective. However, transmission rates with the unmoulted control insects were so low as to make comparison impossible.

Successful transmission of CSSV 1A isolate by moulted nymphs of P. njalensis was reported by RoIvarnen (1971). Not more than one day old nymphs 
were given an AAT of 120 hours on infected seedlings and after this they were transferred into moulting cages, one nymph per cage, for 20 hours. Moulting was indicated by presence of exuvial skins in the cages, and the moulted and unmoulted nymphs were put on separate half beans at a rate of $\mathbf{1 - 5}$ per bean. After an IAT of 24 hours the nymphs were killed, the beans were planted and the germinated seedlings were examined for virus symptoms. In seven tests the moulted insects gave a total infection rate of $35 / 259(14 \%)$ and the unmoulted control insects $45 / 254(18 \%)$, the difference was not significant.

In the present study a test is reported on the transmission of CMLV $1 \mathrm{C}$ isolate by moulted nymphs of $P$. njalensis (see 3.8 .7 ), however, only one test plant out of 65 was infected by moulted nymphs and six out of 65 by the unmoulted ones.

In accordance with discussion by LONGWORTH and ENTwistle (1965), and RoIvAINEN (1971), experimentation with moulted mealybugs was limited by several factors in the present study, e.g. partial loss of infectivity during the 20 hour period in moulting cages, generally low and very erratic rate of moulting, and excessive handling of mealybugs. However, with a large material consistent results should be obtainable. It is not known whether settling and feeding behaviour of moulted and unmoulted mealybugs on test beans differs to such an extent as to make direct comparison of infection rates unjustified.

It is suggested that CSSV $1 \mathrm{~A}$ isolate is transmitted after a moult and thus the virus is circulative in the vector $P$. njalensis. More data on the transmission mechanism of cocoa viruses in their mealybug vectors is highly desirable.

\subsection{Inoculation feed}

Virus infection is manifested in symptoms of virus in the test plants aft $\mathrm{r}$ inoculation feed. With $1 \mathrm{~A}$ isolate of CSSV, accumulated experience has shown that Amelonado-type cocoa seedlings, infected as beans, show symptoms of virus on the first or the second leaf flushes, or $\mathbf{1 7 - 2 5}$ days and $40-50$ days after planting of the beans, respectively. Symptomless seedlings can be considered healthy (Posnette and Strickland 1948). Such 'healthy' seedlings can be used to calculate the infection rate, but they cannot be considered as healthy for any critical experiment because occasionally symptoms develop during later flushes (e.g. 3.9.1). It is generally accepted that symptom development in this respect is largely the same in seedlings infected by other cocoa viruses.

Although the length of the IAT or the number of mealybugs on test beans during IAT may be considered as obvious factors influencing the final infection rate, there can be other factors which are less obvious, e.g. KENTEN (in the press) found that the moisture status of cocoa test beans influences the infection rate, probably because of mealybug preferences towards moisture. No difference was detected between infection rates obtained with beans from over-ripe or underripe pods. In the present study the location of mealybugs on the test beans at the end of IAT did not affect the infection rate. 


\subsubsection{Length of inoculation feed}

Posnette and Strickland (1948) used P. njalensis and isolate $1 \mathrm{~A}$ of CSSV while testing the effect of length of the IAT on the infection rate. The length of the IAT was 3-192 hours. No clear relationship was found between the infection rate and the length of the IAT; by and large the infected test plants were randomly distributed with some infected test plants almost in all the treatments.

The length of the IAT and its effect on the infection rate with $1 \mathrm{M}$ isolate of CSSV and $P$. njalensis was investigated more in detail by PosNETTE and RoBERTSON (1950). In the first experiment the length of the IAT was $1-12$ hours and the infection rate varied only between 32 and $40 \%$. In the second experiment the length of the IAT was reduced to $10-60$ minutes with $10 \mathrm{mi}-$ nute intervals. First infections occurred at 20 minutes and the infection rate increased with the length of the IAT up to $\mathbf{5 0}$ minutes.

DALE (1954 a, b, 1955 a) carried out similar experiments with the $1 \mathrm{~A}$ isolate of CSSV and P. njalensis. The vectors could often infect a test plant after an IAT of 15 minutes, and from this the infection rate rose rapidly with increasing length of the IAT up to one hour and more slowly up to four hours. When the mealybugs settled rapidly, maximum infection rate was obtained with an IAT of two hours.

MARTINI (1959 a) reported that $P$. njalensis transmits most frequently during the $\mathbf{4 5 - 7 5}$ minutes of IAT, and only few transmissions occur during the first 30 minutes or after 150 minutes on the test plants.

F. virgata transmitted the CSSV $1 \mathrm{~A}$ isolate during an IAT of six hours (Posnette and Strickland 1948). In experiments by Kirkpatrick (1950) with the CTV, an IAT of $3-7$ hours was as effective as one of $18-24$ hours. Shorter periods were not investigated in detail but transmissions were obtained after an IAT of 90 or 100 minutes.

The available data indicates that the inoculation access threshold is about 15 minutes. Probability of infection rises rapidly during the first hours of the IAT up to about three hours and there is usually no further increase after longer inoculation feeds.

In the present study the settling rate of mealybugs on cocoa seedlings or $10 \%$ sucrose solution reached a maximum in $8-24$ hours (see Tables 11, 12, $14,24,34)$, and although mealybugs may settle down to feed on half beans faster (Posnette and Robertson 1950) it is possible, in view of the short IAT required for maximum transmission, that mealybugs transmit virus into cocoa beans also during short probes preceding actual feeding on the beans.

\subsubsection{Number of mealybugs on test plants during inoculation feed}

Using 1M isolate of CSSV and P. njalensis, Posnette and Robertson (1950) found that the infection rate rose from $18 \%$ with one insect to $53 \%$ with five and to $77 \%$ with ten insects per test plant. When the number of insects was increased from one in steps of five up to 30 per test plant, the infection rate rose from 10 to over $90 \%$ with the isolates $1 \mathrm{~A}$ and $1 \mathrm{M}$ of CSSV. 
DALE (1955 b) used $1 \mathrm{~A}$ isolate of CSSV and P. njalensis in two experiments. With $1,2,4,6,8$ and 10 mealybugs per test plant, the infection rate rose from 18 to $92 \%$ in the first experiment and from 44 to $97 \%$ in the second, while the increase of infection rate was relatively faster with low insect numbers.

Adegbola (1965), while testing the relative efficiency of $P$. njalensis and F. virgata, used Egbeda isolate of CSSV and 10, 20 and 30 crawlers per test plant. The infection rates for the two species were 12 and 6,19 and 26,30 and $28 \%$, respectively.

In experiments with $F$. virgata and $1 \mathrm{~A}$ isolate of CSSV, PosNetTE and STRICKLAND (1948) obtained an infection rate of $80 \%$ with five insects on test beans.

According to KIRKPATRICK (1950) the virus CTV was transmitted by $P$. citri at a rate of $14-32 \%$ with $1-8$ mealybugs per test plant.

It is concluded that the infection rate generally increases with the number of insects used during the IAT, as demonstrated by several authors and including the present report (see Tables 25, 26, 28-30), although the increase may be obscured by variation in and between tests as experienced in the present study, and e.g., also by KENTEN and LEGG (1970). The infection rate increases with rising insect numbers according to the laws of probability as demonstrated by Posnette and Robertson (1950) and confirmed in the present study (see 3.9.2, Fig. 26). Therefore, there is no mass action effect of virus involved, or in other words, individual mealybugs do not inject subminimal doses of virus which can accumulate to produce infection when groups of these insects are used.

Selection of the right number of insects for inoculation of test plants is an important factor because it influences the sensitivity and statistical significance of the results. This was demonstrated under 3.9.3.

Among the numerous papers, including the present one, where the number of mealybugs on test plants and the infection rate is reported, the probability of transmission with single mealybugs shows wide variation. However, with the accumulated knowledge on optimum conditions for transmission a probability of about $0.2-0.3$ can be maintained, and with more elaboration of experimental technique a probability of 0.5 or more can be achieved (DALE 1958) (see Table 35).

\subsubsection{Inoculation feed with virus resistant/tolerant cocoa}

Posnette and Todd (1951) were the first to show that some Upper Amazon cocoa types are more resistant to infection and more tolerant of infection with CSSV than the Amelonado-type. This observation is now generally accepted. Mealybugs have been used as vectors of virus to show that some cocoa types are more difficult to infect than others. A good example of such investigations is given by Blencowe and AtTAFUAH (1959) as follows. When 50 CMLV 1C isolate infected mealybugs were fed on each of 250 fan cuttings taken from Amazon-type cocoa the infection rate was $119 / 250$. At the same time, and with similar technique Amelonado cocoa was infected at a rate of 19/20. Similarly, when three CSSV 1A infective mealybugs were fed on each of 380 Amelonado beans the infection rate was $63 \%$, while an equal batch of Amazon 
beans was infected at a rate of only $43 \%$. Also, with batches of Amelonado and Amazon beans, five infective mealybugs per bean were required to infect $50 \%$ of the Amelonado beans, whereas nine mealybugs were needed to attain the same level of infection with the Amazon beans.

In the present study, possibilities in the use of $P$. njalensis for resistance and tolerance testing were demonstrated under 3.9.3. However, since the original discovery of mechanical transmission of CSSV by BRUNT and KENTEN (1960), suitable techniques have been developed to test resistance and tolerance with manual transmission of virus. According to Kenten and LEGG (1970) manual inoculation technique not only improves the sensitivity of the estimation of resistance but also considerably simplifies such studies, because the mealybug method is so difficult to standardize and is so unreliable that it is impracticable to use mealybugs for largescale tolerance and resistance studies.

It is obvious that the mealybug technique of virus transmission suffers from many known and unknown factors that may be difficult to standardize, and all these factors contribute to variation experienced between replicates and tests, however, it is as yet not known why the manual method and the mealybug method do not seem to measure resistance and tolerance in the same scale. For example, Kenten and LegG (1970) obtained almost similar infection rates of 13.3 and $12.6 \%$ with the manual and the mealybug method, respectively, while testing a resistant and tolerant Amazon-type. In the same experiment a cocoa type of intermediate resistance and tolerance was infected at a rate of 50.0 and $19.5 \%$ and the susceptible Amelonado gave infection rates of 95.1 and $32.2 \%$ with the two inoculation methods, respectively. It is apparent that the manual method overestimates the resistance/tolerance value of the Amazon-type in comparison with that of the Amelonado, and although the manual method will probably yield highly resistant and tolerant cocoa types (LEGG and KENTEN 1970), the final evaluation must be done with mealybugs which transmit the virus in the field.

\subsection{Effect of vector age on virus transmission}

Posnette and Strickland (1948) suggested that crawlers (= first and second instar nymphs) of $P$. njalensis may be more efficient vectors of CSSV $1 \mathrm{~A}$ isolate than older nymphs or adults. Ten to 14 crawlers infected $31 \%$, $5-8$ older nymphs $12 \%$ and $4-5$ adults $13 \%$ of the test plants.

$\operatorname{DALE}(1955 \mathrm{a}, \mathrm{b})$ used CSSV $1 \mathrm{~A}$ isolate and three insects (P.njalensis) per test plant in similar experiments. The infection rate was $68 \%$ with crawlers, $74 \%$ with older nymphs and $75 \%$ with young adults. With single insects on test beans, adults infected $57 \%$ and nymphs $54 \%$ of the test plants (DALE 1958). If unskilled assistants carried out the transfer of insects and two adults were compared with six nymphs, the infection rates were 75 and $95 \%$, respectively. Similarly, five adults infected $26 \%$ of the test plants and 15 nymphs $61 \%$. These tests indicated that unskilled handling did not favour the more robust adults (DALE 1957). 
Posnette and RoBertson (1950) compared adults and nymphs of $P$. citri by using five insects per test plant. The adults infected $47 \%$ of the test plants and the nymphs $29 \%$. The difference was significant at $5 \%$ level.

With the virus CTV and $P$. citri as the vector, KIRKPATRICK (1950) obtained transmission rates of $33 \%$ with first instars, $22 \%$ with second, $24 \%$ with third, and $17 \%$ with adults. The difference was thought to be due to insect behaviour as usually more nymphs than adults settled and apparently fed on the test beans. No transmissions were obtained when parturient females or second instar males were tested.

Five adults, four third instar nymphs and seven crawlers of $F$. virgata on test plants were compared by Posnette and Strickland (1948). The infection rates were $1 / 20$ for adults, $2 / 20$ for the third instar nymphs and 4/16 for the crawlers.

Nymphs of $P$. njalensis removed at birth from females, colonizing CSSV $1 \mathrm{~A}$ isolate infected seedlings, did not transmit virus when transferred to 66 test beans at a rate of 10 per bean (DALE 1958).

At the Cocoa Research Institute of Ghana, nymphs for routine screening tests are from field collected females of $P$. njalensis which are cleaned and kept in reproduction cages. Every second day for six days nymphs are collected from the cages and the source plants infested. Thus, nymphs after the usual 48 hour AAT vary in age from 2 to 4 days when used for the IAT. Kenten (in the press) investigated the effect of age of the nymphs on transmission efficiency with batches of nymphs aged $2-3$ days and $3-4$ days after AAT. The 3-4 days old nymphs gave an infection rate of $52 \%$ and were seemingly slightly more efficient transmitters than those aged $2-3$ days which gave an infection rate of only $38 \%$. The difference was significant at $\mathrm{P}=0.05$ level. A possible reason for the difference was that the older nymphs are larger, more robust, and so less easily damaged during manipulation.

The three successive batches of nymphs which were taken from the fasting adults in the reproduction cages were also compared (KENTEN in the press). As the adults aged, their nymphs were less efficient as vectors. After angular transformation the infection rate of the first batch was 61.7 , of the second 50.3 and of the third 42.0 (L.S.D. $=7.1, \mathrm{P}=0.05$ ).

However, the variation in efficiency of transmission between the nymphs of different ages and those from adults of different ages was less than the variation between different individual virus source plants and, therefore, considered of no advantage to alter the procedure outlined above for collecting nymphs for routine screening work.

It is quite well established that there are no consistent differences in the efficiency of vectors of varying age, apart from old adult females, or males that may not feed at later developmental stages. Passage of virus-into nymphs in the female reproductive organs does not seem to occur. The single report of Posnette and Robertson (1950) on differences between nymphs and adults of $P$. citri, and the findings reported by KENTEN (in the press) on young nymphs of $P$. njalensis, need to be confirmed. 


\subsection{Efficiency and virus/vector specificity of vector species}

Results obtained with $P$. citri, D. brevipes, D. sp. near brevipes, F. virgata and Pseudococcus comstocki (Kuwana) transmitting the virus CTV in Trinidad suggest that there is little if any difference in the efficiency of these five species as transmitters (KIRKPATRICK 1950, 1953 b).

According to DALE (1955 a), F. virgata was much inferior to $P$. njalensis as a vector of CSSV $1 \mathrm{~A}$ isolate, but $F$. virgata seemed unsuited to the method used because of the large amount of wax produced. The insects became entangled within the paper cone attached to the seedlings and few settled down to feed. Consequently a fair comparison was not obtained between the species.

LONGWORTH (1964 a) allowed crawlers of $P$. njalensis and $F$. virgata to feed either on leaves or stems of CSSV infected seedlings. Infection rates were $50 \%$ from stems and $6 \%$ from leaves with $P$. njalensis but $4 \%$ from stems and $48 \%$ from leaves with $F$. virgata. A very plausible explanation for this difference was given by ENTwistLE and LoNGwORTH (1963) who investigated the feeding behaviour of three mealybug species. In transverse sections of cocoa stems, 164 out of 345 stylets of $P$. njalensis were seen to end in the phloem. Stylets of $F$. virgata were seen also in the phloem but less often. Phenacoccus madeiriensis Green, which is not a vector of cocoa viruses, fed differently; its stylets did not end in the phloem. The authors suggested, therefore, that mealybugs acquire virus from the phloem and must deposit virus in the phloem to infect a plant. Thus the rarity of virus transmission by $F$. virgata from stem may be explained by the infrequency its stylets reach the phloem. The low infection rate obtained with $P$. njalensis from leaves may indicate feeding preference, for LoNGworTh (1964 a) has clearly demonstrated that $F$. virgata prefers the leaf as a feeding site, whereas P. njalensis, although feeding to some extent on leaves, prefers leaf axils, crevices between veins and pulvinus and scars and crevices on the stem.

In the present study $P$. njalensis transmitted CSSV $1 \mathrm{~A}$ isolate more efficiently when confined in feeding cages on stems than on leaves during the AAT. (see Table 15). Also, $P$. njalensis was a more efficient vector than $F$. virgata when both species were kept in feeding cages on stems during the AAT (see Table 27).

Adegbola (1965) tested the relative efficiency of $P$. njalensis and $F$. virgata using Egbeda isolate of CSSV infected source plants and either seedlings or beans as test plants. There was a slight indication that $P$. njalensis is a more efficient vector when beans are used as test plants, whilst $F$. virgata is superior when seedlings are used as test plants.

IGWEGBE (1966 a) compared the relative efficiency of $P$. njalensis and $F$. virgata when virus acquisition was done on (a) leaves, (b) stems and petioles, and (c) whole seedlings. There was little difference between the two species when leaves were used as the source but otherwise $P$. njalensis was a more efficient vector.

AdEgBola (1971) did not find any difference between the transmission efficiency of P.njalensis and F. virgata with Egbeda isolate of CSSV. However, 
differences caused by operator skills were obvious and P. njalensis was claimed to be more difficult to handle than $F$. virgata.

It is clear that under identical conditions $P$. njalensis and $F$. virgata are capable to transmit virus with different efficiency. The reason for this seems to be the preference for different feeding sites and the frequency with the phloem is reached by feeding insects during the acquisition feed.

The failure reported by PosnetTe and RoBertson (1950) to obtain transmissions in certain experiments suggested that strains of mealybugs unable to transmit might occur within the species. In tests that followed, 10 gravid females of $P$. njalensis were collected from widely separated points within a radius of about one mile of the laboratory of the Cocoa Research Institute, Ghana. The females and their progenies were reared separately on isolated plants in insect proof greenhouses. When tested, each of the 10 progenies transmitted the $1 \mathrm{M}$ isolate of CSSV with no striking differences in the infection rates.

Lister (1953) tested colonies of $P$. njalensis reared from single females. The results did not provide any evidence that there are non-transmitting strains of this species. Likewise, in the present study, differences in efficiency of transmission were not found between four populations of $P$. njalensis (see Table 16).

Posnette and Robertson (1950) reported that non-transmitting strains of $P$. citri do occur, however. Evidence of this was obtained with CSSV $1 \mathrm{~A}$ isolate, but some strains were lost through parasitism before the tests could be concluded. Experiments with $1 \mathrm{C}$ isolate of CMLV showed that one strain of $P$. citri, which was cultured from a single female collected at Tafo, consistently failed to transmit under conditions suitable for transmission by the mixed progeny of five females collected at Kpeve. It was confirmed that the types were within the normal range of variation of $P$. citri as then recognized in West Africa.

Some mealybug species such as $P$. njalensis, $P$. hargreavesi and $P$. citri transmit a wide range of cocoa virus isolates. Indeed, $P$. njalensis has transmitted virtually every West African isolate of cocoa viruses known to have mealybugs as vectors. In some mealybug species, however, the ability to transmit seems to be restricted to certain viruses or isolates as first reported by Posnette (1950) and repeatedly confirmed by many other-authors. Thus, F. virgata is a more or less efficient vector of a number of isolates, but has consistently failed to transmit different CMLV isolates and $1 \mathrm{M}$ isolate of $\mathrm{CSSV}^{\mathbf{1}}$ ) $P$. longispinus has failed to transmit all other isolates, except 1C of CMLV and $1 \mathrm{M}$ of CSSV. A detailed account of the different vectors and their transmission of various cocoa viruses and isolates is given in Appendices I and II.

1) '...Ps. longispinus also transmitted virus $1 \mathrm{M}$ which, except in one experiment, was not transmitted by Ferrisia virgata. When fed on plants infected with virus $1 \mathrm{~A}$ and $1 \mathrm{M}, F$, virgata transmitted only $1 \mathrm{~A}$. We do not understand why $F$. virgata transmitted virus $1 \mathrm{M}$ in one experiment; it is possible that a biological race was involved as with Pseudococcus citri discussed below, but no transmission was obtained when the experiment was repeated using insects from the same source. The possibility of contamination with another vector species cannot be eliminated, but seems improbable because of the precautions taken and the distinctive appearance of Ferrisia virgata.' (Posnetre 1950). 


\subsection{Effect of physical factors on virus transmission}

Asomaning and Lockard (1964 a, b) and Asomaning and Kwakwa (1968) studied the effects of low and high intensity of solar radiation on development of swollen shoot disease (CSSV 1A) in cocoa seedlings. Development of virus symptoms in stems and roots was faster and more prominent in seedlings exposed to radiation of low intensity. In general, the seedlings showed the usual leaf symptoms of CSSV $1 \mathrm{~A}$ infection. The low intensity seedlings produced the 'fern-leaf' pattern while the high intensity seedlings produced the 'speckled' pattern.

LONGWORTH (1965 b) performed similar studies with Egdeba isolate of CSSV. Bean infected cocoa seedlings were kept in darkness and in full sunlight. Germination and growth of the beans planted in full sunlight was poor and symptom recognition was confused by symptoms of scorch and mineral deficiencies. There was an indication, however, that placing the plants in the dark immediately after infection and storing them in the dark for several weeks may increase transmission rates.

It is obvious that intensity of solar radiation influences development of that part of CSSV infection which is visible in symptoms, but further studies are needed to show that radiation can change the proportion of actually infected plants.

In the present study, different combinations of light and dark during preliminary fasting and acquisition feed did not influence the infection rate when the IAT was carried out in the dark (see 3.10.1). Temperature had an influence upon the feeding of mealybugs and virus transmission (see 3.10.2).

The effect of light on the availability of $1 \mathrm{~A}$ isolate of CSSV from cotyledons was tested with $P$. njalensis (Anon. 1951 b). Fresh cocoa beans were infected by application of 30 infective crawlers per bean. After infection the embryonic axis was removed and the remaining mutilated cotyledons were used as virus source plants. These were kept in almost complete darkness or exposed to light and the availability of virus for mealybugs was tested at various intervals. In both treatments virus was first transmitted from the cotyledons seven days after infection, and virus was equally available from light and darkness treated cotyledons. The main conclusion from this result was that the essential activity of virus takes place at a level in the host cell deeper than the chloroplast system. Certainly, symptom production appears to be a secondary effect of the virus. This is supported by the tendency even of virulent isolates to enter upon symptomless phases of infection during which transmission is still possible.

\subsection{Transmission of virus complexes}

When Posnette and Robertson (1950) infected cocoa plants with both CSSV $1 \mathrm{~A}$ and $1 \mathrm{M}$ isolates they were not mutually antagonistic. The symptoms caused by each isolate occurred independently on some leaves, but periodically leaves were formed with a characteristic 'complex' mosaic quite unlike the symptoms caused by either isolate. To find out whether the isolates were 
so intimately associated in the plant that they would be simultaneously transmitted by single insects, four plants infected with both isolates were colonized with $P$. njalensis. After AAT the insects were transferred one to each test plant. One source plant gave only isolate 1A transmissions and another only isolate $1 \mathrm{M}$, but from two source plants both isolates were transmitted simultaneously by single vectors.

\subsection{Latent period of virus in the vector}

The possibility that mealybug transmitted cocoa viruses undergo a latent period in the vector was briefly discussed by DALE (1955 a). Although virus has been acquired and transmitted by $P$. njalensis in seven hours, composed of a four hour AAT and a three hour IAT (PosNetTe and STRICKLAND 1948), or within five hours (DALE $1955 \mathrm{a}$ ), much longer periods are required on source plants to achieve maximum rates of transmission. In the present study a short AAT of one hour was tested with postacquisition fasting of $0-4$ hours and IAT of one hour, but no transmissions occurred (see 3.7.2). There is no direct evidence to conclude on the presence or absence of a latent period of virus in the mealybugs.

\subsection{Type of transmission}

Twelve characteristics of stylet-borne (non-persistent) and circulative (persistent) viruses transmitted by homopterous insects have been selected to analyse properties of cocoa viruses with their mealybug vectors (Table 36 ). The data presented and discussed in this paper has been used in the analysis. However, where evaluation of data has been more difficult or definition of a characteristic is not exact, the judgement may reflect the opinion of the present author.

Although the mealybug transmitted cocoa viruses have some anomalous properties, on the whole they have more characteristics of circulative viruses than of stylet-borne viruses. In view of this, it is suggested that these viruses are grouped with persistent circulative viruses rather than non-persistent styletborne or semi-persistent viruses. 
Table 36. Properties of mealybug-borne cocoa viruses according to characteristics of styletborne and circulative viruses.

$\mathrm{S}=$ phoperty of cocoa viruses is characteristic of stylet-borne viruses.

$\mathrm{C}=$ property of cocoa viruses is characteristic of circulative viruses.

$\mathrm{NK}=$ property of cocoa viruses not known.

\begin{tabular}{|c|c|c|c|}
\hline \multicolumn{2}{|c|}{ Characteristics } & & \multirow[b]{2}{*}{ Property of cocoa viruses } \\
\hline Stylet-borne viruses & Circulative viruses & & \\
\hline $\begin{array}{l}\text { Short transmission } \\
\text { cycle (seconds) }\end{array}$ & $\begin{array}{l}\text { Long transmission } \\
\text { cycle (hours) }\end{array}$ & $\mathrm{C}$ & $\begin{array}{l}\text { Minimum cycle } 5-7 \text { hours, } \\
\text { longer more typical }\end{array}$ \\
\hline $\begin{array}{l}\text { No latent period } \\
\text { in vector }\end{array}$ & $\begin{array}{l}\text { Latent period } \\
\text { in vector }\end{array}$ & NK & \\
\hline $\begin{array}{l}\text { Pre-AAT fasting } \\
\text { increases vector } \\
\text { efficiency }\end{array}$ & $\begin{array}{l}\text { Pre-AAT fasting } \\
\text { does not increase } \\
\text { vector efficiency }\end{array}$ & $\mathrm{S}$ & $\begin{array}{l}\text { Increases settling and } \\
\text { food uptake and, thus } \\
\text { vector efficiency }\end{array}$ \\
\hline $\begin{array}{l}\text { Short AAT (minutes) } \\
\text { more efficient } \\
\text { than long }\end{array}$ & $\begin{array}{l}\text { Long AAT (hours) } \\
\text { more efficient } \\
\text { than short }\end{array}$ & C & $\begin{array}{l}\text { Minimum } 1.5-2 \text { hours, } \\
48-72 \text { hours more } \\
\text { efficient }\end{array}$ \\
\hline $\begin{array}{l}\text { Vector capable } \\
\text { of infecting one } \\
\text { or few plants }\end{array}$ & $\begin{array}{l}\text { Vector capable } \\
\text { of infecting } \\
\text { many plants }\end{array}$ & $\mathrm{S}$ & Two plants \\
\hline $\begin{array}{l}\text { Vector } \\
\text { specificity } \\
\text { not marked }\end{array}$ & $\begin{array}{l}\text { Vector } \\
\text { specificity } \\
\text { often marked }\end{array}$ & $\mathrm{C}$ & $\begin{array}{l}\text { Only mealybug vectors, } \\
\text { specificity of } F \text {. virgata } \\
\text { and } P \text {. longispinus }\end{array}$ \\
\hline $\begin{array}{l}\text { Virus } \\
\text { non-persistent } \\
\text { in vector }\end{array}$ & $\begin{array}{l}\text { Virus } \\
\text { persistent } \\
\text { in vector }\end{array}$ & $\mathrm{C}$ & $\begin{array}{l}\text { Maximum persistence } 72-96 \\
\text { hours, } 50 \% \text { persistence } \\
\text { about } 12 \text { hours }\end{array}$ \\
\hline $\begin{array}{l}\text { Virus not retained } \\
\text { in vector through } \\
\text { a moult }\end{array}$ & $\begin{array}{l}\text { Virus retained } \\
\text { in vector through } \\
\text { a moult }\end{array}$ & $\mathrm{C}$ & \\
\hline $\begin{array}{l}\text { Virus generally } \\
\text { transmitted by } \\
\text { mechanical means }\end{array}$ & $\begin{array}{l}\text { Virus not generally } \\
\text { transmitted by } \\
\text { mechanical means }\end{array}$ & $\mathrm{C}$ & $\begin{array}{l}\text { Mechanical transmission } \\
\text { occurs after } \\
\text { chemical processing }\end{array}$ \\
\hline $\begin{array}{l}\text { Virus affects mainly } \\
\text { epidermal tissue }\end{array}$ & $\begin{array}{l}\text { Virus affects mainly } \\
\text { conductive tissue }\end{array}$ & C & \\
\hline $\begin{array}{l}\text { Virus not recoverable } \\
\text { from haemolymph } \\
\text { of vector }\end{array}$ & $\begin{array}{l}\text { Virus recoverable } \\
\text { from haemolymph } \\
\text { of vector }\end{array}$ & NK & \\
\hline $\begin{array}{l}\text { Vector not infective } \\
\text { after inoculation of } \\
\text { virus into haemocoele }\end{array}$ & $\begin{array}{l}\text { Vector infective } \\
\text { after inoculation of } \\
\text { virus into haemocoele }\end{array}$ & NK & \\
\hline
\end{tabular}




\section{Summary}

Several experiments concerning mealybugs (Pseudococcidae) and their transmission of cocoa viruses are described and discussed in this paper. $P$. njalensis, $P$. citri and $F$. virgata reacted positively towards low intensity of light in $25-27^{\circ} \mathrm{C}$. and $40-60 \% \mathrm{RH}$. In the same temperature the three mealybug species and $P$. longispinus reacted more positively towards high than to low humidities. $P$. njalensis reacted more positively towards $20-25^{\circ} \mathrm{C}$. than higher or lower temperatures. The most favourable temperature for reproduction of fasting females of $P$. njalensis was $25-33^{\circ} \mathrm{C}$. with $55-75 \% \mathrm{RH}$. Partial fecundity of field collected females was then 92 nymphs per female.

Biological half-life of ${ }^{32} \mathrm{P}$ in feeding $P$. njalensis was 11.4 or 15.3 days depending on external conditions. The amount of food uptake, measured in ${ }^{32} \mathrm{P}-$ activity from virus infected plants was positively related to the infectivity status of $P$. njalensis with CSSV 1A. Plant radioactivity was positively related to mealybug radioactivity. There was a positive correlation between the amount of honeydew excreted by $P$. njalensis and the radioactivity of the honeydew. Frequency distribution of radioactivity in $P$. njalensis after feeding on ${ }^{32} \mathrm{P}$ active seedlings or sucrose solution was closely similar. Radiation effects on infectivity of $P$. njalensis were not detected at a level of $30 \mu \mathrm{Ci} / \mathrm{ml}$ of ${ }^{32} \mathrm{P}$ in seedling culture solution.

With the virus CSSV $1 \mathrm{~A}$ and $P$. njalensis as the vector, preliminary fasting increased the rate of settling down to feed, the amount of food uptake and the infectivity of mealybugs. Virus was transmitted more frequently from the stems than the leaves of infected plants. Groups of young seedlings of $\mathbf{2 9 - 5 4}$ days were almost equally good sources of virus for mealybugs, and availability of virus varied significantly between source plants of the same age in closely similar conditions. Mean duration of stylet withdrawal from source plants was 240 seconds. The optimum length of acquisition access time for maximum rate of transmission with prestarved mealybugs was 48-72 hours, with shorter or longer acquisition access time the infection rate was lower. Virus was not acquired by mealybugs during short probes on source plants or short feeds of one hour maximum. Virus was readily acquired from infected seedlings via a parafilm membrane by mealybugs as indicated by subsequent transmission into test plants. Acquisition of virus from liquid leaf extract via a parafilm membrane and subsequent transmission was rare. After acquisition feed the virus persisted in the mealybugs up to $72-96$ hours and loss of infectivity was exponential with time. The half-life of persistence was $12-13$ hours. Virus persisted in the mealybugs through postacquisition moulting. Postacquisition feeding increased virus persistence. Latent period of virus in the test plants 
was short and normally over $98 \%$ of the infected plants sowed symptoms of virus in three months. With different numbers of mealybugs on test plants during the inoculation feed, the infection rate was according to laws of probability. The use of mealybugs while testing virus resistant and tolerant cocoa types is demonstrated. No evidence was obtained that location of feeding mealybugs on test beans influences the rate of virus transmission. Virus transmission by mealybugs was not affected by light or dark. The amount of food uptake by mealybugs was higher and also virus was transmitted more frequently in $29-36^{\circ} \mathrm{C}$. than in lower temperatures.

Although investigated to a lesser extent, the transmission characteristics of CSSV 1M or CMLV 1C with $P$. njalensis as the vector, or CSSV 1A with $F$. virgata, were closely similar to those of CSSV 1A with $P$. njalensis as the vector.

A general mathematical formula is given to describe the increase of infectivity in mealybugs during acquisition feed on basis of linear food uptake and exponential loss of infectivity. 


\section{REFERENCES}

Adegbola, M. O. K. 1965. The relative efficiency of Planococcoides (= Pseudococcus) njalensis (Laing) and Ferrisiana virgata (Ckll) in the transmission of CSSV. Ann. Rep. Cocoa Res. Inst. Nigeria $1963-64$, p. $43-44$.

- -1971 . The efficiency of mealybug handlers as a factor in laboratory transmission of cocoa swollen shoot virus (CSSV). Niger. Ent. Mag. 2: 75-82.

Anon. 1950. Virus-host relationships. (a) A newly-discovered locus of infection in the plant. Ann. Rep. W. Afr. Cacao Res. Inst. 1948-49, p. 13-14.

_ 1951 a. Laboratory rearing of mealybugs. Ann. Rep. W. Afr. Cacao Res. Inst. 1949-50, p. $65-66$.

- 1951 b. Virus-host relationships. Ann. Rep. W. Afr. Cacao Res. Inst. 1949-50, p. $13-19$.

- 1953 a. Rearing of mealybugs for parasite breeding. Ann. Rep. W. Afr. Cacao Res. Inst. $1950-51$, p. $41-42$.

- 1953 b. Quart. Rep. W. Afr. Cacao Res. Inst. $32: 7$ (mimeogr.).

- - 1955. Quart. Rep. W. Afr. Cocoa Res. Inst. 39: 16 (mimeogr.).

- - 1957. Quart. Rep. W. Afr. Cocoa Res. Inst. 47: 6 (mimeogr.).

- - 1958. Quart. Rep. W. Afr. Cocoa Res. Inst. 52: 5-6 (mimeogr.).

- - 1959. Quart. Rep. W. Afr. Cocoa Res. Inst. 56: 7 (mimeogr.).

_- 1963. Half-Yearly Rep. Cocoa Res. Inst. Ghana 2: 13 (mimeogr.).

Asomaning, E. J. A. \& Kwakwa, R. S. 1968. Effects of degrees of shading on the growth of virus-infected seedlings. Ann. Rep. Cocoa Res. Inst. Ghana 1965-66, p. 114-125.

- - \& LockARD, R. G. 1964 a. The effects of solar radiation on the growth of cocoa infected with New Juaben virus. Ann. Rep. Cocoa Res. Inst. Ghana 1962-63, p. 88.

- 1964 b. Studies on the physiology of cocoa (Theobroma cacao L.). I. Suppression of swollen-shoot virus symptoms by light. Ann. Appl. Biol. 54: 193-198.

Attafunh, A. \& Brunt, A. A. 1960. Classification of isolates. Ann. Rep. W. Afr. Cocoa Res. Inst. $1958-59$, p. $16-17$.

BAKER, R. E. D. \& DALE, W. T. 1947. Notes on a virus disease of cacao. Ann. Appl. Biol. 34: $60-65$.

Banks, C. J. \& Nixon, H. L. 1959. The feeding and excretion rates of Aphis fabae Scop. on Vicia faba L. Ent. Exp. Appl. 2: 77-81.

Blencowe, J. W. 1961. A virus disease of cocoa in Sierra Leone. Ann. Rep. W. Afr. Cocoa Res. Inst. $1959-60$, p. 20.

- - 1962. Future plans for cocoa breeding in Ghana. Rep. Cocoa Conf. London 1961, p. $141-145$.

- - \& Aтtafuah, A. 1959. Resistance and tolerance. Ann. Rep. W. Afr. Cocoa Res. Inst. $1957-58$, p. $24-25$.

- - , Brunt, A. A., Kenten, R. H. \& Lovi, N. K. 1963. A new virus disease of cocoa in Sierra Leone. Trop. Agric. (Trinidad) 40:233-236.

Box, H. M. 1945. Insect transmission of the 'swollen-shoot' virus in West Africa. Nature (London) 155: 608-609.

Brunt, A. A. \& Kenten, R. H. 1960. Mechanical transmission of cocoa swollen-shoot virus. Virology 12: $328-330$.

- -1962 . Mechanical transmission of cocoa swollen-shoot virus to and from cocoa and other hosts. Ann. Appl. Biol. 50: 749-754.

CArter, W. 1956. Notes on some mealybugs (Coccidae) of economic importance in Ceylon. FAO Pl. Protect. Bull. 4: 49-52. 
CARTer, W. 1961. Report to the International Cooperation Administration and USOM/Ghana. 31 p. (mimeogr. available at Cocoa Res. Inst. Ghana).

-, - 1963. Mealybug wilt of pine-apple; a reappraisal. Ann. N. Y. Acad. Sci. 105: 741 - 764.

Chase, G. D. \& Rabinowitz, J. L. 1962. Principles of radioisotope methodology. 372 p. Minneapolis.

Cornwell, P. B. 1957. A preliminary investigation into the uptake and translocation of phosphorus-32 in Theobroma cacao L. Trop. Agric. (Trinidad) 34: 117-132.

Cotrerell, G. S. 1943. Swollen-shoot virus. Rep. Centr. Cocoa Res. Sta. Tafo 1938-42, p. 51-55.

Dale, W. T. 1954 a. Quart. Rep. W. Afr. Cacao Res. Inst. 33: 7 (mimeogr.).

-1954 b. Quart. Rep. W. Afr. Cacao Res. Inst. 34: 6 (mimeogr.).

- 1954 c. Quart. Rep. W. Afr. Cacao Res. Inst. 35: 9 (mimeogr.).

-1954 d. Quart. Rep. W. Afr. Cacao Res. Inst. 36: 5 (mimeogr.).

- 1955 a. Optimum conditions for transmission. Ann. Rep. W. Afr. Cocoa Res. Inst. $1954-55$, p. $33-35$.

- 1955 b. Quart. Rep. W. Afr. Cacao Res. Inst. 37: 5-6 (mimeogr.).

,- 1957. Insect transmission studies. Ann. Rep. W. Afr. Cocoa Res. Inst. 1955-56, p. $30-31$.

,- 1958. Insect-transmission studies. Ann. Rep. W. Afr. Cocoa Res. Inst. 1956-57, p. $22-24$.

- 1962. Diseases and pests of cocoa. A. Virus diseases. Agriculture and Land Use in Ghana. p. 286-316. London.

DAy, M. F. \& IrzyкiEwicz, H. 1953. Feeding behaviour of the aphids Myzus persicae and Brevicoryne brassicae, studied with radiophosphorus. Austr. J. Biol. Sci. 6:98-108.

- $-\&$ McKinnon, A. 1951. A study of some aspects of the feeding of the jassid Orosius. J. Sci. Res. Ser. B 4:125-135.

Decker, F. E. 1956. Quart. Rep. W. Afr. Cocoa Res. Inst. 41: 8 (mimeogr.).

- 1957. Mass-breeding of mealybugs. Ann. Rep. W. Afr. Cocoa Res. Inst. 1955-56, p. 41-42.

Donald, R. G. 1954 a. Quart. Rep. W. Afr. Cacao Res. Inst. $33: 7$ (mimeogr.).

- 1954 b. Quart. Rep. W. Afr. Cacao Res. Inst. 35: 18 (mimeogr.).

- 1954 c. Quart. Rep. W. Afr. Cacao Res. Inst. 36: 20 (mimeogr.).

- -1955 . Quart. Rep. W. Afr. Cacao Res. Inst. 37: 21 (mimeogr.).

--1957 . Mass-breeding of mealybugs. Ann. Rep. W. Afr. Cocoa Res. Inst. 1955-56, p. 41-42.

DuFfus, J. E. \& GolD, A. H. 1967. Relationship of tracer-measured aphid feeding to acquisition of beet western yellows virus and to feeding inhibitors in plant extracts. Phytopath. 57: $1237-1241$.

Eguagie, W. E. 1970. Non-transmittability of Offa-Igbo isolate of cocoa swollen shoot virus (CSSV) by Aphis gossypii Glover (Homoptera: Aphididae). Niger. Ent. Mag. 2: 49-55.

Elmer, C. H. 1922. Mosaic cross-inoculation and insect transmission studies. Science 56: 370.

- - 1925. Transmissibility and pathological effects of the mosaic diasease. Res. Bull. Iowa Agric. Exp. Sta. 82: 39.

Entwistle, P. F. \& Longworth, J. F. 1963. The relationship between cacao viruses and their vectors: the feeding behaviour of three mealybug (Homoptera: Pseudococcidae) species. Ann. Appl. Biol. 52: 387-391.

FaJARdo, T. C. 1930. Studies of the mosaic disease of the bean (Phaseolus vulgaris). Phytopath. 20: 469 .

GiBbs, A. J. \& Gower, J. C. 1960. The use of a multiple-transfer method in plant virus transmission studies - some statistical points arising in the analysis of results. Ann. Appl. Biol. 48: 75-83.

Hafez, M. \& Salama, H. S. 1970. Biological studies on the sugar cane mealy bug, Saccharicoccus sacchari Ckll., in Egypt. Bull. Soc. Ent. Egypte 53: 499-516.

- - , Salama, H. S. \& Amin, A. H. 1967. Population dynamics of the plum scale, Parlatoria oleae (Colvee), in Egypt (Coccidae). Bull. Soc. Ent. Egypte 51: 347-357.

Hamilton, M. H. 1935. Further experiments on the artificial feeding of Myzus persicae (Sulz.). Ann. Appl. Biol. 22: 243-258. 
Hughes, W. A. \& Lister, C. A. 1953. Lime dieback in the Gold Coast, a virus disease of the lime, Citrus aurantifolia (Christerum) Swingle. J. Hort. Sci. 28: 131.

Igwegbe, E. C. K. 1966 a. The preferences shown by Planococcoides njalensis (Laing) and Ferrisiana virgata (Ckll.) for different feeding sites and its effect on their efficiency as vectors. Ann. Rep. Cocoa Res. Inst. Nigeria 1964-65, p. 60-62.

- 1966 b. Availability of C.S.S.V. in different cocoa clones to Planococcoides njalensis (Laing). Ann. Rep. Cocoa Res. Inst. Nigeria 1964-65, p. 62-65.

Imss, A. D. 1957. A general textbook of entomology. 886 p. London.

James, H. C. 1937. Sex ratios and the status of the male in Pseudococcinae (Hem. Coccidae). Bull. Ent. Res. 28:429-461.

Kenten, R. H. Factors affecting the transmission of virus by mealybugs. Ann. Rep. Cocoa Res. Inst. Ghana $1972-73$ (in the press).

- - \& LEGG, J. T. 1967. Some properties of cocoa mottle leaf virus. J. Gen. Virol. 1: 465470.

- -1970 . Methods of assessing the tolerance and resistance of different types of cocoa to cocoa swollen-shoot virus. Ann. Appl. Biol. 65: 419-424.

- - 1971. Serological relationships of some viruses from cocoa (Theobroma cacao L.) in Ghana. Ann. Appl. Biol. 67: 195-200.

- - \& Owusu, G. K. 1970. Cocoa necrosis virus. Ann. Rep. Cocoa Res. Inst. Ghana 1968-. 69, p. 35.

KirкPAтrick, T. W. 1950. Insect transmission of cacao virus disease in Trinidad. Bull. Ent. Res. 41: 99-117.

- 1953 a. Insect pests of cacao and insect vectors of cacao virus disease. Rep. Cacao Res. Imp. Coll. Trop. Agric. Trin. 1945-51, p. 122-125.

- -1953 b. Notes on minor insect pests of cacao in Trinidad. Rep. Cacao Res. Imp. Coll. Trop. Agric. Trin. 1952, p. 62-71.

KNight, R. \& Tinsley, T. W. 1958. Some histological observations on virus-infected Theobrobroma cacao L. Ann. Appl. Biol. 46: 7-10.

LEGG, J. T. \& Bonney, J. K. 1967. The host range and vector species of viruses from Cola chlamydantha K. Schum., Adansonia digitata L. and Theobroma cacao L. Ann. Appl. Biol. 60: 399-403.

- - 1968 a. Insect transmission studies. Ann. Rep. Cocoa Res. Inst. Ghana 1965-66, p. $30-31$.

- 1968 b. Availability of CSSV in sensitive and tolerant varieties of cocoa. Ann. Rep. Cocoa Res. Inst. Ghana $1966-67$, p. 27-28.

- $-\&$ KEnTEN, R. H. 1970. The resistance and tolerance of different cocoa varieties to cocoa swollen-shoot virus in Ghana. Ann. Appl. Biol. 65: 425-434.

Lister, R. M. 1953. Ann. Rep. W. Afr. Cacao Res. Inst. 1952-53, p. 9-10.

- $-\&$ Thresh, J. M. 1954. Mealybug vectors. Ann. Rep. W. Afr. Cacao Res. Inst. 195354 , p. 13.

Lockard, R. G. \& Asomaning, E. J. A. 1963. Composition of complete nutrient solutions. Ann. Rep. W. Afr. Cocoa Res. Inst. $1961-62$, p. 56-57.

Lodos, N. \& BoAfo, E. O. 1968. Studies of ants associated with mealybugs and virus vector investigations. Ann. Rep. Cocoa Res. Inst. Ghana 1966-67, p. 38.

Longworth, J. F. 1964 a. The preference shown by $P$. njalensis and $F$. virgata for different feeding sites, and its effect on their efficiency as vectors. Ann. Rep. Cocoa Res. Inst. Nigeria $1962-63$, p. 29-30.

- - 1964 b. Availability of CSSV in different cocoa types. Ann. Rep. Cocoa Res. Inst. Nigeria $1962-63$, p. $31-33$.

- 1964 c. Half-Yearly Rep. W. Afr. Cocoa Res. Inst. (Nigeria) 2: 20-21 (mimeogr.).

-1965 a. Ann. Rep. W. Afr. Cocoa Res. Inst. (Nigeria) 1963-64, p. 34.

- $1965 \mathrm{~b}$. The effect of light on transmission of cocoa swollen shoot virus by insects and mechanical methods. Ann. Rep. Cocoa Res. Inst. Nigeria 1963-64, p. 46.

- - - \& Entwistle, P. F. 1965. Virus/vector relationships. Ann. Rep. Cocoa Res. Inst. Nigeria $1963-64$, p. $40-43$.

MADGE, D. S. 1961. The control of relative humidity with aqueous solutions of sodium hydroxide. Ent. Exp. Appl. 4: 143-147. 
Markкula, M. 1963. Studies on the pea aphid Acyrthosiphon pisum Harris (Hom., Aphididae). with special reference to the differences in the biology of the green and red forms. Ann. Agric. Fenn. 2, Suppl. 1: 1-30 p.

Martini, C. K. H. 1959 a. Quart. Rep. W. Afr. Cocoa Res. Inst. 55: 12-13 (mimeogr.).

- 1959 b. Quart. Rep. W. Afr. Cocoa Res. Inst. 56: 16 (mimeogr.).

,- 1960 . Insect transmission studies. Ann. Rep. W. Afr. Cocoa Res. Inst. 1958-59, p. 67-68.

- - 1961. Transmission of Nigerian cocoa viruses. Ann. Rep. W. Afr. Cocoa Res. Inst. 195960 , p. $68-69$.

- 1962. Vectors of Nigerian cocoa viruses. Ann. Rep. W. Afr. Cocoa Res. Inst. 1960-61, p. $75-76$.

Mittler, T. E. \& DAdD, R. H. 1964. An improved method for feeding aphids on artificial diets. Ann. Ent. Soc. Amer. 57: 139-140.

Newton, W. 1953. Transmission of tobacco mosaic by citrus mealybug. FAO Pl. Protect. Bull. 2: 40 .

Nicol, J. 1950. Quart. Rep. W. Afr. Cacao Res. Inst. 25: 4 (mimeogr.).

Oкusanya, В. А. М. 1968. Studies of cacao swollen shoot disease. Ann. Rep. Cocoa Res. Inst. Nigeria $1966-67$, p. $66-69$.

- - 1969. Cocoa swollen shoot virus. Ann. Rep. Cocoa Res. Inst. Nigeria 1967-68, p. 88-92.

-1970 . Transmission of CSSV. Ann. Rep. Cocoa Res. Inst. Nigeria 1968-69, p. 55-56.

- 1971. Breeding of Pseudococcus njalensis. Ann. Rep. Cocoa Res. Inst. Nigeria 196970, p. $46-47$.

Olitsky, P. K. 1925. The transfer of tobacco and tomato mosaic diseases by Pseudococcus citri. Science $62: 442$.

Owusu, G. K. 1959. The availability of swollen shoot virus to mealybug vectors in tolerant and sensitive cocoa. Ann. Rep. Cocoa Res. Inst. Ghana 1967-68, p. 32-34.

- 1970. Availability of cocoa swollen shoot virus to mealybugs from tolerant and sensitive cocoa. Ann. Rep. Cocoa Res. Inst. Ghana 1968-69, p. 31-33.

,- 1971 a. Cocoa necrosis virus in Ghana. Trop. Agric. (Trinidad) 48: 133-139.

- 1971 b. Availability of cocoa swollen shoot virus to mealybugs from tolerant and sensitive cocoa. Proc. 3rd Intern. Cocoa Res. Conf. 1969, p. 512-517.

- - 1972. Acquisition of swollen shoot virus by mealybugs from cocoa plants during the period of latent infection. Ann. Rep. Cocoa Res. Inst. Ghana 1969-70, p. 60-61.

- -1973 . Availability of cocoa swollen shoot virus to mealybugs from tolerant and sensitive cocoa. Ann. Rep. Cocoa Res. Inst. Ghana $1970-71$, p. 63.

- - \& Bonney, J. K. 1972. Studies of CSSV isolates from Ashanti region. Ann. Rep. Cocoa Res. Inst. Ghana $1969-70$, p. 63-65.

- - \& Kenten, R. H. 1972. Cocoa necrosis virus. Ann. Rep. Cocoa Res. Inst. Ghana 196970 , p. $61-63$.

Posnette, A. F. 1940. Transmission of swollen-shoot. Trop. Agric. (Trinidad) 17: 98.

-1 1941. Swollen-shoot virus disease of cacao. Trop. Agric. (Trinidad) 18: 87 -89 .

- - 1944. Virus diseases of cacao in Trinidad. Trop. Agric. (Trinidad) 21: 105-106.

- 1947 a. Virus diseases of cacao in West Africa. I. Cacao viruses 1A, 1B, 1C and 1D. Ann. Appl. Biol. 34: 388-402.

$-1947 \mathrm{~b}$. The use of seeds in the insect transmission of some plant viruses. Nature (London) 159:500.

- -1950 . Virus diseass of cacao in West Africa VII. Virus transmission by differen? vector species. Ann. Appl. Biol. 37: 378-384.

- 1951. Virus research at the West African Cacao Research Institute, Tafo, Gold Coast. Trop. Agric. (Trinidad) 28:133-142.

- $-\&$ Robertson, N. F. 1950. Virus diseases of cacao in West Africa. VI. Vector investigations. Ann. Appl. Biol. 37: 363-377.

$--\&$ Strickland, A. H. 1948. III. Technique of insect transmission. Ann. Appl. Biol. 35: $53-63$.

- $-\&$ Todd, J. McA. 1951. VIII. The search for virus resistant cacao. Ann. Appl. Biol. 38: $785-800$.

-1955 . IX. Strain variation and interference in virus 1A. Ann. Appl. Biol. 43: 433-453. 
Rorvarnen, O. 1968. Insect transmission studies. Ann. Rep. Cocoa Res. Inst. Ghana 1966-67, p. $28-30$.

- - 1969. Effect of vector feeding on virus transmission. Ann. Rep. Cocoa Res. Inst. Ghana $1967-68$, p. 40.

- -1970 . Virus/vector relationships. Ann. Rep. Cocoa Res. Inst. Ghana 1968-69, p. $29-30$.

- -1971 . Circulative transmission of cocoa swollen shoot virus by the mealybug Planococcoides njalensis (Laing) (Homoptera: Pseudococcidae). Proc. 3rd Intern. Cocoa Res. Conf. 1969, p. $518-521$.

- 1972 a. Mechanism of transmission. Ann. Rep. Cocoa Res. Inst. Ghana 1969-70, p. 59-60.

- 1972 b. Optimum conditions for transmission. Ann. Rep. Cocoa Res. Inst. Ghana 196970, p. $57-59$.

- -1973 . Viruses and Coccoidea. Front. Biol. 31: 455-462. Amsterdam.

Salama, H. S. 1970 a. Reactions of the grape mealy bug, Planococcus vitis Nied., towards some environmental factors. Bull. Soc. Ent. Egypte 53: 271-281.

- 1970 b. Population dynamics of the scale insect Mycetaspis personatus (Comstock) in Egypt (Homoptera-Coccoidea). Z. Angew. Ent. 66: 42-46.

Semangun, H. 1961. Mosaic symptoms on cocoa leaves in Java. Phytopath. Lab. Fac. Agr. For. Univ. Gadjahmada, Jogjakarta, Indonesia 2: 1-9 p.

Seuge, J., Morere, J. L. \& Ferradini, C. 1971. Effect of food preirradiation on the fecundity of two insects: Mealy bugs (Pseudaulacaspis pentagona Targ.) and Indian-meal moths (Plodia interpunctella Hübn.). Radiat. Res. 45: 210-215.

Snedecor, G. W. \& Cochran, W. G. 1968. Statistical methods. 593 p. Ames.

Solomon, M. E. 1945. The use of cobalt salts as indicators of humidity and moisture. Ann. Appl. Biol. 32: 75-85.

Steven, W. F. 1936. A new disease of cocoa in the Gold Coast. Gold Coast Farm. 5: 122. (reprinted Trop. Agric. (Trinidad) 14:84).

Strickland, A. H. 1951. The entomology of swollen shoot of cacao. I. - The insect species involved, with notes on their biology. Bull. Ent. Res. 41: 725-748.

Sylvester, E. S. 1958. Aphid transmission of plant viruses. Proc. 10th Intern. Congr. Ent. 1956, 3: 195-200.

Teliz, D., Grogan, R. G. \& Lownsberry, B. F. 1966. Transmission of tomato ringspot, peach yellows bud mosaic, and grape yellow vein viruses by Xiphinema americanum. Phytopath. 56: $658-663$.

Thorold, C. A. 1975. Diseases of cocoa. 423 p. London.

Thresh, J. M. 1958 a. The control of cacao swollen shoot disease in West Africa. Techn. Bull. W. Afr. Cocoa Res. Inst. 4: 1-36 p.

-1958 b. The spread of virus disease in cacao. Techn. Bull. W. Afr. Cocoa Res. Inst. 5: 1-36 p.

- $1958 \mathrm{c}$. The availability of cacao swollen-shoot virus to mealybugs feeding on infected trees. Ann. Rep. W. Afr. Cocoa Res. Inst. 1956-57, p. $78-81$.

- $-\&$ Trnsley, T. W. 1959. The viruses of cacao. Techn. Bull. W. Afr. Cocoa Res. Inst. 7: $1-32 \mathrm{p}$.

Youdeower, A. 1967. The reactions of Dysdercus intermedius (Heteroptera, Pyrrhocoridae) to moisture, with special reference to aggregation. Ent. Exp. Appl. 10: 194-210.

- - 1968. The behaviour of a cotton stainer Dysdercus intermedius (Heteroptera, Pyrrhocoridae) in a temperature gradient and the effect of temperature on aggregation. Ent. Exp. Appl. 11: 68-80.

Watson, M. A. \& Nixon, H. L. 1953. Studies on the feeding of Myzus persicae (Sulz.) on radioactive plants. Ann. Appl. Biol. 40: 537-545.

WeLsh, M. F. 1961. Terminology of plant virus diseases. Can. J. Bot. 39: 1773-1780. 


\title{
SELostus
}

\section{Villakirvat (Homoptera: Pseudococcidae) kaakaopuun virusten siirtäjinä}

\author{
Osmo RoIvainen \\ Maatalouden tutkimuskeskus, Tuhoeläintutkimuslaitos, 01301 Vantaa 30
}

Tässä julkaisussa selostetaan Ghanassa 1966-71 suoritettuja tutkimuksia kaakaopuun viruksista ja niiden villakirvavektoreista (Pseudococcidae). Planococcoides njalensis, Planococcus citri ja Ferrisia virgata osoittivat käyttäytymisellään, että niillä on positiivinen valoreaktio. Samat kolme villakirvalajia ja Pseudococcus longispinus hakeutuivat n. $90 \%$ :n suhteelliseen kosteuteen ja karttoivat kuivia olosuhteita. $P$. njalensis-lajin lämpöpreferenssialue oli $20-25^{\circ} \mathrm{C}$., mutta suotuisin lisääntymislämpötila oli $25-33^{\circ} \mathrm{C}$. suhteellisen kosteuden ollessa $55-75 \%$.

Radiofosforin biologinen puoliintumisaika $P$. njalensis-lajissa oli 11.4-15.3 päivää. Villakirvojen viruksen saastuttamista kasveista ottaman ravinnon määrän ja viruksensiirtokyvyn välillä oli positiivinen korrelaatio. Ravintokasvin radioaktiivisuutta lisättäessä myös villakirvojen radioaktiivisuus lisääntyi samassa suhteessa. Villakirvojen erittämän mesikasteen spesifinen radioaktiivisuus vaihteli vähän. Radioaktiivisen fosforin frekvenssijakautuma oli samanlainen villakirvoissa, jotka olivat syöneet radioaktiivista kasvia tai sakkaroosiliuosta. Villakirvojen kyky siirtää virusta ei huonontunut radioaktiivisesta fosforista, jota käytettiin $30 \mu \mathrm{Ci} / \mathrm{ml}$ kasvien ravintoliuoksessa.

Tutkittaessa kaakaovirusta CSSV 1A ja $P$. njalensis-lajia vektorina, syömään asettuminen nopeutui, ravinnonotto lisääntyi ja viruksensiirtokyky parani kun vektoreita paastotettiin ennen saamasyöntiä. Vektorit siirsivät virusta tehokkaammin kaakaopuun varsista kuin lehdistä. Nuoret 29-54 päivää vanhat kasviryhmät olivat vektoreille yhtä hyviä viruslähteitä, mutta yksittäiset kasvit erosivat toisistaan tässä suhteessa suurestikin. Vektorilta kului aikaa keskimäärin 240 sekuntia suuosien pois vetämiseen kasvisolukosta. Vektorit siirsivät virusta tehokkaimmin kun saama-aika oli 48-72 tuntia. Kun saama-aika oli yksi tunti tai lyhyempi vektorit eivät siirtäneet virusta. Lehtien mehusta valmistetusta uutteesta vektorit siirsivät virusta vain harvoin. Virus oli vektorissaan puolipysyvä ja 72-96 tunnin kuluttua saamasyönnistä saastunta oli miltei kokonaan hävinnyt. Saastunnan häviäminen oli eksponentiaalista luonteeltaan. Häviämisen puoliintumisajaksi saatiin 12-13 tuntia. Saama-ajan jälkeinen nahanluonti, paastoaminen tai syöminen eivät poistaneet vektorin viruksensiirtokykyä. Viruksen piilovaihe kasveissa oli lyhyt ja noin kolmen kuukauden kuluttua inokulaatiosyönnistä yli $98 \%$ virustartunnan saaneista testikasveista osoitti taudin oireita. Lisättäessä vektorien lukumäärää inokulaatiosyönnin aikana, viruksensiirtotehokkuus kasvoi todennäköisyysoppien mukaan. Valo tai pimeys eivät vaikuttaneet siirtotehokkuuteen, sen sijaan lämpötilalla oli merkitystä. Kahdella muulla kaakaoviruksella tai isolaatilla ja $F$. virgata-lajilla saatiin edellä selostetun kaltaisia tuloksia.

Tutkimuksessa pohditaan myōs villakirvojen soveltuvuutta kaakaolajikkeiden virusresistenssin mittaamiseen. Lisäksi on johdettu siirtämistehokkuuden muutoksia kuvaava matemaattinen malli jota on testattu kokeellisesti. 
Appendix I. Vectors of cocoa viruses (with some mealybug species synonyms that most often appear in cocoa virus literature)

Abbreviations: $\mathrm{CMLV}=$ cocoa mottle leaf virus $\quad \mathrm{CTV}=$ cocoa Trinidad virus

$\mathrm{CSSV}=$ cocoa swollen shoot virus $\mathrm{CCV}=$ Ceylon cocoa virus

\begin{tabular}{|c|c|c|}
\hline Vector species & Virus & Reference \\
\hline $\begin{array}{l}\text { 1. Delococcus tafoensis (Strickland) } \\
\text { syn. Formicoccus tafoensis Strickland }\end{array}$ & CSSV & ANon. 1958 \\
\hline \multirow[t]{3}{*}{ 2. Dysmicoccus brevipes (Cockerell) } & CMLV & Posnette 1950 \\
\hline & CSSV & Posnette 1950 \\
\hline & CTV & KIRKPATRICK 1950 \\
\hline 3. Dysmicoccus sp. near brevipes (Cockerell) & CTV & KIRKPATRICK 1950 \\
\hline \multirow[t]{2}{*}{ 4. Ferrisia virgata (Cockerell) } & CSSV & Posnette and Strickland 1948 \\
\hline & CTV & KIRKPATRICK 1950 \\
\hline $\begin{array}{l}\text { 5. Maconellicoccus ugandae (Laing) } \\
\text { syn. Phenacoccus sp. (H } 6418 \text { in Tafo } \\
\text { Collection) }\end{array}$ & CSSV & Posnette 1950 \\
\hline $\begin{array}{l}\text { 6. Paracoccus sp. near proteae (Hall) } \\
\text { syn. Pseudococcus sp. near proteae }\end{array}$ & CSSV & LISTER 1953 \\
\hline $\begin{array}{l}\text { 7. Paraputo anomalus (Newstead) } \\
\text { syn. Paraputo ritchiei Laing }\end{array}$ & CSSV & Posnetre 1950 \\
\hline \multirow[t]{2}{*}{ 8. Planococcoides njalensis (Laing) } & CMLV & Posnette 1950 \\
\hline & CSSV & Posnette and Strickland 1948 \\
\hline \multirow{6}{*}{$\begin{array}{l}\text { 9. Planococcus sp. near celtis (Strickland) } \\
\text { syn. Pseudococcus sp. near celtis Strickland } \\
\text { 10. Planococcus citri (Risso) }\end{array}$} & CMLV & Posnette 1950 \\
\hline & CSSV & Posnette 1950 \\
\hline & CMLV & Posnette 1950 \\
\hline & CSSV & Posnette 1950 \\
\hline & CTV & KIRKPATRICK 1950 \\
\hline & $\mathrm{CCV}$ & Carter 1956 \\
\hline \multirow[t]{2}{*}{ 11. Planococcus kenyae (Le Pelley) } & CMLV & DaLe 1957 \\
\hline & CSSV & Dale 1957 \\
\hline 12. Planococcus lilacinus (Cockerell) & $\mathrm{CCV}$ & CARTER 1956 \\
\hline 13. Pseudococcus comstocki Kuwana & CTV & KIRKPATRICK 1953 a \\
\hline \multirow[t]{2}{*}{ 14. Pseudococcus concavocerarii James } & CMLV & AtTAFUAH and BRUNT 1960 \\
\hline & CSSV & Posnette 1950 \\
\hline \multirow{4}{*}{$\begin{array}{l}\text { 15. Pseudococcus sp. near fragilis Brain } \\
\text { syn. Pseudococcus sp. near gahani Green } \\
\text { 16. Pseudococcus hargreavesi Laing } \\
\text { syn. Pseudococcus bukobensis (Laing) }\end{array}$} & CMLV & Attafuah and Brunt 1960 \\
\hline & CSSV & Posnette 1950 \\
\hline & CMLV & Posnette 1950 \\
\hline & CSSV & Posnetre 1950 \\
\hline $\begin{array}{l}\text { 17. Pseudococcus longispinus (Targioni Tozzetti) } \\
\text { syn. Pseudococcus adonidum (L.) }\end{array}$ & cssv & Posnette 1950 \\
\hline 18. Pseudococcus sp. near masakensis James & CSSV & Posnette 1950 \\
\hline 19. Tylococcus westwoodi Strickland & cSSV & $\begin{array}{l}\text { ANON. } 1953 \mathrm{~b} \text {, LISTER and } \\
\text { THRESH } 1954\end{array}$ \\
\hline
\end{tabular}


Appendix II. Cocoa virus isolates and their vectors. $+=$ transmission, $-=$ no transmission

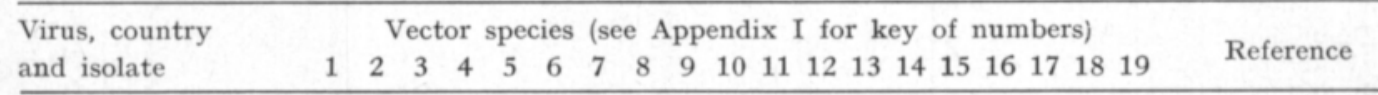

\section{CSSV, Ghana}

Aboboya

Acherechere

Adiembra

Aiyiboso

Amafie

Amakom

Anibil

Ankra-Nkwanta

Asuboi Cement

Bisa

Bobiriso

Bosomtwe

Bosomuoso

Dawa

Enchi

Koben

Konongo

Mampong (1M)

Morso

New Juaben (1A) $+\quad+$

$+$

$-$

Nkawkaw

Nsaba

Onyimso

Osino

Peki

Sedi-Nkawie

Wiawso

Worawora

\section{CSSV, Nigeria}

Akanran (Egbeda)

Balogun

Ife

Ikire

Ilare

Ilesha

Klepe

$$
+
$$

\section{$+$}

$+$

$+$

$+$

$+$

$+$

$+$

$+$

$+$

$+$

$+$

$+$

$+$

$+$

$-+$

$-$

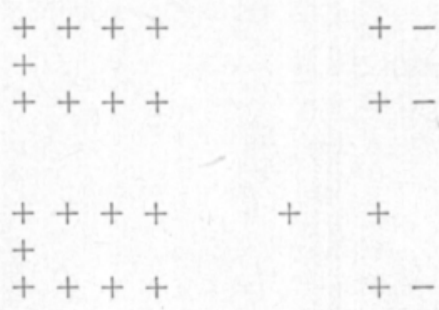

$+$

$+$

$++++$

$+$

$+\quad+$

$++t+$

$++t+$

$+++$

$+\quad+$

$+$

$++$

$+\quad+$

$++t+$

$+$

$+++$

$+$

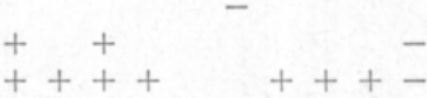

$+$

$++++$

$+$

$+$

$+$

$+\quad+$

$+$

$+++++$

$+$
LEGg and BoNNEY 1967

Anon. 1963

LEGg and BONNEY 1967

DALE 1958

DALE 1958

Attafuah and Brunt 1960

OWUsu and BONNEY 1972

LEgG and BONNEY 1967

DALE 1958

ANoN. 1963

Posnette 1947 a

AtTAFUaH and BRUnt 1960

OWUSU and BoNNEY 1972

Posnette 1950

Attafuah and Brunt 1960

DALE 1958

Attafuah and Brunt 1960

Posnetre 1950

Anon. 1963

Owusu and Bonney 1972

Posnette 1950

Posnette 1950

Attafuah and Brunt 1960

OWUsu and BonNey 1972

Posnette 1950

DALE 1955 a

DALE 1957

ANon. 1958

DALE 1958

Anon. 1959

Posnette 1950

Attafuah and Brunt 1960

Anov. 1957

Owusu and BONNEY 1972

DALE 1958

DALE 1958

DALE 1958

+-+ Posnetre 1950

Dale 1958

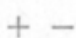

Posnette 1950

THRESH ${ }^{1}$ )

OKUSANYA 1968

THRESH ${ }^{1}$ )

THRESH $^{1}$ )

PosnetTe 1950

THRESH ${ }^{1}$

1) Communication by letter June 1976 


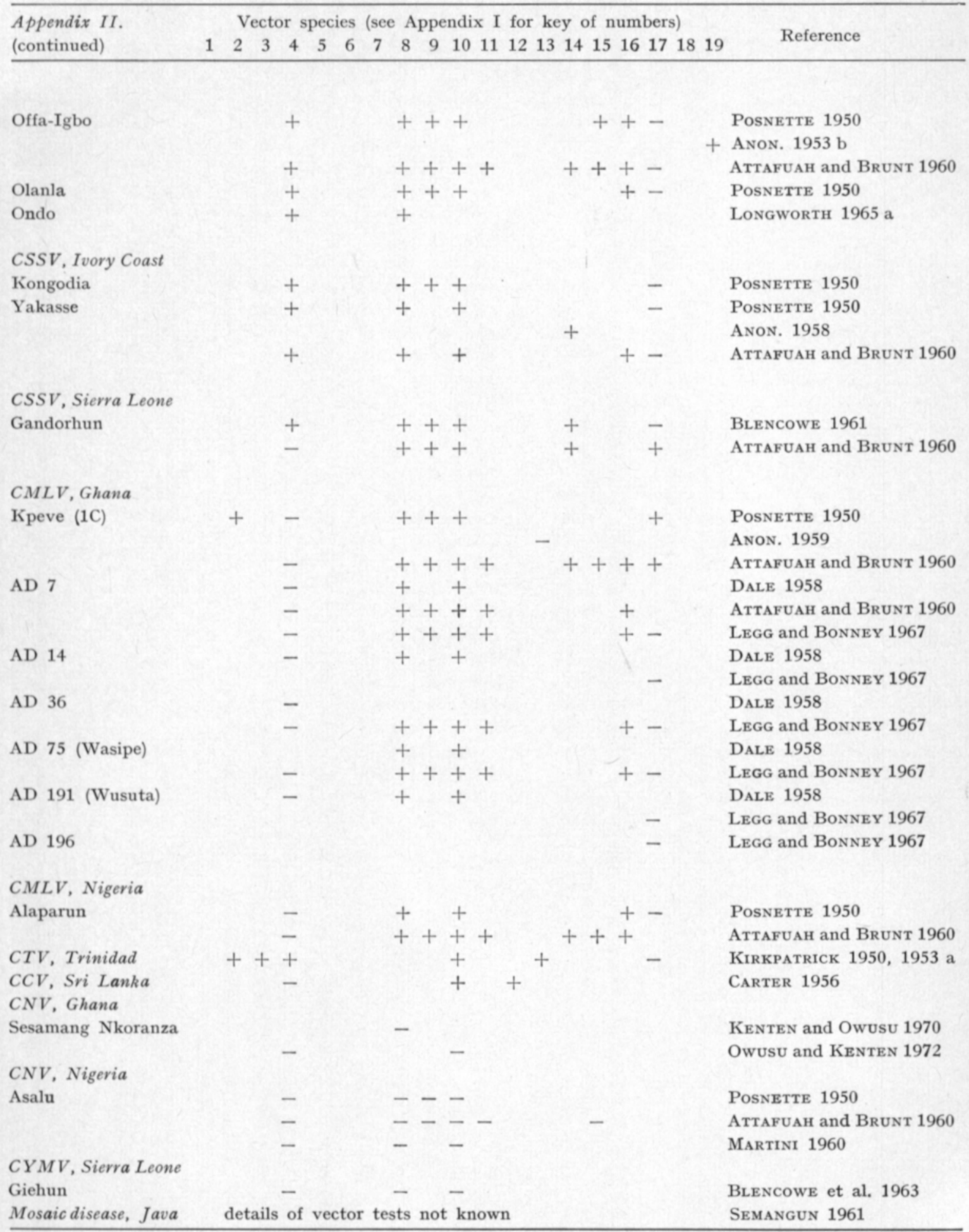


Appendix III. Insect species that have failed to transmit cocoa viruses.

\begin{tabular}{|c|c|c|}
\hline Insect species & Virus & Reference \\
\hline Aphis gossypii Glover ${ }^{\mathbf{1}}$ ) & $\begin{array}{l}\text { CSSV } \\
\mathrm{CNV}\end{array}$ & $\begin{array}{l}\text { Martini 1961, 1962, Longworth } 1964 \text { c, } \\
\text { Eguagie } 1970\end{array}$ \\
\hline Mesohomotoma tesmanni Aulman & $\begin{array}{l}\text { CSSV } \\
\text { CNV }\end{array}$ & $\begin{array}{l}\text { Box 1945, Posnette and Strickland } \\
\text { 1948, Lister 1953, Martini } 1960\end{array}$ \\
\hline Toxoptera aurantii B.d.F. & $\begin{array}{l}\text { CSSV } \\
\text { CNV }\end{array}$ & $\begin{array}{l}\text { Box 1945, Posnette and Strickland } \\
\text { 1948, Lister 1953, Martini } 1960, \\
\text { Carter } 1961\end{array}$ \\
\hline Toxoptera citricidus Kirkaldy & $\mathrm{CNV}$ & MARTINI 1960 \\
\hline Geococcus coffeae Green & CSSV & Posnette 1951, Anon. 1955 \\
\hline Geococcus sp. & CSSV & Lodos and BoAfo 1968 \\
\hline Orthezia insignis Browne & CTV & KIRKPATRICK 1950 \\
\hline Orthezia praelonga Douglas & CTV & KIRKPATRICK 1953 b \\
\hline Phenacoccus madeiriensis Green & CSSV & Posnette 1950 \\
\hline Phenacoccus sp. & CTV & KIRKPATRICK 1950 \\
\hline $\begin{array}{l}\text { Pseudococcus sp. near comstocki } \\
\text { Kuwana }\end{array}$ & CTV & KIRKPATRICK 1953 b \\
\hline Puto barberi (Cockerell) & CTV & KIRKPATRICK 1950 \\
\hline Steatococcus sp. & CSSV & Posnette 1951 \\
\hline Stictococcus sjostedti (Cockerell) & CSSV & Cotterell 1943 \\
\hline Bryocoropsis laticollis Schum. & CSSV & CotTERELL 1943 \\
\hline Sahlbergella singularis Haglund & $\mathrm{CNV}$ & MARTINI 1961 \\
\hline Cletomorpha lancigera $\mathrm{F}$. & CSSV & Cotterell 1943 \\
\hline Selenothrips rubrocinctus Giard & CSSV & CotTerell 1943 \\
\hline Fulgeridae sp. & CSSV & CotTERELl 1943 \\
\hline Gargara sp. & CSSV & CotTERELL 1943 \\
\hline Criphyle sp. & CSSV & Cotterell 1943 \\
\hline Cercopidae sp. & CSSV & CotTerell 1943 \\
\hline Ricania mediana Mel. & CSSV & CotTERELL 1943 \\
\hline Ricanopsis semihyalina Mel. & CSSV & CotTERELl 1943 \\
\hline Ricanopsis nebulosa Mel. & CSSV & Cotterell 1943 \\
\hline Epitemna carbonaria Walk. & CSSV & Cotterell 1943 \\
\hline Pochazia fasciata F. & CSSV & Cotterell 1943 \\
\hline
\end{tabular}

1) Evidence of transmission and non-transmission of CSSV available. 